Renata Spolon

\title{
Um Editor Gráfico para um
}

\section{Ambiente de Simulação Automático}

Dissertação apresentada ao Instituto de Ciências Matemáticas de São Carlos da Universidade de São Paulo como parte dos requisitos para obtenção do título de Mestre em Ciências - Área: Ciências de Computação e Matemática Computacional.

\section{São Carlos}

agosto de 1994 
Renata Spolon

\section{Um Editor Gráfico para um}

\section{Ambiente de Simulação Automático}

Dissertação apresentada ao Instituto de Ciências Matemáticas de São Carlos da Universidade de São Paulo como parte dos requisitos para obtenção do título de Mestre em Ciências - Área: Ciências de Computaçāo e Matemática Computacional.

Área de Concentração:

Sistemas Distribuídos e Programação Concorrente

Orientadora:

Profa. Dra. Regina Helena Carlucci Santana

São Carlos

agosto de 1994 
Aos meus pais, Meiri e Dorival, pelo eterno amor, carinho e compreensāo. 
"Qualquer coisa que você for capaz de fazer; ou sonhe que é capaz de fazer; comece-a. A coragem traz consigo gênio, podere magia."

Goethe 


\section{Agradecimentos}

À Regina, pela orientação sempre dedicada e segura, e pela amizade com que proporcionou um ótimo ambiente para o desenvolvimento deste trabalho.

À Roberta, irmã e amiga, pelas palavras de apoio e incentivo com que sempre me encorajou; pelo excelente trabalho conjunto na definição da Tabela de Especificação e pela valiosa ajuda na revisão desta dissertação.

Ao Prof. Dr. Marcos José Santana, pelas sugestōes ao trabalho e pela amizade com que fui recebida no Grupo de Sistemas Distribuídos e Programação Concorrente do ICMSC.

Ao Prof. Dr. Eduardo Marques, pela amizade e permanente incentivo.

Aos funcionários do LASD, José Eduardo Amorim Pires e José Luis de Souza Cabral, pela atenção, eficiência e paciência com que sempre me atenderam.

Ao amigo Cidinho, pela troca de idéias sobre simulação, e à Prof. Dra. Maria Creusa B. Salles, pelo auxílio durante a fase de revisão bibliográfica.

Aos amigos Marquinho, Ana Luisa, Tchelo, Ricardo (Hasegawa) e Walter, e a todos que direta ou indiretamente contribuíram para a realização deste trabalho.

À FAPESP, pelo auxílio financeiro. 


\title{
Sumário
}

\author{
Lista de Figuras
}

Lista de Tabelas

Resumo

"Abstract"

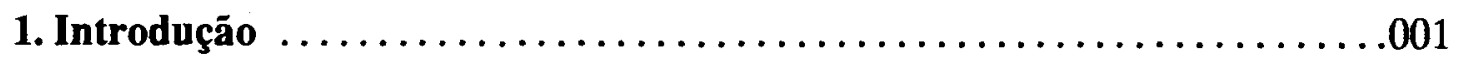

\section{Simulação}

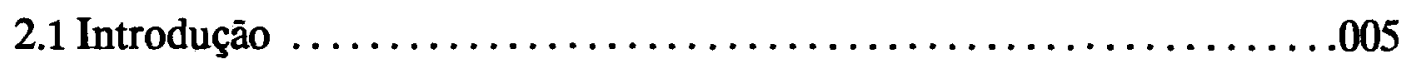

2.2 Ferramentas para Avaliação de Desempenho ................006

2.3 Desenvolvimento do Modelo e Testes .....................008

2.3.1 Fase de Desenvolvimento ..........................008

2.3.2 Fase de Testes .................................. 011

2.3.3 Fase de Análise ............................... 012

2.4 Simulação Discreta ................................. 013

2.5 Modelagem para Simulação Discreta $\ldots \ldots \ldots \ldots \ldots \ldots \ldots \ldots \ldots . . \ldots 14$

2.5.1 Simulação Orientada a Evento ........................ 015

2.5.2 Simulação Orientada a Processo $\ldots \ldots \ldots \ldots \ldots \ldots \ldots \ldots \ldots . . . .16$

2.5.3 Simulação Orientada a Atividade $\ldots \ldots \ldots \ldots \ldots \ldots \ldots \ldots \ldots . . \ldots 18$ 
2.6 Implementação de um Modelo de Simulação ..................019

2.6.1 Linguagens de Simulação ............................. 019

2.6.1.1 Linguagens Orientadas a Atividade ..................020

2.6.1.2 Linguagens Orientadas a Evento ....................020

2.6.1.3 Linguagens Orientadas a Processo .................... 021

2.6.2 Pacotes de Simulação de Uso Específico ..................021

2.6.3 Linguagens de Programação ........................022

2.6.4 Extensōes Funcionais .............................. 022

2.7 Conclusão .......................................023

\section{Parâmetros de Entrada e Análise Estatística de Resultados}

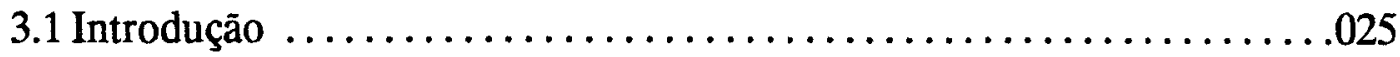

3.2 Redes de Filas ..................................... 026

3.3 Modelos Baseados em Redes de Filas ........................027

3.4 Aquisição e Representação dos Parâmetros .................032

3.5 Análise Estatística dos Resultados . . . . . . . . . . . . . . . . . 036

3.5.1 Influência das Condições Iniciais nos Resultados da Simulação . . . .036

3.5.2 Teste de Parada e Precisāo dos Resultados .................037

3.6 Medidas de Desempenho ............................. 038

3.7 Conclusão ......................................... 038

\section{Interface Gráfica com o Usuário}

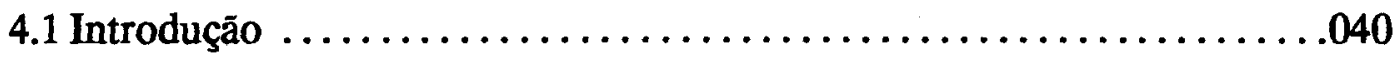

4.2 Objetivos no Projeto de Interface com o Usuário ................041

4.3 Forma e Contéudo do Diálogo Homem-Máquina ...............043

4.4 Estilos da Interface com o Usuário ........................044

4.5 Metodologia de Projeto .............................. 047

4.6 Interface Gráfica do Usuário Através do Microsoft Windows ........048

4.6.1 Multitarefa e Gerenciamento de Memória .................049

4.6.2 Programação Orientada a Eventos e Mensagens ..............050 
4.6.3 Elementos de Uma Aplicação Windows ..................052

4.6.4 Uma Introdução a GDI ............................ 057

4.7 Conclusão .......................................059

\section{Sistemas de Simulação Automáticos}

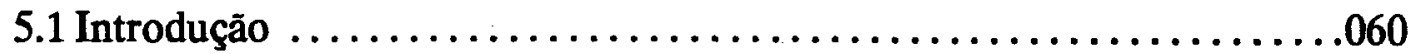

5.2 Sistemas Existentes .................................. 061

5.3 ASiA - Ambiente de Simulação Automático ...................064

5.3.1 Estrutura Geral do ASiA $\ldots \ldots \ldots \ldots \ldots \ldots \ldots \ldots \ldots \ldots . . .064$

5.3.2 Editor Gráfico ................................ 065

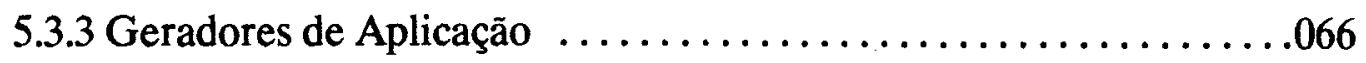

5.3.4 Sistema para Simulação ............................ 069

5.3.5 Estágio de Saída ................................. 070

5.4 Conclusão ..................................... 070

\section{Definição do Editor Gráfico}

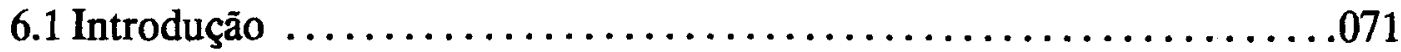

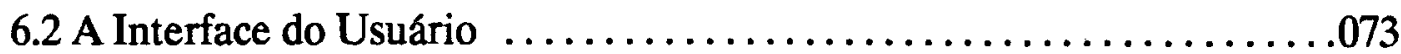

6.3 Obtenção do Modelo e Parâmetros .........................074

6.4 Consistência, Armazenamento e Manutenção ..................081

6.5 Conclusão ....................................... 082

\section{Implementação do Editor Gráfico}

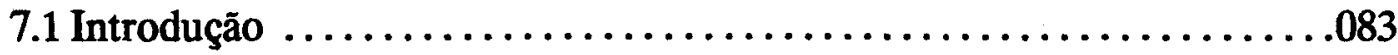

7.2 Consideraçōes Sobre o Projeto ........................... 083

7.3 A Interface do Usuário $\ldots . \ldots \ldots \ldots \ldots \ldots \ldots \ldots \ldots \ldots \ldots . . . .684$

7.3.1 Janela de Edição Gráfica ........................... 085

7.3.2 Barra de Ferramentas $. . . \ldots \ldots \ldots \ldots \ldots \ldots \ldots \ldots \ldots . . . .686$

7.3.3 Barra de Menus ................................. 087 
7.3.4 Elementos Utilizados para a Captação dos Parâmetros Necessários a

Um Modelo de Simulação ............................090

7.3.5 Distribuições Definidas Pelo Usuário .....................095

7.3.6 Como Definir Eventos ..............................096

7.4 A Implementação do EdGraf ...........................097

7.4.1 Interface do Usuário ...............................098

7.4.2 Manutenção das Informaçōes .........................101

7.4.3 Tratamento de Arquivos .............................107

7.4.4 Verificação de Consistência ...........................109

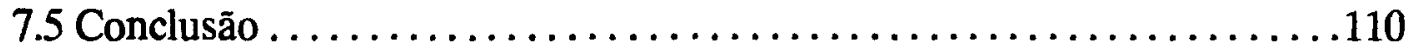

\section{Conclusões}

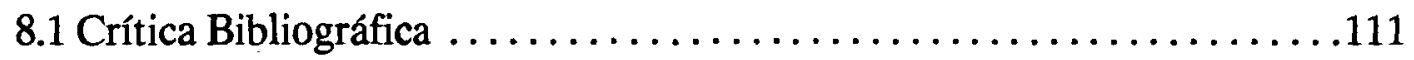

8.2 Contribuições do Trabalho $\ldots \ldots \ldots \ldots \ldots \ldots \ldots \ldots \ldots \ldots \ldots \ldots \ldots \ldots \ldots \ldots$

8.3 Conclusões ..................................... 115

8.4 Sugestões Para Trabalhos Futuros . . . . . . . . . . . . . . . . 116

Referências Bibliográficas . ...............................118

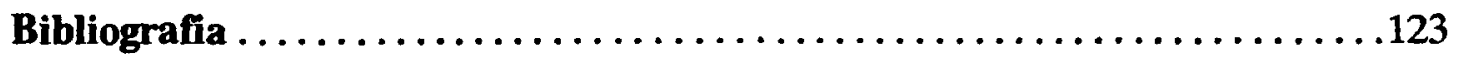

Apêndice A - Exemplo ...................................124

Apêndice B - Lista de Siglas . . . . . . . . . . . . . . . . . . . . . 138 


\section{Lista de Figuras}

Figura 2.1 O Processo de Modelagem e Análise $. . . \ldots \ldots \ldots \ldots \ldots \ldots . . .009$

Figura 2.2 Relação entre Evento, Processo e Atividade ...............013

Figura 3.1 Centro de Serviço - Uma Fila e Um Servidor ..............027

Figura 3.2 Centro de Serviço - Uma Fila e Vários Servidores .............028

Figura 3.3 Centro de Serviço - Várias Filas e Um Servidor $\ldots \ldots \ldots \ldots \ldots . . \ldots 28$

Figura 3.4 Centro de Serviço - Vários Servidores e Filas ...............029

Figura 4.1 Laços de Mensagem .............................. 051

Figura 4.2 Janela $\ldots \ldots \ldots \ldots \ldots \ldots \ldots \ldots \ldots \ldots \ldots \ldots \ldots \ldots \ldots \ldots . . .652$

Figura 4.3 Caixa de Diálogo Abrir $\ldots \ldots \ldots \ldots \ldots \ldots \ldots \ldots \ldots \ldots . . \ldots 54$

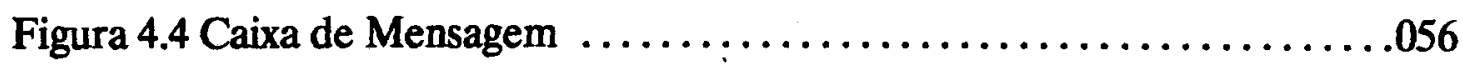

Figura 4.5 Fluxo de Informação Aplicação/"Driver" .................058

Figura 5.1 Símbolos Gráficos Utilizados pelo QMG $\ldots \ldots \ldots \ldots \ldots \ldots \ldots .062$

Figura 5.2 Visão Geral do ASiA $\ldots \ldots \ldots \ldots \ldots \ldots \ldots \ldots \ldots \ldots \ldots \ldots \ldots \ldots$

Figura 5.3 Estrutura de Um Gerador de Aplicação . . . . . . . . . . . . . . 067

Figura 5.4 Utilização de um Gerador de Aplicação ..................068 
Figura 6.1: Uma Visão Geral do Editor Gráfico

Figura 7.1: Tela Principal do EdGraf $\ldots \ldots \ldots \ldots \ldots \ldots \ldots \ldots \ldots \ldots \ldots \ldots \ldots, \ldots \ldots \ldots$

Figura7.2 : Barra de Ferramentas ..........................086

Figura7.3: Caixa Modelo $\ldots \ldots \ldots \ldots \ldots \ldots \ldots \ldots \ldots \ldots \ldots \ldots \ldots \ldots . \ldots . \ldots . \ldots 1$

Figura 7.4: Caixa Dados do Recurso . . . . . . . . . . . . . . . . . . . 092

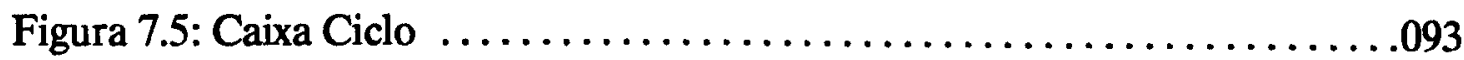

Figura 7.6: Caixa Ramificação $\ldots \ldots \ldots \ldots \ldots \ldots \ldots \ldots \ldots \ldots \ldots \ldots . \ldots . \ldots . \ldots . \ldots \ldots$

Figura 7.7: Caixa Ligação Principal ...........................093

Figura 7.8: Caixa Chegada $\ldots \ldots \ldots \ldots \ldots \ldots \ldots \ldots \ldots \ldots \ldots \ldots \ldots . . . \ldots 94$

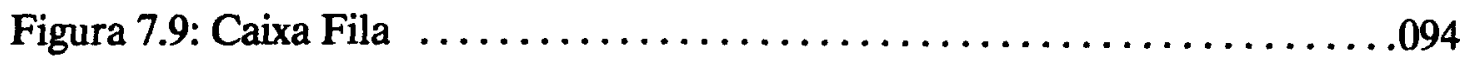

Figura 7.10: Caixa Serviço $\ldots \ldots \ldots \ldots \ldots \ldots \ldots \ldots \ldots \ldots \ldots \ldots \ldots \ldots . . \ldots 95$

Figura 7.11 Caixa Distribuição Tabelada $\ldots \ldots \ldots \ldots \ldots \ldots \ldots \ldots \ldots \ldots . . .096$

Figura 7.12: Caixa Evento .............................. 096

Figura 7.13: Grupos de Módulos do EdGraf $\ldots \ldots \ldots \ldots \ldots \ldots \ldots \ldots \ldots . . \ldots 98$

Figura 7.14: M6dulos da Interface do Usuário . . . . . . . . . . . . . . 099

Figura 7.15: Módulos da Manutenção das Informações $. . \ldots \ldots \ldots \ldots \ldots . . . .102$

Figura 7.16: Orientação dos Eixos x e y ........................

Figura 7.17: Módulos do Tratamento de Arquivos .................108

Figura A.1: Um Modelo Simples ..........................124

Figura A.2: Caixa de Apresentação do EdGraf ...................125

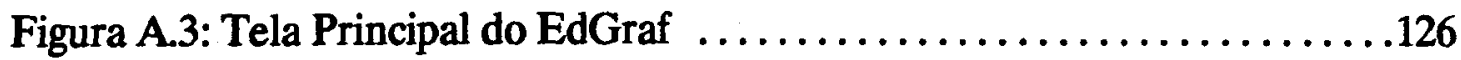


Figura A.4: Desenhando a Especificação Gráfica do Modelo .127

Figura A.5: Indicando a Entrada do Modelo .....................127

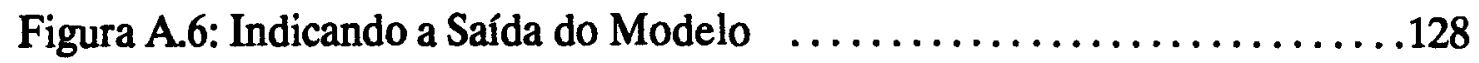

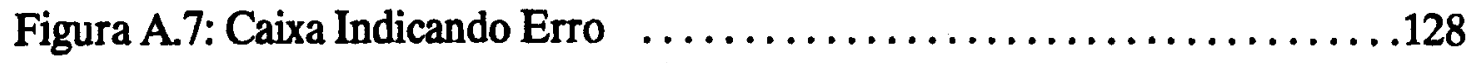

Figura A.8: Parametrizando o Modelo ........................129

Figura A.9: O Menu Modelo ..............................129

Figura A.10:Utilizando o Menu Parametrizar (Recursos) $\ldots \ldots \ldots \ldots \ldots \ldots . . \ldots$

Figura A.11: Recurso Selecionado para Parametrização $\ldots \ldots \ldots \ldots \ldots \ldots . . .131$

Figura A.12: O Submenu Parametrizar $\ldots \ldots \ldots \ldots \ldots \ldots \ldots \ldots \ldots \ldots \ldots \ldots \ldots \ldots$

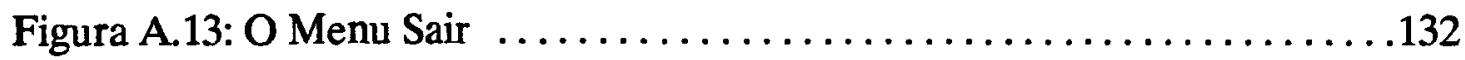

Figura A.14: Modelos Utilizando Vários Símbolos .................133

Figura A.15: Um Modelo Fechado .........................134

Figura A.16: Um Modelo com Decisāo . .......................134

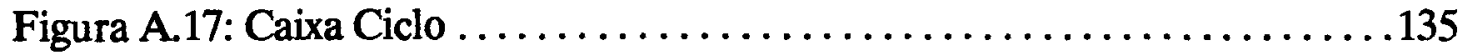

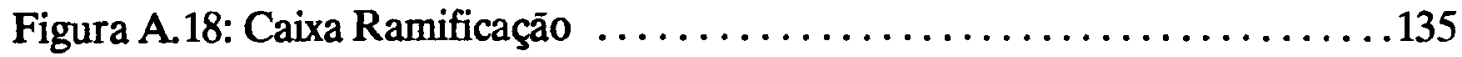

Figura A.19: Caixa Ligação Principal . .......................136 


\section{Lista de Tabelas}

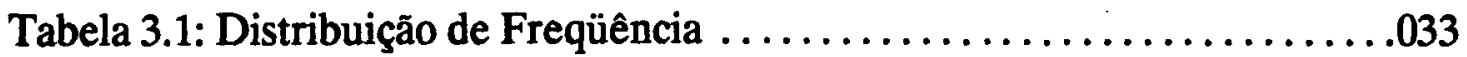

Tabela 3.2: Distribuição de Freqüência Acumulada $\ldots \ldots \ldots \ldots \ldots \ldots \ldots . \ldots . \ldots . \ldots$ 


\section{Resumo}

Este trabalho descreve o projeto e implementaçāo do módulo de interface (Editor Gráfico) para o ASiA (Ambiente de Simulação Automático) que está em desenvolvimento no Grupo de Sistemas Distribuídos e Programação Concorrente do Instituto de Ciências Matemáticas de São Carlos-USP. Através do Editor Gráfico, o ambiente ASiA capta todas as informações necessárias a um programa de simulação. Automaticamente, um Gerador de Aplicaçāo produz o programa correspondente ao modelo definido. Um último estágio do ASiA deve oferecer ao usuário a possibilidade de visualização gráfica dos resultados obtidos na simulação.

O Editor permite que o usuário especifique graficamente um modelo do sistema em estudo e obtém do usuário, através de menus e caixas de diálogo, todos os parâmetros necessários. Esses parâmetros são organizados em tabelas, utilizadas pelo Gerador de Aplicação para produzir o programa de simulação. 


\section{Abstract}

This dissertation describes the design and implementation of the ASiA (Automatic Simulation Environment) user-interface (the graphics editor). The ASiA has been developed by the Distributed System and Concurrent Computation Group at the Computer Science Department - ICMSC-USP. All the information required for the production of a simulation program is obtained by means of a graphic editor, on which the users draw their models and enter their parameters. The simulation program is produced by an application generator system, that manipulates all the information captured by the graphics editor and generates the adequate commands, according to a target simulation system. The ASiA environment also has a module that deals with the output results from the simulation program.

This editor allows a user to describe graphically a sytem model through classical queue network symbols and to provide several parameters, by means of drop-down menus and dialog boxes. All this information is organized in tables that in turn are used by the application generator module. 


\section{Capítulo 1}

\section{Introdução}

A evolução dos sistemas computacionais desde sua origem até os dias atuais tem perseguido duas metas: desempenho e confiabilidade. Em termos de confiabilidade, tem-se atualmente técnicas que aumentam a disponibilidade e a segurança dos sistemas computacionais e dos dados armazenados. Em termos de desempenho, observou-se um dos mais rápidos desenvolvimentos tecnológicos da história da humanidade. Um assunto que vem preocupando os projetistas e usuários de sistemas computacionais é a análise de desempenho de sistemas computacionais. A avaliação de desempenho é atrativa uma vez que essa grandeza indica a qualidade do trabalho executada pelo sistema, e é de vital importância na seleção de sistemas alternativos, no projeto de novos sistemas e na análise de sistemas existentes.

Diferentes ferramentas podem ser utilizadas na avaliação de desempenho, como instrumentaçāo, construção de protótipos, "benchmarks" ou técnicas de modelagem. Cada uma dessas ferramentas pode ser utilizada em diferentes situações que dependem dos objetivos do sistema em estudo, das ferramentas disponíveis, etc.

A utilização de "benchmarks" pode ser interessante na análise e comparação de sistemas existentes. A instrumentação do sistema deve ser criteriosa para não perturbar o funcionamento do mesmo, não interferir nos resultados e não atrapalhar sua utilização por outros usuários. Nem sempre é possível conciliar todos esses requisitos. Quando o sistema nāo existe, pode-se utilizar um protótipo, mas deve-se considerar sua falta de flexibilidade e o seu custo relativamente alto.

As técnicas de modelagem são utilizadas para abstrair as características de um sistema em um modelo. Através desse modelo pode-se analisar um sistema sem interferir no seu funcionamento, ou mesmo analisar sistemas que ainda estão em fase 
de projeto. A aplicação de ferramentas analíticas para a solução de modelos pode oferecer uma solução simples em alguns casos, porém sua utilização é limitada pela complexidade. Muitas vezes, para que um modelo seja tratável analiticamente, hipóteses não muito realistas sobre o sistema e/ou sobre sua operação têm que ser feitas, o que pode comprometer seriamente a credibilidade do modelo resultante. Porém, em situações onde a solução analítica é conhecida, sua utilização é recomendada, devido ao fato de apresentar resultados exatos.

Simulação possibilita maior flexibidade, pois é fácil realizar alterações no modelo para refletir mudanças no projeto ou no sistema real. Porém, modelos de simulação devem ser validados para que se obtenha um grau de confiabilidade nas medidas obtidas (a validação é uma tarefa complexa).

As vantagens e facilidades envolvidas no uso de simulação implicam na sua utilização em áreas diversificadas como na meteorologia, na avaliação de redes de telecomunicações, no estudo de sistemas computacionais e biológicos, etc. $\mathrm{Na}$ área de sistemas computacionais, de modo geral, simulação vem sendo utilizada como ferramenta básica para avaliação de desempenho de sistemas que sejam reais (aqueles já implementados, em uso diário e que requeiram algum tipo de avaliação de desempenho) ou sistemas em fase de projeto (aqueles que figuram apenas nas pranchetas ou na imaginação de seus idealizadores). Em ambos os casos simulação é importante: no primeiro, por uma questão de respeito à comunidade de usuários (experimentações com o sistema podem perturbar o seu funcionamento); no segundo caso, o sistema não existe, e portanto uma abstração do mesmo deverá ser elaborada e a simulação poderá ser utilizada. Existem ainda situações onde a simulação é fundamental, pois a experimentação (quer seja com o sistema real, quer seja com um protótipo) pode ser catastrófica, e a solução analítica pode ser muito complexa. Um exemplo dessa situação são os testes de sistemas computacionais que controlam usinas nucleares.

Contudo, apesar das características que fazem da simulação uma ferramenta atrativa, quando se utilizam programas computacionais para a implementação de modelos uma grande dificuldade pode residir na descrição do modelo. Normalmente, o interessado em simular um dado sistema deve inicialmente estudar o sistema e construir um modelo; existindo o modelo, deve-se então proceder à implementação de um programa computacional que represente o modelo selecionado. Essa tarefa pode 
não ser difícil para pessoas especializadas, familiarizadas tanto com simulação quanto com programação. Porém, para aqueles que não possuem os conhecimentos e experiências necessários, a tarefa de simular pode se tornar difícil, uma vez que o usuário deve estar familiarizado com três áreas distintas: simulação, programação e a área a que pertence o sistema a ser simulado.

Para tornar a simulação uma ferramenta útil para aqueles que não tem experiência em programação, e mesmo para minimizar $o$ trabalho daqueles capacitados, $e$ atrativo a elaboraçāo de um sistema que permita a um usuário não se preocupar com detalhes referentes à programação. $O$ usuário se restringe a fornecer os dados necessários à construção do modelo. Considerando o fato de que o usuário geralmente não é um especialista em programação, o modo mais fácil de fornecer esses dados é graficamente.

Baseado nessas considerações, o Grupo de Sistemas Distribuídos e Programação Concorrente do ICMSC-USP está desenvolvendo o ambiente ASiA (Ambiente de Simulação Automático). ASiA tem como objetivo automatizar o processo de construção do programa de simulação, e constitui-se basicamente de um editor gráfico, um gerador de aplicação e um estágio de saída.

Nesta dissertação são discutidos o projeto e implementação de um editor gráfico para o ambiente ASiA. O editor permite que o usuário descreva graficamente $o$ modelo que deseja simular. Além disso, o editor obtém do usuário todos os dados necessários a um modelo de simulação, organizando-os de forma que o Gerador de Aplicação possa produzir automaticamente o programa correspondente.

Um requisito inicial para o desenvolvimento do editor grafico é o conhecimento de simulação de sistemas, dos elementos e parâmetros envolvidos em uma simulação, e da análise dos dados obtidos. Esses tópicos são discutidos nos capítulos 2 e 3 da dissertação.

Como o objetivo deste trabalho é construir a parte do sistema que interage com o usuário, uma revisão sobre interfaces homem-máquina e interfaces gráficas com o usuário é considerada. A interface com o usuário é um elemento que influencia no sucesso de um sistema computacional. Além disso, o uso de cores e imagens facilita a aceitação e compreensão do sistema por parte do usuário final. $O$ capítulo 4 apresenta os requisitos para que uma interface seja amigável e diferentes estilos que podem ser 
empregados no projeto de uma interface. Também são apresentados os principais elementos da interface gráfica oferecida pelo Microsoft Windows 3.1.

No capítulo 5 são apresentadas as principais características de sistemas semelhantes ao que está em desenvolvimento no ICMSC-USP. E detalhado o ambiente ASiA (Ambiente de Simulação Automático).

O Editor Gráfico desenvolvido é discutido nos capítulos 6 e 7. No capítulo 6 é apresentado o projeto desenvolvido e no capítulo 7 detalhes referentes a implementaçāo do mesmo.

Finalmente no capítulo 8 são apresentadas as conclusões e sugestões de trabalhos futuros, objetivando complementar e melhorar o sistema. São feitas também críticas referentes à bibliografia consultada.

Encerrando a dissertação, o apêndice A exemplifica a utilização da interface oferecida pelo Editor para compor um modelo de simulação, e 0 apêndice $B$ apresenta a lista de siglas utilizadas no trabalho. 


\section{Capítulo 2}

\section{Simulação}

Este capítulo discute tópicos relevantes sobre modelagem e simulação de sistemas

discretos. Apresentam-se as ferramentas mais utilizadas para análise de desempenho $e$ ressaltam-se as vantagens $e$ desvantagens de cada uma e em especial da simulação. Também são descritas as etapas envolvidas em uma simulação: desenvolvimento de um modelo para o sistema a ser simulado, implementação do modelo, validaçāo da simulação e análise dos resultados.

\subsection{Introduçāo}

Um problema crítico no desenvolvimento de sistemas computacionais é a obtenção de uma ferramenta que auxilie na avaliação do desempenho de tais sistemas. Dentre as técnicas disponíveis, cabe ressaltar a solução de modelos por simulação discreta ou por técnicas analíticas, experimentação ou utilização de "benchmarks". Essas técnicas serão abordadas na seção 2.2 .

Simulação é uma ferramenta que vem se tornando cada vez mais atuante nas mais diversas áreas de aplicação, devido a sua flexibilidade e baixo custo [PEG91]. Como exemplos pode-se citar sua aplicação em meteorologia, na análise do comportamento de reatores nucleares, em estudos sobre os efeitos econômicos e ambientais de políticas administrativas, na avaliação de redes de telecomunicações [ROT92, SHA92], em estudos de linhas de montagens e na área médica, etc. Em sistemas computacionais essa técnica vem sendo utilizada para análise de comportamento e verificação de desempenho [MAC87, KOB78, GRA78, NUT78, SOA90, SHA92]. 
Originalmente, a palavra simular significa imitar. Portanto, para simular é necessário imitar algo [ROB83]. O primeiro passo de uma simulação é o desenvolvimento de um modelo que descreva o comportamento dinâmico do sistema a ser simulado. Um modelo constitui uma simplificaçāo do sistema, podendo representá-lo segundo vários níveis de detalhe (e cada nível representando um grau de abstração) [MAC75]. Esses modelos podem ser organizados segundo três unidades básicas: atividades, processos e eventos. Construído o modelo, deve-se estimar (ou medir) os parâmetros que serão utilizados no programa de simulação.

O programa de simulação é implementado para manusear o modelo, e pode seguir três enfoques básicos: desenvolvimento do simulador em uma linguagem convencional (como Pascal ou C), utilização de uma linguagem de simulação de uso geral (ou uma extensão de tal linguagem) ou então um pacote de simulação de uso específico. Como descrito na seção 2.6, essas linguagens podem seguir orientações a processo, evento ou atividade.

Um programa de simulação, para ser confiável, deve ser verificado e validado, garantindo assim que o programa é uma implementação válida do modelo e este reproduz o comportamento do sistema com fidelidade (verificação e validação de um programa de simulação são discutidas na seção 2.3). Todas as suposições efetuadas durante o processo de modelagem devem ser consideradas no momento de se analisar os dados obtidos, antes de aceitar e utilizar tais resultados. Os parâmetros de entrada e a análise dos resultados merecem atenção especial neste trabalho e são discutidos no capítulo 3.

\subsection{Ferramentas para Avaliação de Desempenho}

Diferentes ferramentas podem ser consideradas para modelagem e análise de desempenho de sistemas [NUT78, EDW92]. Dentre elas cabe ressaltar:

.solução de modelos por técnicas analíticas;

.soluçâo de modelos por simulação discreta;

.instrumentação do sistema;

."benchmarks". 
Nutt [NUT78] cita ainda a solução de modelos para análise de desempenho baseada em valores médios de variáveis (tanto para os parâmetros de entrada como os de saída). Tais modelos são relativamente fáceis de analisar, porém erros podem ser introduzidos já que os mesmos consideram pequena a variância desses parâmetros. Os modelos resolvidos através de técnicas analíticas são mais precisos, permitindo incorporar mais detalhes do que simplesmente valores médios. Devido aos detalhes, tornam-se mais complexos e portanto mais difícil de resolver, geralmente abrangendo um pequeno número de soluções práticas e impondo simplificações que podem levar à descaracterização do modelo.

A solução de modelos por simulação discreta possibilita uma maior flexibilidade, além de incorporar mais detalhes, desde que um programa pode ser escrito para manipular cada componente do modelo. Uma dificuldade encontrada em modelos de simulação é a validação do mesmo (validação é tratada com mais detalhes na seçāo 2.3.2).

A análise de desempenho pode ainda ser feita através da instrumentação do sistema. Em muitas situaçōes essa técnica torna-se impraticável, pois pode influir nas medidas obtidas ou danificar o sistema em questão (por exemplo, a análise de um desastre para acionar bombeiros e hospitais [DAV89]). No caso do sistema não existir, um protótipo pode ser utilizado, produzindo uma cópia do sistema real (ou do projeto), porém protótipos são caros, pouco flexíveis e normalmente exigem tempo para serem construídos e testados [NUT78].

Uma forma de avaliação de desempenho que vem se tornando bastante popular é a utilização de "benchmarks" [LUC71, NIC88]. Um "benchmark" constitui-se de um programa codificado em uma linguagem específica, executado na máquina cujo desempenho será avaliado. $O$ uso de "benchmarks" apresenta algumas desvantagens pois sua utilizaçāo fica limitada a sistemas existentes [REI90, ABU88, NIC88].

Simulação é uma ferramenta para análise de desempenho viável para a maioria dos casos. Essa técnica permite fazer inferências sobre sistemas que são apenas projeto (sem a necessidade de construí-los), sobre sistemas que não permitem experimentos (sem perturbá-los) e permite determinar os limites de funcionamento do sistema sem destruí-lo [PEG91]. 
No desenvolvimento de um modelo de simulação pode-se optar por uma abordagem discreta ou contínua. $\mathrm{Na}$ abordagem contínua as mudanças de estado do sistema ocorrem continuamente no tempo, e na abordagem discreta as mudanças ocorrem em intervalos discretos. Para a simulação de sistemas computacionais, que é o enfoque deste trabalho, adota-se, normalmente, simulação discreta.

\subsection{Desenvolvimento do Modelo e Testes}

O passo chave no processo de modelagem, segundo MacDougall [MAC87], consiste em abstrair as características de um sistema em um modelo, valendo toda a experiência do modelador com trabalhos desse gênero. $O$ processo de modelagem pode ser dividido em três fases: desenvolvimento, teste e análise, com cada fase compreendendo vários passos, como mostra a figura 2.1. Ressalta-se que embora o processo de desenvolvimento seja descrito de forma sequencial, ele de fato não o é, pois normalmente existe interação entre os diversos passos. É importante destacar também que alguns dos passos que compõem o desenvolvimento de uma simulação são comuns a uma resoluçăo analítica.

\subsubsection{Fase de Desenvolvimento}

\section{Descrição do Sistema}

O primeiro passo na elaboração de uma simulação é o entendimento do sistema considerado. $O$ sistema deve ser definido com grande precisão $e$ as metas pretendidas devem ser claras e objetivas [MAR80, PEG91]. MacDougall, em [MAC87], destaca que o tempo gasto em organizar e escrever essa descrição é compensado devido aos possíveis erros eliminados. A forma da descrição depende do tipo de sistema sendo modelado, e uma das maneiras de representar o sistema é através de um diagrama de fluxo. 


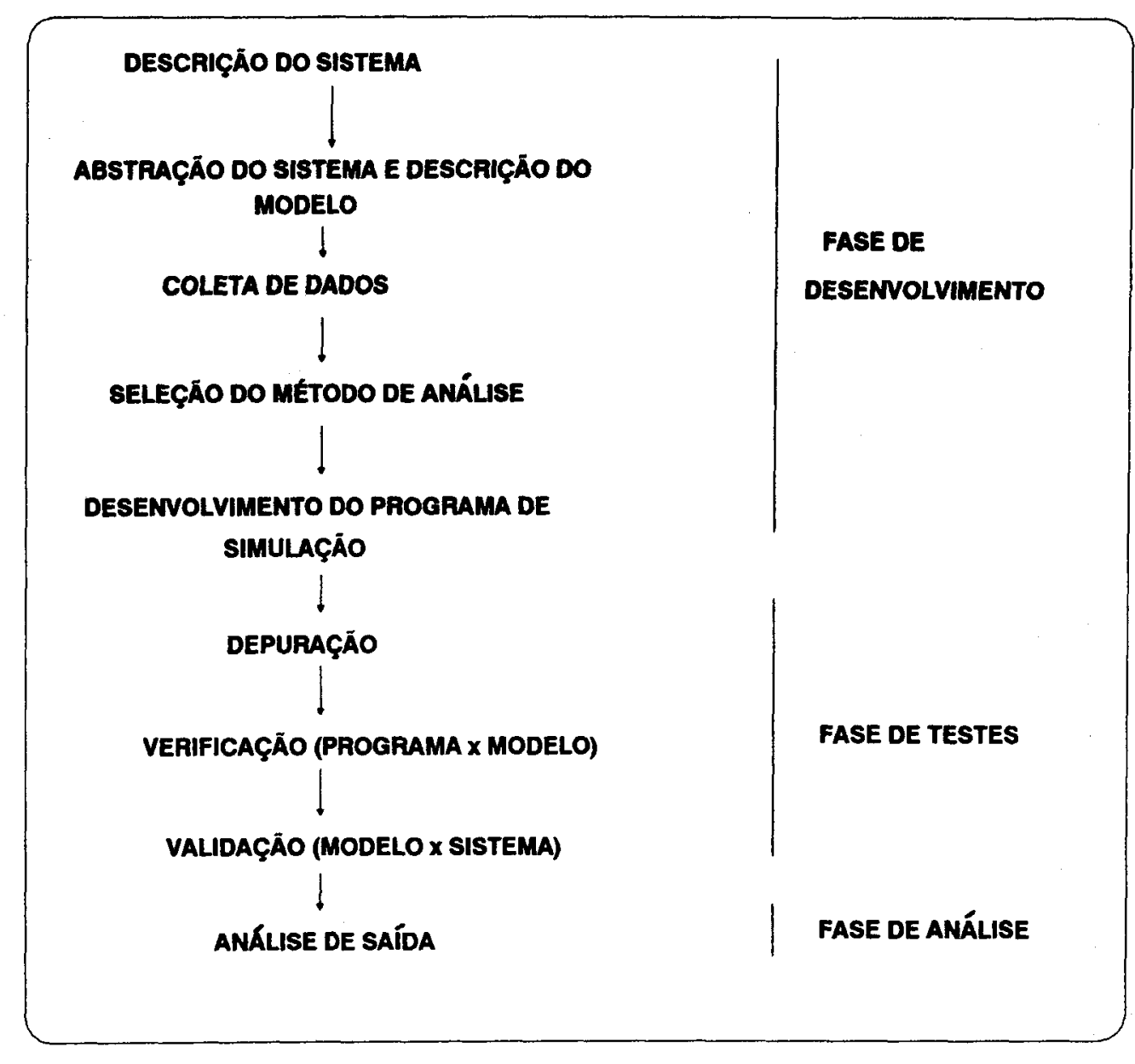

Figura 2.1: O Processo de Modelagem e Análise

\section{Abstração do Sistema e Descrição do Modelo}

Uma vez formalizado o problema e definido os objetivos a estudar, inicia-se o processo de construção do modelo. Um modelo é uma abstração de um sistema, e representa uma visão particular do mesmo. Ao criar o modelo, uma tarefa relativamente difícil é a decisão sobre quais elementos do sistema devem ser incluídos no modelo, e a quantidade de detalhes incluída deve ser baseada no propósito para o qual o modelo está sendo construído [MAC87, PEG91, SOA90]. Nesse passo descreve-se o que deve ser representado no modelo, e a escolha do método (modelos são descritos em termos do método utilizado para obter medidas de desempenho, podendo ser modelo analítico ou de simulação) fica para o passo seguinte. 


\section{Coleta de Dados}

A fase de formulação do modelo gera os requisitos para os dados de entrada, que servirão como parâmetros do mesmo. Quando a modelagem é feita sobre um sistema existente, os parâmetros para o modelo podem ser medidos diretamente (via instrumentação de "hardware" ou "software") ou indiretamente [MAC87]. Ao se modelar um projeto, os valores dos parâmetros do modelo devem ser estimados (mais detalhes são analisados no capítulo 3 ).

\section{Seleção do Método de Análise}

O passo seguinte, seleção do método de análise, consiste em escolher entre o método analítico ou simulação. Diversos autores [MAC87, DAV89, SOA90] defendem o uso de ferramentas analíticas sempre que for viável. Porém, em diversos casos a utilização de soluçōes analíticas não é adequada, principalmente devido a falta de flexibilidade (uma simples modificação no projeto pode implicar em reformulação do modelo) e a dificuldade em representar muitos detalhes (aumentar os detalhes em um modelo analítico pode aumentar a complexidade da soluçâo analítica). Nesses casos, simulação deve ser considerada.

\section{Desenvolvimento do Programa de Simulação}

O próximo passo, no caso de escolha de modelagem por simulação, consiste em traduzir o modelo para uma forma aceitável pelo computador. Pode-se seguir os seguintes enfoques [SAN89a, SAN89b]:

.desenvolvimento do programa de simulação em uma linguagem convencional (como C, Modula 2, Pascal): neste caso, o programador é responsável por criar todo o ambiente necessário para a simulação. Oferece a vantagem de que o programador (ou modelador) tem liberdade para escolher uma linguagem que seja de seu conhecimento, porém tem que desenvolver todas as estruturas exigidas num ambiente de simulação;

.utilização de um pacote de uso específico para criar o programa de simulação: deve existir um pacote que se ajuste às necessidades do sistema sendo modelado. Nesse caso, fica fácil construir o programa, já que normalmente só é necessário parametrizar o modelo pronto. Essa alternativa representa para o programador (modelador) a aprendizagem de uma nova linguagem, além de fornecer pouca flexibilidade a mudanças, por 
ser muito específico para um determinado tipo de sistema;

uso de linguagens de simulação de uso geral: permitem que um número maior de sistemas seja modelado do que em pacotes especificos. Nesse caso, as linguagens já contém todas as estruturas necessárias para a criação de um ambiente de simulação, livrando o programador da necessidade de executar tal tarefa. Como essas linguagens são menos específicas, permitem a simulação de um número maior de sistemas. $O$ usuário pode ter que aprender uma nova linguagem;

.através de uma extensão funcional de uma linguagem de programação de uso geral: utilizando este enfoque, tem-se os aspectos gerais de uma linguagem de programação unidos ao caráter específico de uma linguagem de simulação. Isso permite ao usuário codificar seu programa utilizando primitivas de uma biblioteca e uma linguagem convencional.

\subsubsection{Fase de Testes}

\section{Depuração do Programa}

O programa de simulação deve ser conferido para garantir que está livre de erros (de programação, de lógica, etc), devendo produzir resultados que pareçam coerentes.

\section{Verificação}

O passo seguinte no processo de modelagem é verificar se o programa de simulação é uma implementaçāo válida do modelo. Para modelos pequenos, pode ser feito por inspeção, para modelos maiores uma análise mais detalhada se torna necessária. A técnica normalmente utilizada consiste em uma revisão cuidadosa no programa e no modelo [SAN89b]. A verificação pode ser feita através da comparação com modelos analíticos. Provavelmente existirão variações nos resultados, porém deve-se levar em conta a variabilidade estatística dos resultados, referentes à geração de amostras aleatórias. A utilização de diferentes sementes de números aleatórios em diversas execuções da simulação pode minimizar essa variabilidade [MAC87]. 


\section{Validação}

O modelo de simulação deve ser uma representação válida do sistema atual, ou seja, deve reproduzir o comportamento do sistema com fidelidade, para satisfazer aos objetivos da análise. É tarefa da validação comparar o modelo com o sistema, e se o resultado não for satisfatório, a lógica do modelo, bem como as suposiçōes e simplificações efetuadas e os dados coletados devem ser analisados cuidadosamente [DAV89]. Quando o sistema sendo modelado já existe, medidas do mesmo são comparadas com resultados de uma simulação do sistema e se os resultados coincidem, o programa de simulação é considerado válido, podendo ser utilizado para análise do sistema e para predizer os efeitos de modificações no mesmo [SAN89b]. Quando a simulação é feita sobre um projeto, a validação é feita examinando-se o projeto do sistema, e cada suposição e abstração é justificada. A validação pode também se basear em comparações com outros modelos do sistema já validados, como por exemplo modelos analíticos [SOA90, SAR84].

Técnicas para verificação e validação são demoradas mas importantes quando se deseja que o modelo fique livre de erros e tenha credibilidade, e consistem em um dos aspectos mais críticos de um estudo via simulação [MAR80, SAR84].

\subsubsection{Fase de Análise}

\section{Análise de Saída da Simulação}

Uma questão importante em simulação é por quanto tempo (e quantas vezes) executar o programa de simulação. As entradas da simulação são obtidas através da geração de variáveis aleatórias de distribuições de probabilidades, as saídas da simulação são funções dessas variáveis, e portanto a análise de saída é um problema estatístico (os resultados das execuções de uma simulação devem ser cuidadosamente analisados para entender o seu significado). Existem vários métodos descritos na literatura para determinar quando parar um programa de simulação, baseado no cálculo de um intervalo de confiança para a média de uma variável de saída (citados no capítulo 3). Ressalta-se que métodos para análise de saída auxiliam na obtenção de uma estimativa precisa de uma medida de desempenho de um modelo; o quão precisamente tal medida representa o desempenho do sistema depende da validade das suposições utilizadas para construir o modelo [MAC87]. 


\subsection{Simulação Discreta}

Um modelo de simulação descreve o comportamento dinâmico de um sistema, isto é, a maneira como este executa um determinado trabalho. A sensibilidade dos resultados da simulação à mudanças nos parâmetros de entrada pode ser avaliada pela realização de uma série de repetições da simulação, variando-se tais parâmetros. Esse procedimento permite analisar alternativas para o sistema modelado.

Os objetos de um sistema são definidos como sendo entidades [SOA90]. O objetivo de um modelo para simulação é reproduzir as atividades das entidades engajadas e a partir daí conhecer algo sobre o comportamento e desempenho do sistema.

Um sistema pode ser visto como uma coleção de processos interativos, cada processo composto por diversas atividades e com as interações controladas e coordenadas pela ocorrência de eventos [MAC87]. A relação entre esses conceitos pode ser melhor entendida pela figura 2.2 .

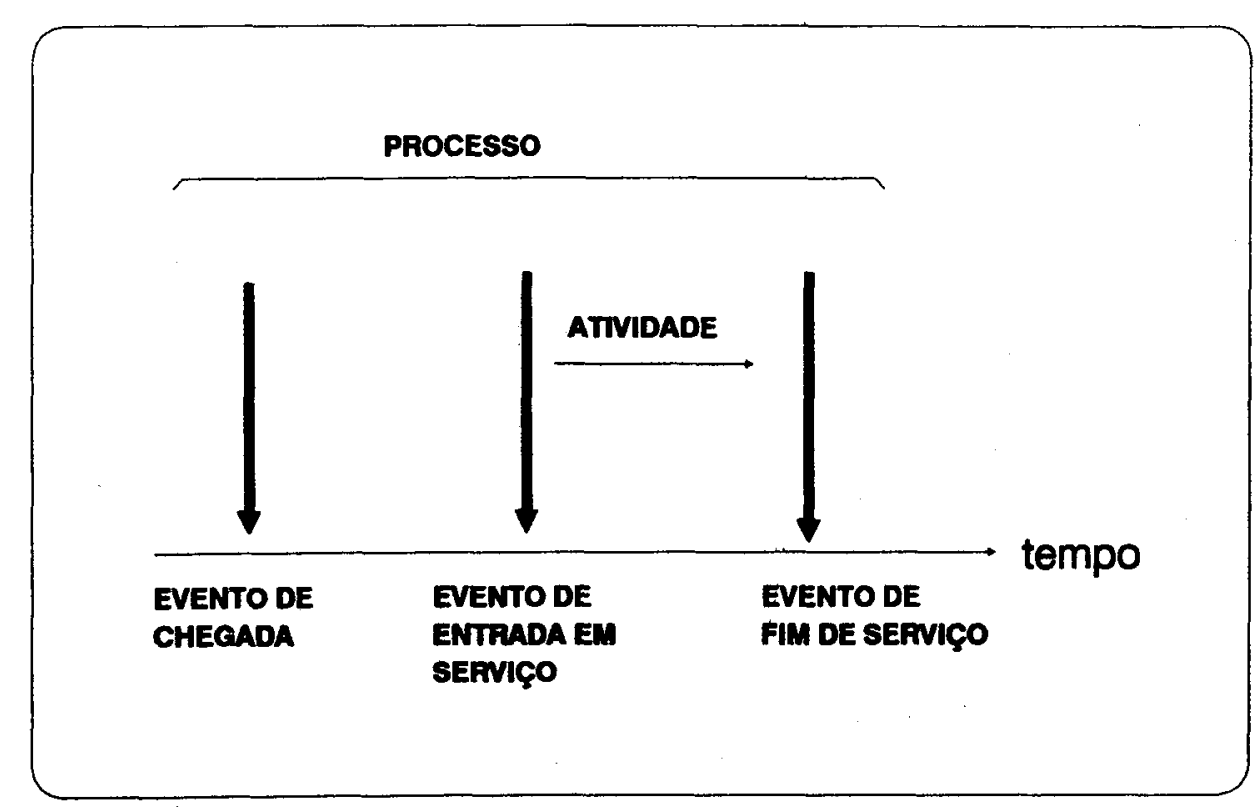

Figura 2.2: Relação entre Evento, Processo e Atividade 
.atividade: é a menor unidade de trabalho, e depende da visão particular do sistema (toda atividade tem um tempo associado). Uma atividade pode ser por exemplo a execução de um passo de uma instrução ou uma tarefa toda, dependendo do nível de detalhamento considerado;

processo: um processo é um conjunto de atividades logicamente relacionadas, como por exemplo a execução de uma operação de disco (composta das seguintes atividades: posicionamento, atraso de rotaçâo, transferência dos dados). A definição dos processos de uma simulação depende do nível de abstração adotado, por exemplo, um programa inteiro pode ser visto como um processo (compreendendo atividades de computação, leitura e escrita de dados). Em um outro nível, a execução de uma atividade de escrita pode ser vista como um processo compreendendo posicionamento, latência e transferência de dados. Tal programa poderia ser visto ainda como uma atividade de um sistema maior. Assim, uma operação definida como uma atividade em um nível de abstração pode ser definida como um processo compreendendo um conjunto de atividades em um outro nível de abstração, e a distinção entre atividade e processo depende do nível de detalhamento;

.evento: um evento consiste em uma mudança instantânea do estado de alguma entidade do sistema (um evento ocorre em um ponto isolado do tempo, no qual decisões devem ser tomadas de forma a iniciar ou terminar uma atividade). A simulação do sistema é produzida pela execução da lógica associada a cada evento, em seqüência ordenada no tempo [SOA90].

\subsection{Modelagem para Simulação Discreta}

Um modelo para simulação discreta pode ser organizado baseado em três entidades básicas, resultando em uma das seguintes orientações:

.orientação a evento: pela definição das mudanças nos estados que podem ocorrer em cada tempo de evento;

.orientação a atividade: através da descrição das atividades nas quais as entidades do sistema se envolvem; 
.orientação a processo: por meio da descrição dos processos através dos quais as entidades fluem.

A seguir $e$ apresentada uma breve descrição dos ambientes de simulação voltados para cada uma das orientações.

\subsubsection{Simulação Orientada a Evento}

Na simulação orientada a evento, um sistema é modelado pela definição das mudanças que ocorrem no tempo de evento. O modelador deve determinar os eventos que podem causar a mudança no estado do sistema e desenvolver um algoritmo associado a cada evento. O sistema é simulado pela execução dos algoritmos em uma seqüência ordenada no tempo.

Essa sequiência ordenada no tempo é mantida em uma estrutura de lista, denominada lista de eventos futuros, na qual cada entrada contém o tempo de ocorrência de um evento juntamente com um identificador que define as ações que devem ser consideradas quando $o$ evento ocorrer. $O$ identificador de evento correspondente é inserido na lista de eventos futuros por um mecanismo de escalonamento. Após completar todas as operações possíveis em um particular tempo de simulação, o mecanismo escalonador é ativado para selecionar o próximo evento a ser executado [MAC75]. Escalonar um evento significa então gerar o tempo em que ocorrerá o próximo evento e inserí-lo na lista de eventos futuros, em forma ordenada pelo tempo de ocorrência.

Como um exemplo, considera-se o atendimento a clientes, por caixas de um banco [MAR80]. Ao chegar ao banco, o cliente entra na fila e espera sua vez de ser atendido. Após terminar suas operações no caixa, o cliente deixa a agência bancária. Mudanças de estado no sistema ocorrem devido aos seguintes eventos:

.um cliente chega para pagar suas contas;

um cliente já foi atendido por um caixa e parte do sistema.

A lógica associada aos eventos pode ser descrita da seguinte forma [SOA90]: 


\section{.Evento Chegada de Cliente}

Escalone a próxima chegada

Se o caixa está ocupado então

Aumente o número de clientes na fila

Senão

Torne o estado do caixa ocupado

Escalone o fim de atendimento para tempo_corrente + tempo_atendimento

\section{.Evento Término de Atendimento}

Se existe algum cliente na fila então

Retire um cliente da fila para atendimento

Escalone o fim de atendimento para tempo_corrente + tempo_atendimento

Senão

Torne o estado do caixa desocupado

O programa de simulação pode ser organizado da seguinte forma:

Escalone a primeira chegada

Selecione o primeiro evento

Avance o tempo de simulação para o tempo de ocorrência do evento

Se final de simulação então

Imprima estatísticas

Senão

Se evento $=$ Chegada de Cliente então

Trata chegada de Cliente

Senão

Trata término de atendimento

\subsubsection{Simulação Orientada a Processo}

Em simulação orientada a processo, o sistema sendo simulado é visto como uma coleção de processos interativos, controlados e coordenados pela ocorrência de eventos [MAC75]. Como visto na seção 2.4, um processo é um conjunto de atividades logicamente relacionadas. 
O programa de simulação é organizado como um conjunto de processos, os quais executam concorrentemente durante a simulação. A descrição de um processo tem a forma de um procedimento de uma linguagem de programação [MAC75].

Como na orientação a eventos, também existe um mecanismo de escalonamento e uma estrutura de lista, com a diferença de que cada entrada na lista define um processo e seu ponto de reativação (para processos que são bloqueados e novamente postos para executar).

Basicamente, uma simulação orientada a processo deve seguir os seguintes passos:

.definir as entidades do sistema;

.criar um processo para cada entidade descrevendo suas etapas;

.executar concorrentemente os processos.

No exemplo dos clientes sendo atendidos por caixas de uma agência bancária, descrito na seção anterior, seguindo esse tipo de orientação temos o processo cliente organizado da seguinte maneira:

\section{.Processo Cliente}

Se o caixa está desocupado então

Torne o estado do caixa ocupado

O cliente ocupa o caixa pelo tempo de atendimento (escalone processo para tempo_corrente + tempo_atendimento)

Torne o estado do caixa desocupado

O cliente parte do sistema

Senão

O cliente entra na fila de espera

A chegada de novos clientes ao sistema (o banco) pode ser descrita como no processo Chegada de Clientes:

.Processo Chegada de Clientes

Indique chegada de novo cliente

Escalone processo para tempo_corrente + tempo_entre_chegadas 
O programa de simulação executa concorrentemente vários processos Cliente, que chegam segundo uma distribuição de probabilidade, requisitam serviços e vão embora.

\subsubsection{Simulação Orientada a Atividade}

Utilizando essa orientação, o modelador descreve cada atividade possível para cada entidade do sistema, definindo as condições que causam seu início e seu término. Os eventos que iniciam ou finalizam uma atividade não são escalonados pelo modelador, mas são iniciados a partir das condiçōes especificadas para a ativiciade. Conforme o tempo de simulação avança, as condições para o início ou término de uma atividade são examinadas, e no caso de alguma condição ser satisfeita, a atividade correspondente é escalonada para execução no tempo de simulação corrente [SOA90, MAC75, MAR80].

No exemplo dos clientes sendo atendidos por caixas de um banco, temos as seguintes atividades:

.chegada de um cliente;

.término de atendimento.

A estrutura básica do programa de simulação é mostrada a seguir.

Início

tempo de simulação $=1$

Enquanto não fim de simulação

Verificar o conjunto de atividades

Se chegada de cliente então

Processa chegada

Se término de atendimento então

Processa término

tempo de simulação $=$ tempo de simulação +1

Imprimir Estatísticas

Para a implementação de uma simulação segundo uma das orientações apresentadas, existem linguagens e pacotes de simulação que possibilitam ao 
modelador escrever programas de simulação orientados a evento, processo ou atividade, como abordado na seção 2.6.

\subsection{Implementação de um Modelo de Simulação}

Como visto na seção 2.3.1, pode-se usar os seguintes enfoques para a implementação de um modelo de simulação:

linguagens de programaçāo convencionais;

linguagens de simulaçāo;

.pacotes de uso específico;

.extensōes funcionais.

Um requisito importante para as linguagens de simulação é a presença de mecanismos para representação do tempo. Enquanto o sistema sendo modelado executa em tempo real, a simulação trabalha com um relógio próprio, que marca a passagem do tempo no programa de simulação (para refletir a passagem desse tempo, pode ser utilizada uma variável, atualizada a cada avanço do relógio simulado) [MAC75]. Outro requisito consiste em oferecer facilidades para coleta de estatísticas e emissão de relatórios.

O uso generalizado da simulação como uma ferramenta de análise de sistemas deu origem a uma série de linguagens especificamente projetadas para este fim. Soares [SOA90] classifica os pacotes para simulação existentes em pacotes de uso específico e linguagens de simulação.

\subsubsection{Linguagens de Simulação}

Essas linguagens de simulação são projetadas para a modelagem de sistemas de vários tipos [SOA90].

As linguagens para simulação discreta são classificadas em orientadas a atividades, processos ou eventos, baseado na organização imposta [MAC87, TAN94]. Cada classe de linguagem impõe ao modelador uma visão diferente do sistema, o que 
implica no fato do modelo de simulação poder ser visto como um conjunto de atividades, de processos ou de eventos.

\subsubsection{Linguagens Orientadas a Atividade}

Nesse caso, o programa de simulação é organizado como um conjunto de descriçōes de atividades, uma para cada tipo de atividade no sistema.

Soares, em [SOA90], afirma que para certos tipos de problemas o uso dessa abordagem provê um modelo conciso, adequado para situações onde a duração da atividade é indefinida. A organização do modelo de simulação por atividades não tem sido largamente adotada, merecendo pouco destaque na literatura [MAC75].

Um exemplo de linguagem de simulação orientada a atividade é CSL [MAC75].

\subsubsection{Linguagens Orientadas a Evento}

Nesse tipo de orientação o programa de simulação é organizado como um conjunto de rotinas ou seções de eventos [MAC75]. A execução das rotinas de evento é sequencializada por um mecanismo de lista (chamada lista de éventos futuros).

As linguagens orientadas a evento tendem a impor uma visão global e de alto nível do sistema ao modelador. Existe ainda a tendência de se englobar operaçōes sobre atividades logicamente nâo relacionadas em um único evento. Para sistemas complexos, isso pode ocasionar a perda de identidade com a estrutura do sistema real, devido a extensão do programa de simulação, e a programas mais difíceis de serem modificados [MAC75].

Devido aos fatores apresentados, linguagens de simulação orientadas a evento são adequadas a modelos de pequeno e médio porte. Com o aumento da complexidade, MacDougall apresenta o uso de linguagens orientadas a processo como melhor alternativa.

Exemplos de linguagens de simulação orientadas a evento são SIMSCRIPT [KOB78, MAC75] e SLAM II [SOA90]. 


\subsubsection{Linguagens Orientadas a Processo}

Saydam [SAY85] justifica o uso de linguagens orientadas a processo em análise de sistemas que vem se tornando cada vez mais complexos, como ocorre em áreas como a robótica, projeto de sistemas computacionais e redes de comunicação. Segundo o autor, linguagens orientadas a processo são a ferramenta adequada para a modelagem desse tipo de sistema que necessitam de altos investimentos e portanto exigem que o comportamento dos parâmetros custo-projeto-desempenho sejam investigados antes da construçāo do sistema.

As linguagens orientadas a processo apresentam a vantagem de permitir uma representação mais natural do modelo. Essa característica é importante em sistemas de grande porte, pois o programa de simulação tende a se tornar uma descrição do comportamento do sistema real, estabelecendo assim maior identidade com o mesmo (o que facilita a tarefa de garantir que o modelo é uma representação válida do sistema) [MAC75].

Alguns exemplos de linguagens de simulação orientadas a processo são GPSS, Q-GERT [SOA90], ASPOL [SOA90, MAC75], SIMULA [MAC75, SAY85], SOL [MAC75], SIMPL/I X [SAY85], RESQ e SLAM II [SOA90].

\subsubsection{Pacotes de Simulação de Uso Específico}

Os pacotes de uso específico são voltados para a avaliação de sistemas particulares. Devido ao fato de serem muito específicos para uma dada aplicação, esses pacotes oferecem pouca flexibilidade a mudanças.

A formulaçāo do modelo é construída na própria ferramenta, e os parâmetros do modelo são especificados através de uma linguagem relacionada com o sistema modelado. Alguns exemplos são [SOA90]:

.BEST/1, CMF, VMPredictor: apropriados para modelagem de sistemas computacionais e respectivos sistemas operacionais;

.PET, NETWORK II.5: utilizados na modelagem de redes de computadores; 
IDSS 2.0: aplicado na modelagem de sistemas aeroespaciais;

.CROPS: usado em modelagem de sistemas agrícolas.

\subsubsection{Linguagens de Programação}

Em princípio, toda linguagem de programação é uma candidata a linguagem de simulação [SAY85, PEG91]. Porém, linguagens como Fortran, C, Pascal, Modula 2 são projetadas para uso geral, não fornecendo todas as ferramentas (estruturas de dados, facilidades para manipulação de listas e abstração de dados) necessárias para um ambiente de simulação. Procedimentos específicos tornam-se necessários para criar e manipular as interaçōes dessas estruturas de programação.

Para desenvolver um programa de simulação em uma linguagem convencional (como Modula 2, Pascal, C) o programador deve criar todo um ambiente necessário para a simulação. Isto pode ser uma desvantagem pois exige conhecimentos na área de simulaçāo e programação.

Uma vantagem de se implementar um programa de simulação em uma linguagem de programação é que o programador não necessita aprender uma nova linguagem, pois pode trabalhar com a que está habituado. Porém o programador pode não possuir o conhecimento necessário para criar todo o ambiente necessário à simulação, então uma solução pode ser o uso de extensões funcionais juntamente com uma linguagem que seja dominada pelo mesmo. Extensões funcionais sāo tratadas a seguir.

Destaca-se que o programador pode desenvolver um ambiente orientado a eventos, processos ou atividades, dependendo da aplicação.

\subsubsection{Extensões Funcionais}

Extensões são bibliotecas que, quando inseridas em linguagens hospedeiras (como C ou Modula 2), compõem um ambiente completo de simulação. Essas extensões facilitam o trabalho do programador, que não necessita aprender uma nova linguagem. 
Alguns exemplos são:

.extensões da linguagem C: SMPL [MAC87] (orientada a evento), CSIM [EDW92] (orientada a processo) e EFC [SOU92] (orientada a processo);

.extensões da linguagem Modula 2: EFM2 [SPO92] e HPSIM [SHA88] (orientadas a processo).

\subsection{Conclusão}

Simulação é um método que tenta imitar o comportamento do sistema em estudo, constituindo-se em um experimento estatístico que observa o comportamento do modelo no decorrer do tempo. É uma técnica que tem sido amplamente utilizada nas mais diversas áreas do conhecimento humano, devido à sua flexibilidade e baixo custo. Tais características também a tornam preferível em situações onde outras técnicas (como modelagem analítica e instrumentação) não apresentam solução ou então não podem ser aplicadas.

Desenvolver um modelo de simulação envolve seguir várias fases, compreendendo o desenvolvimento, teste e análise dos resultados obtidos. $\mathrm{Na}$ fase de desenvolvimento define-se um modelo para o sistema a ser simulado, identificam-se e obtêm-se os dados que vão alimentar o programa de simulação (considerações sobre os parâmetros do modelo de simulação são feitas no capítulo 3). O programa pode ser desenvolvido utilizando-se uma linguagem de programaçāo, uma linguagem de simulação, um pacote de uso específico ou então uma extensão funcional. $\mathrm{Na}$ fase de testes faz-se a depuração do programa, que é verificado e valịdado para que o modelo seja uma representação razoável do sistema real. Na fase de análise os métodos estatísticos servem de apoio a tomadas de decisão como com relação ao número (e tamanho) das execuções de um programa de' simulação, para que se obtenham resultados razoáveis.

Modelos de simulação para sistemas discretos usualmente envolvem disputa por recursos, levando a formaçâo de filas onde os componentes do sistema devem esperar até que os recursos estejam disponíveis. Os atrasos entre as mudanças de estado são determinados estatisticamente, com o intervalo exato selecionado de acordo com alguma amostragem de uma distribuição de probabilidade [SHA88]. Outros métodos 
estatísticos, como por exemplo para determinar o número de execuções de um programa de simulação, chamado de análise de saída [MAC87], são também necessários, conforme descrito no capítulo 3. 


\section{Capítulo 3}

\section{Parâmetros de Entrada e Análise Estatística de Resultados}

Este capitulo discute tópicos relacionados com os parâmetros de entrada de uma simulação, destacando quais parâmetros são importantes para diferentes tipos de modelos baseados em redes de filas. Também são apresentados métodos que permitem obter os resultados finais do programa de simulação com maior precisão.

\subsection{Introduçāo}

Como visto no capítulo 2, simulação é um método de solução de modelos através de um experimento estatístico que observa o comportamento do modelo no decorrer do tempo. Os passos básicos envolvidos em conduzir um estudo de simulação podem ser divididos em três fases: desenvolvimento, teste e análise. $\mathrm{Na}$ fase de desenvolvimento define-se um modelo para o sistema a ser simulado. Formalizado o problema e definidos os objetivos, inicia-se o processo de construção do modelo. Nessa fase são identificados e obtidos os parâmetros que irão alimentar o programa de simulação. Na fase de testes o programa é verificado e validado, e na fase final utilizam-se métodos estatísticos para a obtenção dos resultados.

A obtenção dos parâmetros para o modelo de simulação tem uma grandé influência sobre a precisão obtida nos resultados da simulação. Os parâmetros devem ser estimados (caso esteja-se modelando um sistema que não existe) ou podem ser medidos (no caso de modelagem de um sistema existente). 
O programa de simulação é executado utilizando-se valores aleatórios, com a finalidade de representar o tempo de chegada de usuários, tempos de serviço, etc. Os valores aleatórios gerados, como veremos no decorrer deste capítulo, não são de fato aleatórios, mas produzidos por um algoritmo, de acordo com uma distribuição de probabilidade [SOA90].

Para a obtenção dos resultados da simulação, devem ser observados o estado inicial do sistema, que pode influenciar as estatísticas obtidas, bem como métodos para se determinar quando parar o programa de simulação.

Este capítulo apresenta uma introdução a redes de filas e uma classificação dos modelos baseados em redes de filas. Discute-se ainda a obtenção dos parâmetros de entrada de uma simulação, relacionados a cada um dos tipos de modelos baseados em redes de filas, e são apresentados métodos para a parada do programa de simulação.

\subsection{Redes de Filas}

A maioria das informações obtidas a partir de uma simulação estão relacionadas com os tempos de espera por serviços ou o número de entidades esperando por um tipo particular de serviço. As linhas de espera são denominadas filas, e modelagem de filas é uma parte essencial em todo o estudo de simulação [MAR80].

Basicamente, uma rede de filas é constituída de entidades denominadas centros de serviço e um conjunto de entidades chamadas usuários (ou clientes), os quais recebem serviço nos centros. Um centro de serviço é constituído por um ou mais servidores (representando os recursos do sistema sendo modelado) que prestam serviço aos usuários, e uma área de espera (denominada fila) para usuários cujos pedidos excedem a capacidade do centro de serviço, e estão esperando pelo serviço requisitado.

Como exemplo de recurso que pode ser modelado como um centro de serviço, tem-se a unidade central de processamento (UCP) de um computador, no qual um cliente do sistema pode ser representado por uma tarefa ou "job". O cliente circula pelo sistema sendo modelado, requisitando serviço nos centros, e esperando em filas quando não existe servidor disponível. 
Os centros de serviço podem ser classificados segundo o número de servidores no centro de serviço e o número de filas de espera para um dado servidor. Assim, pode-se ter centros com uma única fila (ou várias) e um servidor (ou vários), como discutido na próxima seção.

\subsection{Modelos Baseados em Redes de Filas}

Como visto no capítulo 2, um modelo consiste em uma abstração do sistema a ser estudado. Assim, um sistema é modelado pela abstração de sua estrutura e características através de redes de filas.

O modelo mais simples é constituído de um centro de serviço com uma fila e um servidor [MAR80, SOA90]. O comportamento básico de muitos sistemas de filas pode ser representado pelo modelo da figura 3.1. Os clientes chegam a algum servidor (ou centro de serviço), e se o servidor está ocupado, o cliente une-se à fila associada com aquele servidor e espera por sua vez. Eventualmente, o cliente é selecionado para atendimento, de acordo com a disciplina da fila. O serviço requisitado é executado pelo servidor, e ao seu término o cliente deixa o sistema. Um exemplo desse tipo de modelo de filas consiste em um cinema com somente uma bilheteria, onde as pessoas se enfileiram para comprar seu ingresso.

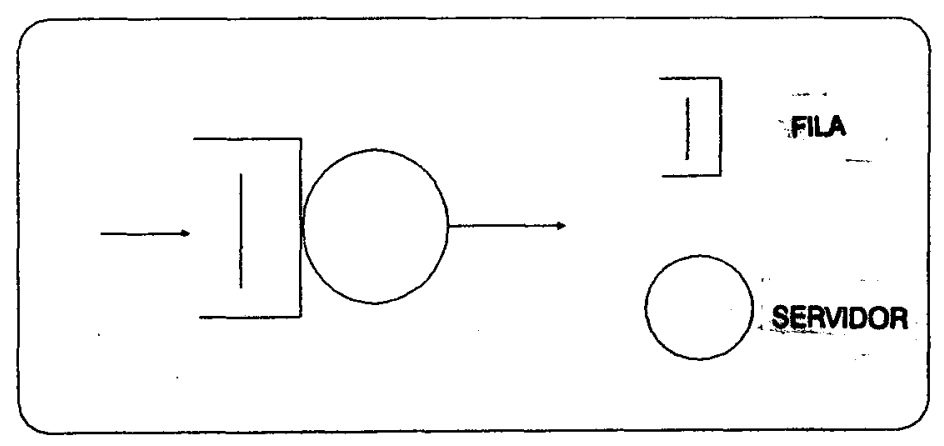

Figura 3.1: Centro de Serviço - Uma Fila e Um Servidor

Uma variação do modelo básico contém um centro de serviço constituído de uma única fila que alimenta vários servidores (figura 3.2). Um exemplo bastante comum 
desse tipo de modelo consiste em uma agência bancária, onde os caixas atendem aos clientes que formam uma fila única.

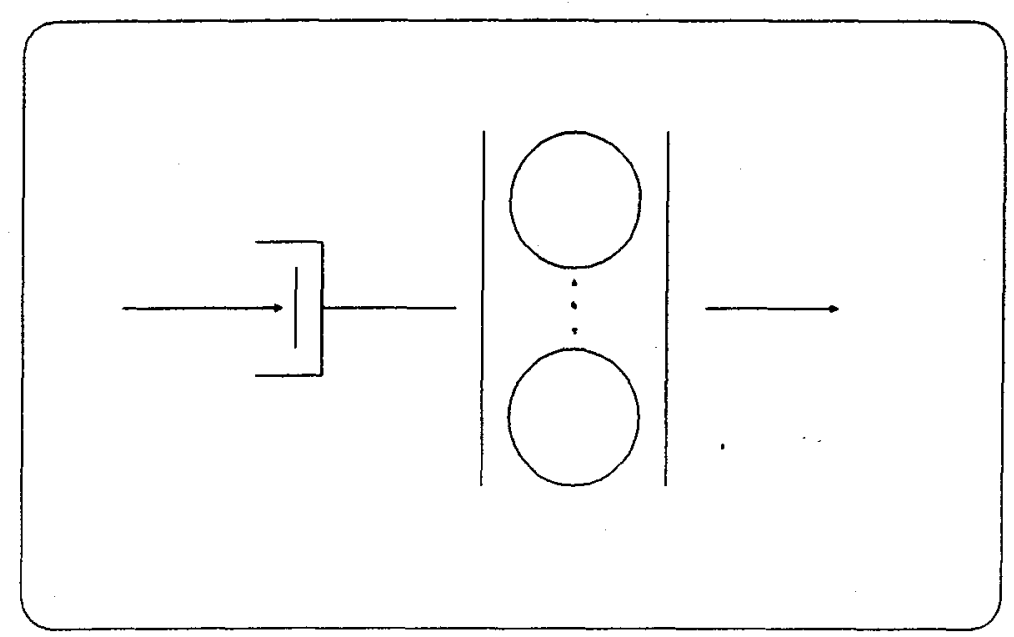

Figura 3.2: Centro de Serviço - Uma Fila e Vários Servidores

Pode-se ter também modelos constituídos de centros de serviço formados por múltiplas filas associadas a um único servidor (figura 3.3). Pode-se considerar como exemplo um guichê de uma repartiçâo pública que atende a usuários os quais formam duas filas diferentes. Uma das filas se destina aos aposentados, e a outra atende as demais pessoas. $O$ atendente dá preferência a fila especial, só atendendo a outra fila quando não houver mais nenhum aposentado aguardando atendimento.

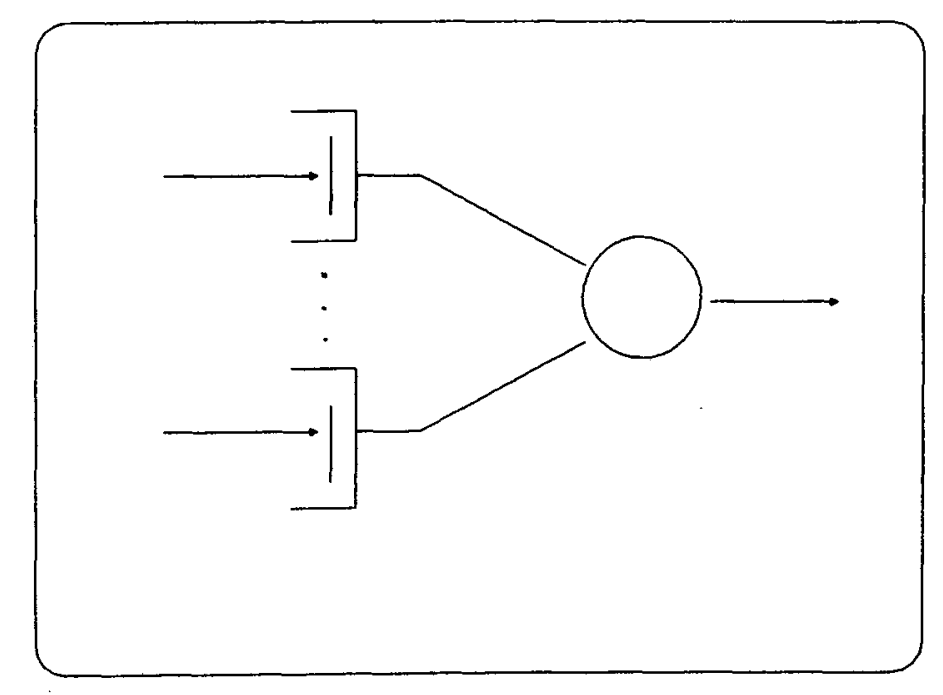

Figura 3.3: Centro de Serviço - Várias Filas e Um Servidor 
O modelo mais complexo, constituído de múltiplas filas e múltiplos servidores é apresentado na figura 3.4. Como exemplo, pode-se considerar uma agência bancária onde os vários caixas atendem a clientes que formam duas filas: uma para os clientes em geral e outra para idosos, gestantes e portadores de deficiências físicas. Os clientes em geral só são atendidos quando não houver ninguém na fila especial.

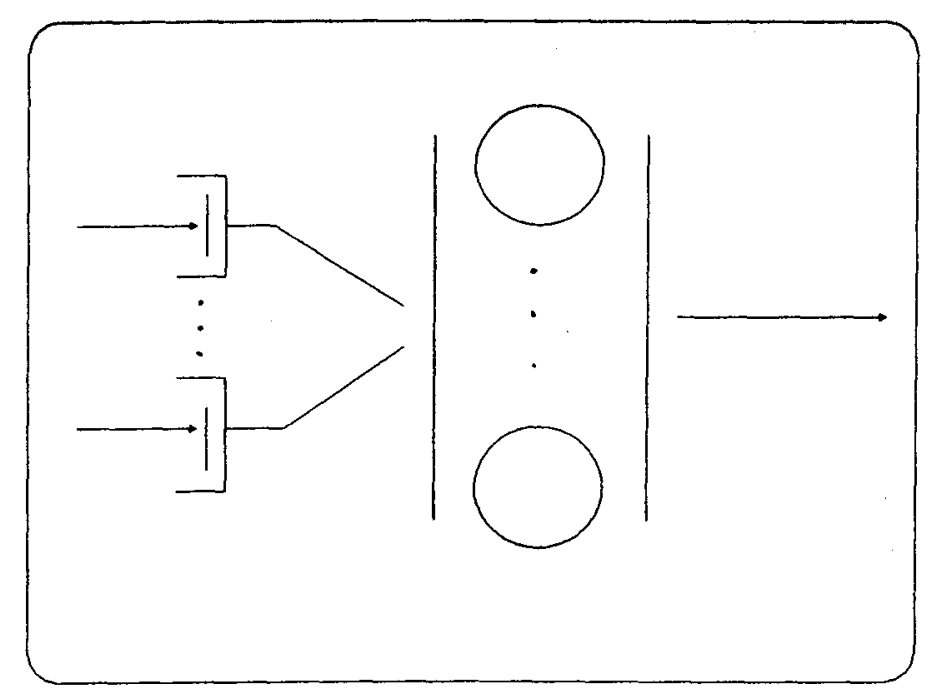

Figura 3.4: Centro de Serviço - Vários Servidores e Filas

Para cada um dos modelos descritos nesta seção, pode-se identificar alguns parâmetros necessários para a especificação completa do modelo. No primeiro modelo (uma fila e um servidor) deve-se definir qual a disciplina da fila, a taxa de chegada de novos usuários e o tempo necessário para executar o serviço.

O modelo constituído de uma fila e vários servidores necessita, além dos parâmetros vistos para o modelo mais simples, da seleção de um servidor quando mais de um está desocupado.

Para o terceiro modelo deve-se, além dos parâmetros necessários ao primeiro, especificar a maneira pela qual uma fila é selecionada quando o servidor fica disponível (para retirar o próximo cliente), e como um cliente escolhe uma fila para aguardar pelo serviço. 
O modelo mais complexo, constituído de centro de serviço com várias filas e vários servidores necessita de todos os parâmetros identificados para os modelos anteriores.

Assim, os seguintes parâmetros foram identificados nos modelos de redes de filas:

\section{Tempo de Serviço}

O tempo de serviço está relacionado com o tempo necessário para que um servidor execute uma tarefa. E usualmente especificado por uma distribuição de probabilidade, embora em alguns casos pode-se utilizar valores médios. A utilização de valores médios facilita a implementação mas acarreta problemas de precisão. Assim, na maioria dos casos são utilizados valores obtidos a partir de números aleatórios. Técnicas para obtenção e representação desses valores são discutidas na seção 3.4 .

\section{Algoritmos de Escalonamento (que regem a disciplina das filas de espera)}

A disputa por recursos do sistema geralmente leva à formação de filas de espera, onde os clientes aguardam sua vez de serem atendidos. Existem vários algoritmos, denominados algoritmos de escalonamento, usados para decidir qual usuário deve entrar em serviço quando um servidor se encontra disponível (tais algoritmos são frequentemente conhecidos como disciplina da fila). Assim uma disciplina de fila é uma regra para adicionar e remover clientes de uma linha de espera. Diferentes tipos de algoritmos de escalonamento podem ser aplicados em um estudo de simulação [MAR80, SOA90], dentre eles cabe ressaltar:

.FCFS("First Come First Served"): consiste em uma fila de espera padrão, a ordem de chegada é a ordem para $o$ atendimento no centro de serviço;

.LCFS("Last Come First Served"): essa disciplina tem a estrutura de uma pilha, onde o último usuário a chegar ao centro é o que entrará em serviço assim que houver disponibilidade do servidor (por exemplo carga a ser colocada em um caminhão);

.RR("Round Robin"): cada cliente é atendido por um pequeno intervalo de tempo, denominado "quantum". Caso não tenha sido suficiente, o cliente volta para o final da fila de espera, e o cliente seguinte entra para receber 
seu "quantum" de serviço. O processo se repete até que o serviço requisitado pelo cliente se complete;

.tempo de serviço: o usuário com o maior (menor) tempo de serviço esperado é retirado da fila. O problema com esse algoritmo é que a fila deve ser ordenada pelo tempo de serviço;

.uso de prioridades: as formas de escalonamento com prioridade são utilizadas para dar preferência a alguns clientes, podendo ser com ou sem preempção. Quando não existe preempção, um cliente em atendimento não é afetado quando um de mais alta prioridade chega, enquanto que no caso de existir preempção a chegada de um cliente com prioridade maior do que o que está sendo atendido faz com que este seja retirado e colocado na fila. O cliente de mais alta prioridade é atendido, e o que foi retirado só retorna ao servidor quando todos aqueles de prioridade maior já tiverem sido atendidos.

Uma importante consideração a ser feita é com relação ao tamanho da fila de espera, que pode ter comprimento limitado ou ser infinita, isto é, não fazer restrições quanto ao número de clientes que aguardam por um serviço.

\section{Tempo Entre-Chegadas}

É necessário alguma função que produza o tempo da próxima chegada ao sistema. No caso mais simples, essa função pode ter valores constantes, porém este caso nāo irá representar o modelo de modo realista. A função que descreve chegadas de clientes ao sistema deve produzir valores aleatórios que correspondam aos tempos entre-chegadas no sistema real [MAR80]. A obtenção e formas de representar esse tempo seguem as mesmas regras do tempo de serviço e serão discutidas na próxima seção.

\section{Algoritmos de Escolha de Servidores}

Quando um usuário requisita serviço e mais de um servidor do centro de serviços está disponível, deve-se escolher qual deles irá atender ao pedido. Esse algoritmo de seleção é muito similar a uma disciplina de fila, podendo ser o servidor selecionado aleatoriamente, o que está a mais (menos) tempo desocupado, ou ainda segundo algum tipo de prioridade [MAR80]. 


\section{Algoritmos para Escolha de Qual Fila Retirar o Próximo Cliente a ser Atendido}

Neste caso, quando o servidor se torna disponível, deve-se determinar de qual fila retirar o próximo usuário. A escolha pode ser feita seguindo algum tipo de prioridade, ou então aleatoriamente.

\section{Algoritmos para o Cliente Escolher em Qual Fila irá Entrar}

Um cliente, quando chega ao centro de serviço, deve optar por uma fila de espera, à sua livre escolha ou então com alguma forma de prioridade.

\subsection{Aquisição e Representação dos Parâmetros}

Aquisição dos dados é o processo de obtenção de dados sobre um fenômeno de interesse [SOA90]. Existem vários métodos que podem ser utilizados na obtenção desses dados, podendo ser através de questionários, pesquisas ou experimentação física, além de poderem ser avaliados por intuição ou pelo conhecimento que se tem do sistema.

Para a simulação de sistemas não existentes, os parâmetros devem ser estimados a partir de outros sistemas semelhantes ou pela intuição.

Para sistemas existentes, pode-se optar pela obtenção dos parâmetros através de experimentações físicas. Soares [SOA90] ressalta que a experimentação física é comumente o método de obtençāo de dados mais caro e que consome mais tempo. Além disso, cuidados devem ser tomados para que os dados obtidos sejam representativos.

Duas das ferramentas mais utilizadas para obtenção de dados de sistemas computacionais existentes são monitores de "hardware" e "software" [SOA90]. Monitores de "hardware" são conectados ao sistema, para medir sinais elétricos, porém tem capacidade limitada para medição. Monitores de "software" são programas que executam no sistema, e portanto competem com os sistemas sobre medição, podendo assim perturbar os valores medidos e degradar o desempenho do sistema em estudo.

Um dos problemas relacionados com a aquisição de dados para a definição das entradas do modelo é o de como converter os dados obtidos em uma forma utilizável [SOA90]. Um método para a transformação de dados em uma forma mais fácil de ser 
manuseada consiste no seu agrupamento em classes. Os dados são resumidos pela tabulação no número de dados que ocorreram dentro de cada classe, numa tabela denominada distribuição de frequiência. Por exemplo, a tabela 3.1 apresenta o tempo entre-chegadas de pessoas, num sistema qualquer.

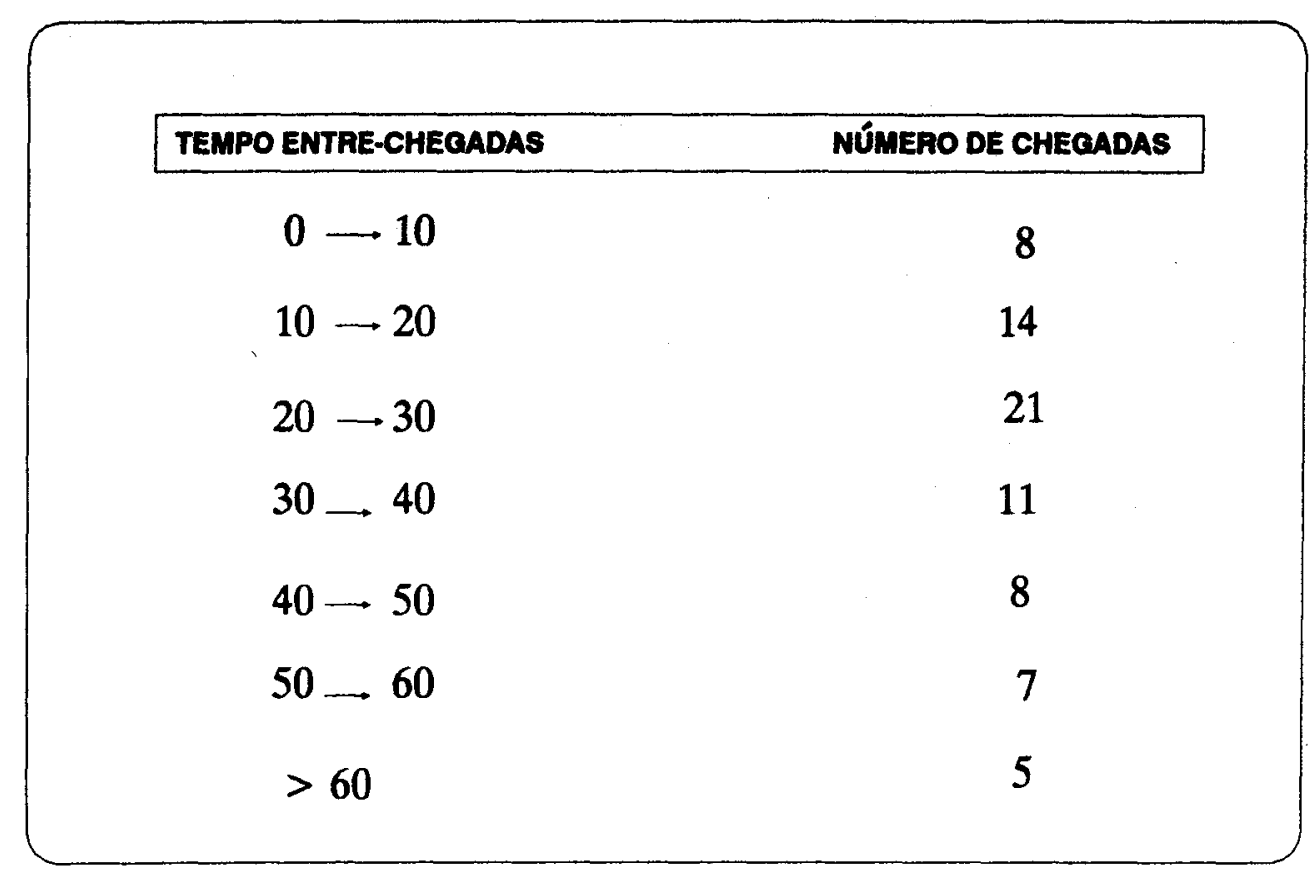

Tabela 3.1: Distribuição de Freqüência

A partir desta distribuição de freqüência, pode-se gerar uma tabela que será utilizada diretamente na simulação ou pode-se ajustar a estes dados uma distribuição teórica. A tabela a ser utilizada diretamente na simulação é a que contém a distribuição de freqüência acumulada obtida pela adição sucessiva das ocorrências da tabela 3.1 (obtém-se assim o número acumulado de chegadas da tabela 3.2), seguida pela divisão do valor acumulado em cada classe pelo número total de ocorrências (tabela 3.2).

O exercício de simulação requer a geração de amostras aleatórias, para indicar por exemplo o tempo da próxima chegada ao sistema ou tempo de serviço. Pode-se obter tais amostras diretamente de tabelas, como a da tabela 3.2, ou se os dados ajustam a uma distribuição teórica, obter a partir desta [PEG91, SOA90]. Ressalta-se que quando o sistema em estudo não existe, pode-se utilizar os dados obtidos a partir 
de um sistema semelhante.

\begin{tabular}{|c|c|c|}
\hline $\begin{array}{c}\text { TEMPO ENTRE-CHEQADAS } \\
\text { MENOR QUE }\end{array}$ & $\begin{array}{c}\text { NúmERO ACUMULADO } \\
\text { DE CHEGADAS }\end{array}$ & $\begin{array}{c}\text { FAEQÜENCLA } \\
\text { ACUMULADA }\end{array}$ \\
\hline 10 & 8 & 0,108 \\
20 & 22 & 0,297 \\
30 & 43 & 0,581 \\
40 & 54 & 0,730 \\
50 & 62 & 0,838 \\
60 & 69 & 0,932 \\
$\infty$ & 74 & 1 \\
\hline
\end{tabular}

Tabela 3.2: Distribuição de Freqüência Acumulada

No caso da tabela, é gerado um número aleatório uniformemente distribuído no intervalo [0,1). Esse número determina um intervalo, a partir do qual é obtido um valor aleatório (podendo ser uniformemente distribuído).

A segunda opção para geração de valores aleatórios consiste na utilização de uma distribuição teórica. Para ajustar os dados observados a uma distribuiçāo teórica conhecida, deve-se comparar o gráfico obtido com os dados da tabela 3.1 com o gráfico de uma função conhecida. Caso tenham um formato parecido, pode-se adotar tal distribuição para a obtençāo de amostras aleatórias na simulação. Soares [SOA90] destaca que esse é o método mais simples de se representar uma distribuição. Algumas distribuições importantes na modelagem de sistemas são [DAV89, SOA90]:

.Distribuição Uniforme;

.Distribuição de Poisson; 


\section{.Distribuição Triangular; \\ .Distribuição Exponencial; \\ .Distribuição Normal; \\ .Distribuição Erlang.}

Uma vez selecionada uma distribuição, deve-se assegurar a qualidade do ajuste. Isto pode ser efetuado com o uso de testes estatísticos, como Qui-quadrado e Kolmogorov-Smirnov [SOA90, PEG91]. Pode-se ainda optar por uma função não conhecida (no caso dos dados não se ajustarem a nenhuma distribuição conhecida). Neste caso deve-se determinar a função de distribuição.

Uma vez obtida a função de distribuição, números aleatórios entre 0 e 1 devem ser gerados para entāo avaliar-se a inversa da função nestes pontos, obtendo-se os valores aleatórios desejados.

Como visto acima, qualquer que seja o método utilizado (tabela ou função de distribuição) torna-se necessário a geração de números aleatórios. Os números aleatórios são obtidos através de funçōes cuidadosamente construídas para dar a aparência de um comportamento aleatório [PEG91, SOA90].

Um bom gerador de números aleatórios deve produzir números que sejam independentes entre si, e com igual probabilidade de ocorrência.

Para a obtenção destes números, emprega-se uma equação recursiva que gera o i-ésimo número aleatório a partir do (i-1)-ésimo número. Os números produzidos são denominados pseudo-aleatórios, porque a seqüência é produzida deterministicamente por uma equação. Bons resultados podem ser obtidos através de métodos simples, como o congruente [MAR80, SOA90], que emprega as equações recursivas:

$$
\begin{aligned}
& z_{i+1}=\left(a z_{i}+b\right)(\bmod c) \quad i=0,1,2 \ldots \\
& r_{i+1}=\left(z_{i}+1\right) / c
\end{aligned}
$$

onde zo é a semente e ri é o i-ésimo número pseudo-aleatório. Os melhores valores para $\mathrm{a}, \mathrm{b}, \mathrm{e} \mathrm{c}$ tem sido objeto de intensa pesquisa [SOA90].

Um gerador de números pseudo-aleatórios iniciando com o mesmo número ou semente irá sempre produzir a mesma seqüência de números. Sementes diferentes 
levam a diferentes seqüências e se as sementes são números não muito próximos no ciclo, os números gerados irão parecer independentes uns dos outros [DAV89]. Destaca-se que quando várias execuções de um programa de simulaçāo são usadas para encontrar médias e variâncias de resultados, cada execução deve ser baseada em seqüências de números diferentes e independentes.

O emprego de aleatoriedade nos parâmetros de entrada das simulações torna necessário um estudo estatístico para a análise e obtenção dos resultados. A seção 3.5 apresenta uma discussão sobre a análise estatística para a obtenção das saídas de uma simulação.

\subsection{Análise Estatística dos Resultados}

Uma parte importante em todo o estudo de simulação refere-se à análise para obtenção dos resultados. Como em um estudo via simulação os resultados obtidos são valores médios, a estatística oferece métodos para o cálculo de intervalos de confiança, o que permite obter dados mais precisos e servem como limitante para as execuções do programa de simulação. Também deve-se cuidar para que o estado inicial do sistema não interfira nas medições efetuadas.

\subsubsection{Influência das Condições Iniciais nos Resultados da Simulação}

As condições iniciais ou estado de partida da simulação são problemas característicos de toda simulação [SOA90]. Em certos casos torna-se necessário um conjunto preciso de condiçōes iniciais para descrever o sistema corretamente.

Algumas simulações descrevem sistemas que operam em um período de tempo curto, como por exemplo o lançamento de um foguete ou a simulação da carga inicial de um sistema de um computador. Tais simulações são denominadas transientes [DAV89]. Nesse caso as condiçōes de partida devem espelhar o estado inicial do sistema.

Já em uma simulação "steady state", as condições iniciais, ou seja, os valores iniciais de todos os parâmetros irão influenciar o tempo necessário para atingir o 
estado estacionário (condiçăo de equilíbrio). Caso os resultados sejam obtidos durante o período todo de simulação, o período inicial (até atingir o equilíbrio) pode influenciar os resultados. Essa influência inicial pode ser compensada através de uma execução mais longa do programa de simulação, evitada rejeitando-se dados coletados no período transiente ou então iniciando-se o experimento com o sistema já em equilíbrio [SOA90, PEG91].

\subsubsection{Teste de Parada e Precisão dos Resultados}

Em estudos de simulação inferências concernentes ao comportamento do sistema em estudo devem ser realizadas, baseadas nos resultados experimentais obtidos da simulação [SOA90]. As técnicas para a análise estatística e obtenção dos resultados da simulação são baseadas em métodos estatísticos [DAV89].

Uma decisão importante a ser tomada no processo de modelagem por simulação diz respeito ao comprimento da seqüência de simulação, ou seja, quando e como parar o programa de simulação [SOA90]. Não é uma questão fácil, e em muitas vezes as execuçōes são "longas o suficiente", determinando-se por intuição quando um resultado é razoável, assumindo-se que os valores de saída são soluções verdadeiras para o problema (sem nenhuma idéia da sua precisāo) [MAC87]. Existem vários métodos para se determinar o final de uma simulação [SOA90]:

.determinar o tempo de duração da simulação;

.especificar o número de entidades a serem processadas pelo sistema;

.utilizar métodos de parada automáticos.

Os métodos de parada automáticos manipulam os resultados da simulação, durante a execução, calculando médias e variâncias da média. A simulação pára quando a estimativa da variância da média está dentro de uma certa tolerância especificada. Como exemplo pode-se citar os métodos Regenerativo, por Replicação e Batch Means.

Determinadas as condiçōes iniciais e escolhido um método para parar o programa de simulação, parte-se para a execução da simulação e obtenção dos resultados que serão utilizados na análise do modelo considerado. A seção seguinte 
apresenta algumas das medidas de interesse em modelagem e análise de desempenho via simulação.

\subsection{Medidas de Desempenho}

Algumas das medidas de desempenho disponíveis em um estudo de simulaçāo são [DAV89, SOA90]:

.utilização de um servidor: mede a fração do tempo em que o servidor está ocupado;

.vazão: medida da taxa em que os usuários completam trabalho;

.comprimento médio da fila de espera: número médio de clientes na fila de um dado centro de serviço;

tamanho máximo da fila: número máximo de clientes na fila;

tempo médio de espera em fila: em média, o quanto um cliente espera na fila para ser atendido;

.tempo médio no sistema: tempo médio que os clientes gastam dentro do sistema, isto é, na fila de espera e recebendo serviço;

.estado do sistema: o estado do sistema quando a simulação termina, por exemplo, se ainda restam clientes aguardando atendimento.

Soares [SOA90] e Maryanski [MAR80] ressaltam a importância dos testes de parada e a análise dos dados obtidos a partir de uma simulação. Erros relacionados a valores incorretos dos parâmetros de entrada, influência das condições iniciais, à geração de números aleatórios, resultados baseados em um único conjunto de números aleatórios e validação insatisfatória do modelo podem levar a estimativas inválidas para as medidas obtidas com a simulação.

\subsection{Conclusão}

Simulação é uma ferramenta que tenta imitar o comportamento do sistema em estudo, através de um modelo. O capítulo 2 apresentou os vários passos envolvidos 
no processo de modelagem, sendo que a obtenção dos dados de entrada para o modelo deve ser uma tarefa cuidadosa, pois as conclusões obtidas a partir da simulação dependem destes dados.

Os modelos são compostos por clientes requerendo algum tipo de serviço, e a capacidade limitada de atendimento acaba levando à contenção de recursos e formação de filas. Os modelos podem se basear em estruturas de redes de filas, as quais se classificam quanto ao número de filas e servidores (combinações de um (vários) servidor (es) e uma (várias) fila (s)).

Para cada um dos modelos, identificam-se os parâmetros necessários para a simulação, como o tempo entre-chegadas de novos clientes ao sistema e o tempo que cada cliente permanece em serviço. Esses parâmetros de entrada podem ser medidos (quando se dispõe do sistema) ou devem ser estimados. Muitos aspectos do sistema em estudo tem a característica de aleatoriedade. Torna-se necessário então a geração de valores aleatórios para representar tempos entre-chegadas, entre-quebras de uma máquina etc. Para isso geram-se números aleatórios uniformemente distribuídos entre 0 e 1, os quais são transformados (com o uso de tabelas ou distribuiçōes teóricas) em valores aleatórios com as distribuiçōes desejadas.

Com os parâmetros de entrada, pode-se alimentar a simulação, e obter medidas de interesse. A pessoa que está desenvolvendo a simulação deve cuidar para que o estado inicial do sistema não influa nas medidas obtidas, e usar métodos estatísticos que determinam quando parar uma execução. Assim, pode-se obter diferentes medidas que irão auxiliar na análise do sistema em questão, como tempos de espera em fila e em serviço, comprimento médio de fila, etc. 


\section{Capítulo 4}

\section{Interface Gráfica com o Usuário}

Este capítulo enfoca tópicos relacionados a interface homem-máquina, abrangendo os objetivos no projeto de interfaces, a forma e o conteúdo do diálogo homem-máquina, estilos e metodologia de projeto para interfaces. Discute também os principais elementos da interface gráfica oferecida pelo Microsoft Windows 3.1.

\subsection{Introdução}

A tecnologia de computadores possibilita as pessoas interagirem com grandes quantidades de dados, utilizando grande número de funçōes. Os comandos de controle do usuário e as respostas do computador constituem uma interface entre máquina e usuário através de uma troca de sinais gráficos e acústicos. Nos primeiros computadores interativos, a interface com o usuário era relativamente simples, mas frequentemente incômoda. Nas interfaces atuais a comunicação é mais rica, feita por computadores mais poderosos, novos dispositivos de entrada e saída, e "softwares" mais sofisticados [MAR91].

Com o surgimento desses recursos, os projetistas de interfaces homem-máquina começaram a reconhecer a necessidade de pesquisa e desenvolvimento de projetos voltados para o usuário. Assim, no projeto de uma interface torna-se imprescindível que as necessidades do usuário sejam consideradas em primeiro lugar.

O projeto de interfaces com o usuário consiste no desenvolvimento de um "software" cujo objetivo é oferecer um ambiente agradável para o usuário [FOL87]. A interface não deve ser um obstáculo ao usuário, pelo contrário, deve ser de fácil 
aprendizado, apresentando baixas taxas de erros e fácil utilização. A seção 4.2 desse capítulo discute os principais objetivos de uma interface homem-máquina.

A interface com o usuário deve facilitar a comunicação deste com o computador, escondendo o "hardware" e o "software" através de um diálogo. A seção 4.3 discute a forma e o conteúdo desse diálogo.

O uso de protótipos permite fazer projeto interativamente, com a participação do usuário final que ajuda a esclarecer o que deseja obter da interface. A seção 4.4 apresenta diferentes estilos que podem ser utilizados no projeto de interfaces com o usuário, e a seção 4.5 discute uma metodologia de projeto.

Para facilitar ainda mais o trabalho do usuário, torna-se atrativo o uso de interfaces gráficas, as quais transmitem informação de uma maneira mais rica, possibilitando o que se chama WYSIWYG. Diversos ambientes que possibilitam interfaces gráficas com o usuário estão disponíveis, como Microsoft Windows, Apple Macintosh OS, OS/2 Presentation Manager [MAR92], e que fornecem ao programador recursos de "software" para o desenvolvimento de interfaces com o usuário baseadas em janelas e utilização do "mouse".

Dentre esses ambientes de interface gráfica, o Windows vem se destacando como um dos mais utilizados. Fornece elementos que permitem desenvolver interfaces agradáveis de se utilizar e geralmente de fácil aprendizado. Além disso, existe um grande número de ferramentas e recursos disponíveis para esse sistema. A seção 4.6 apresenta os elementos básicos da interface gráfica oferecida pelo Microsoft Windows 3.1.

\subsection{Objetivos no Projeto de Interface com o Usuário}

$A$ interface com o usuário vem se tornando cada vez mais importante com o aumento do número de usuários e aplicações. Inicialmente, devido aos custos e ao fato de que poucas pessoas faziam uso dos recursos computacionais, apresentava-se ao usuário interfaces relativamente simples, mas pouco amigáveis. A revolução dos computadores pessoais e a queda nos preços do "hardware" tornou os computadores disponíveis a um grande número de pessoas que passaram a exigir interfaces mais amigáveis. 
O projeto de interfaces com o usuário deve ter como principais objetivos o aumento da velocidade de aprendizagem e de utilização, redução da taxa de erros, estímulo de rápida recordação de como utilizar a interface e consistência [FOL87, SHN87, MIC92b]. Cada um desses objetivos é discutido a seguir:

.velocidade de aprendizagem: diz respeito a quanto tempo um usuário inexperiente com a interface leva para aprender a utilizá-la (quanto mais amigável a interface, mais rápida é a aprendizagem);

.velocidade de utilização: refere-se a quanto tempo um usuário experiente leva para executar alguma tarefa dentro do sistema; a velocidade para definição de uma tarefa e a resposta do sistema devem ser suficientemente rápidas;

.taxa de erros: mede o número de erros cometidos pelo usuário. Essa taxa pode afetar tanto a velocidade de aprendizagem como a velocidade de utilização do sistema, pois se o usuário comete erros com facilidade, o aprendizado leva mais tempo e a velocidade para o desenvolvimento de uma tarefa fica comprometida pois o usuário deve corrigir os erros;

.rápida recordação de como utilizar a interface: o usuário pode passar algum tempo sem fazer uso da mesma sendo que o retorno às atividades não deve implicar em um grande esforço para uma reaprendizagem;

.ser consistente: o propósito básico da consistência é permitir ao usuário generalizar conhecimento sobre um aspecto do sistema para outros aspectos. Por exemplo, a cor vermelha sempre indica "pare" e a cor verde indica "prossiga".

Atender a todos esses objetivos não é tarefa fácil, e depende de vários fatores como as características dos usuários, o ambiente de uso, recursos de "hardware" e "software" disponíveis, etc. E importante também que o projetista leve em consideração as reais necessidades dos usuários, como será discutido na seção 4.5.

Interfaces com o usuário devem facilitar o diálogo do homem com a máquina. Foley [FOL87] e Marcus [MAR91] fazem analogias entre a comunicação entre seres humanos e a comunicação usuário-computador, no sentido de que muitas das características da comunicação humana devem ser preservadas na comunicação com a 
máquina. A seção seguinte discute essa analogia.

\subsection{Forma e Conteúdo do Diálogo Homem-Máquina}

Interfaces com o usuário devem facilitar a comunicação do mesmo com o computador, através de um diálogo que esconda a estrutura dos dispositivos de entrada e saída, sistemas operacionais, redes, etc.

Algumas das características do diálogo entre as pessoas devem ser preservadas na comunicaçāo do usuário com a máquina [FOL87, MAR91]. O diálogo entre seres humanos envolve gestos, palavras, conhecimento compartilhado e um conjunto comum de suposiçōes (as pessoas falam o mesmo idioma e supõe-se que entendam do assunto em questão). Similarmente, usuários e computadores podem compartilhar um vocabulário e conhecimentos comuns. Existe também a possibilidade de se usar a computação gráfica e imagens como uma modalidade de comunicação adicional.

A interface usuário-computador é constituída de duas linguagens, que expressam mensagens do usuário para o computador (via ações aplicadas a dispositivos físicos como "mouse" e teclado), e mensagens do computador para o usuário (através de sons ou graficamente com caracteres e imagens).

Essas linguagens tem dois componentes principais: o significado e a forma. $\mathrm{O}$ significado de uma linguagem diz respeito ao conteúdo, isto é, a mensagem que se deseja expressar. A forma se refere a como expressar essa mensagem. Por exemplo, no diálogo entre duas pessoas, se uma delas quer expressar à outra que está feliz por algum motivo pode utilizar as palavras "Eu estou feliz" ou então "I am happy" (desde que as pessoas falem o mesmo idioma). Nesse caso, a mensagem a ser expressa é o fato de uma das pessoas estar feliz, e a forma escolhida para transmitir esse sentimento, as palavras (uma outra forma poderia ser através de gestos, ou até mesmo um sorriso). Já no diálogo usuário-computador, uma mensagem do usuário para remover um determinado arquivo pode ser expressa por uma das seguintes formas: um comando do tipo "APAGUE nome-arquivo", ou então pela movimentação do ícone que representa o arquivo para uma área de arquivos a serem apagados.

Para fazer um projeto de interface com o usuário, deve-se escolher a maneira como o diálogo vai ser realizado, isto é, como o usuário interage com o computador. A 
seção seguinte apresenta alguns estilos que podem ser considerados em projetos dessa natureza.

\subsection{Estilos da Interface com o Usuário}

Foley [FOL87] apresenta alguns estilos para interfaces com o usuário, como WYSIWYG, manipulação direta, ícones, seleção de menus, linguagens de comandos, diálogo em linguagem natural e diálogo pergunta-resposta. Destaca-se que nenhum desses estilos são exclusivos, isto é, algumas interfaces fundem elementos de vários estilos para atender a objetivos de projeto não alcançáveis com somente um deles. Esta seção faz uma descrição de cada um desses estilos.

\section{WYSIWYG}

WYSIWYG (do inglês "What You See Is What You Get") é um tipo de interface onde a representação com a qual o usuário interage na tela é a mesma que a imagem criada pela aplicação.

Um exemplo de aplicação que utiliza WYSIWYG são os editores de texto, que apresentam na tela os trechos de texto a serem impressos de acordo com sua formatação, isto é, o que deve ser impresso em negrito é apresentado em negrito, caracteres em itálico são mostrados em itálico e assim por diante. Assim, o que é apresentado em tela é exatamente o que vai ser impresso no papel. Em um editor que não apresenta esse tipo de interface, o usuário vê códigos de controle no meio do texto, como na frase a seguir:

Esta frase mostra caracteres em @bnegritoe @iitálico.

A impressão desta frase apresenta como resultado:

Esta frase mostra caracteres em negrito e itálico.

Uma desvantagem apresentada pelo autor é que algumas aplicaçōes não podem ser implementadas com uma interface puramente WYSIWYG. Um exemplo são alguns processadores de texto que fornecem cabeçalhos com informações sobre capítulo, seção, etc. Esse cabeçalho deve ser apresentado na tela, mas nāo faz parte da informação final a ser impressa, e pela definição do tipo de interface WYSIWYG não 
deve ser mostrado ao usuário. Segundo Norman [NOR86], esse estilo de interface é o que permite ao usuário maior facilidade para composição de um texto, pois este não necessita esforçar-se para imaginar a saída final.

\section{Manipulação Direta}

Uma interface com o usuário que utiliza manipulação direta permite que objetos e atributos sejam operados através de ações executadas sobre a representação visual dos mesmos, geralmente utilizando um "mouse" (essa representação visual pode ser por meio de textos ou imagem gráfica, como ícones). Os comandos não são invocados explicitamente por meios tradicionais como menus ou via teclado, e sim implicitamente na ação executada sobre a representação visual do objeto. $O$ compromisso da manipulação direta é que ao invés de um meio computacional abstrato, quase toda a programação é feita graficamente, em uma forma que combina com a maneira como se pensa sobre o problema [NOR86].

Esse estilo de interface é considerado como um dos melhores do ponto de vista do usuário, por apresentar um aprendizado relativamente fácil. Porém, em algumas circunstâncias pode não ser o melhor estilo, como no caso de um usuário que deseja imprimir um arquivo. $O$ usuário deve primeiro encontrar o ícone que representa $o$ arquivo, marcá-lo e depois selecionar o comando de impressão. Um comando do tipo "PRINT nome_arquivo" poderia ser mais rápido.

Norman [NOR86] destaca algumas vantagens relacionadas ao uso de manipulação direta:

.usuários novatos podem aprender a utilizar a interface rapidamente, geralmente através de demonstração feita por um usuário mais experiente;

.fica fácil reter o conhecimento necessário para operar a interface, mesmo para aqueles usúrios que a utilizam esporadicamente.

Geralmente esse estilo de interface incorpora outros estilos, normalmente comandos através de menus ou via teclado, o que reforça o conceito de que um único estilo pode não ser suficiente para uma interface com o usuário satisfatória. 


\section{Icones}

Um ícone é uma representação gráfica de um objeto, uma propriedade, uma ação ou qualquer outro conceito. $O$ uso de ícones apresenta a vantagem da interface poder ser utilizada em diferentes países, se for cuidadosamente projetada. Nesse tipo de interface, os comandos são expressos em símbolos ao invés de palavras.

Podem ser projetados ícones que representam objetos, assim como propriedades sobre objetos (desde que seus valores possam ser apresentados visualmente). Ações sobre objetos também podem ser representadas por ícones, e nesse caso várias estratégias podem ser adotadas. $O$ ícone de comando pode representar o objeto usado na realidade para executar a ação, como por exemplo uma seta para selecionar objetos ou uma borracha para apagar um arquivo. Em alguns casos pode ser difícil para o usuário entender o que representa um determinado ícone, se a representação não for cuidadosamente escolhida. Outra estratégia é apresentar os efeitos do comando antes e depois de executado.

\section{Outras Formas de Diálogo}

As formas de diálogo apresentadas são destacadas por Foley [FOL87] como intrinsicamente gráficas. Outros tipos de diálogo, como menus, linguagens de comando, diálogo pergunta-resposta ou diálogo através de linguagem natural também podem ser utilizados em aplicações gráficas.

O uso de menus pode ser atrativo para usuários novatos, podendo também diminuir a necessidade de memorização para o usuário. Para o projetista, o uso de menus requer cuidados, a fim de garantir que a terminologia escolhida seja consistente [SHN87]. Quando os itens do menu são escritos utilizando-se uma terminologia familiar, os usuários podem selecionar um item facilmente, o que reduz a possibilidade de erros e facilita o trabalho do usuário. Essa técnica é atrativa, principalmente nos casos em que os usuários tem pouco treinamento.

A maneira tradicional de interagir com a máquina é através de uma linguagem de comandos, porém exige maior tempo de aprendizado e erros podem ocorrer com maior freqüência do que com o uso de menus. $O$ uso dessa técnica pode ser atrativa quando os usuários têm conhecimentos sobre o sistema em utilização [SHN87]. 
Outra alternativa para estilos de interface consiste no uso de diálogo com linguagem natural. Um problema dessa estratégia consiste na falta de limites no conjunto de comandos que um programa de aplicação pode manipular. Além disso, os usuários tendem a fazer requisições que não podem ser satisfeitas, o que pode levar a frustração dos mesmos e a um baixo desempenho do sistema.

O diálogo do tipo pergunta-resposta restringe as respostas do usuário a um conjunto pré-definido e limitado que podem ser dadas através do teclado ou através de um menu.

\subsection{Metodologia de Projeto}

Segundo Foley [FOL87] o primeiro passo no projeto de interface é decidir que tarefas devem ser executadas. Essa parte é de grande importância, pois interfaces que funcionam de maneira inadequada podem levar a frustraçāo do usuário e são frequentemente rejeitadas ou sub-utilizadas [SHN87]. Todas as características, habilidades e conhecimentos dos usuários devem ser identificados, assim como se o uso da interface será esporádico ou regular. É de fundamental importância para o projetista lembrar de que o que está a seu gosto não necessariamente implica no fato de que as pessoas para quem a interface está sendo projetada também irão gostar. A sugestão de Norman [NOR86] é de que as necessidades dos usuários devem dominar o projeto da interface.

Foley [FOL87] ressalta o uso de protótipos durante a fase de projeto de interfaces com o usuário (um protótipo de interface com o usuário é uma versão criada rapidamente de parte ou de toda a interface, frequentemente com funcionalidade limitada). Com o protótipo disponível, questões antes sem resposta podem ser respondidas, pois o projetista conta com a ajuda do usuário para esclarecer o que este deseja obter da interface. A prototipação é frequentemente superior a documentos escritos, já que permite ao usuário visualizar o produto (ou parte dele) e assim fornecer novas sugestões e opiniões sobre o produto.

Foley [FOL87] sugere um ciclo interativo para o desenvolvimento de "software" de interface de alta qualidade, através da utilização de protótipos. Assim que alguns elementos da interface tenham sido desenvolvidos, o protótipo pode ser exposto a 
usuários em potencial, que fazem sugestões para a sua melhoria. O protótipo é então modificado para atender às sugestões e novamente apresentado aos usuários. Esse ciclo se repete até que os usuários estejam satisfeitos.

Uma consideração importante a ser feita com relação a projeto de interfaces com usuários diz respeito às mensagens de erros possíveis [NOR86, SHN87]. As mensagens devem ser organizadas de tal forma que não confundam o usuário, isto é, o projetista deve ter em mente que é somente o módulo de interface que está em comunicação com o usuário, e que portanto as informações a serem passadas a ele não devem referenciar assuntos tratados internamente no sistema.

\subsection{Interface Gráfica do Usuário Através do Microsoft Windows}

Desde seu lançamento, em 1985, o Microsoft Windows vem se destacando como um dos mais conhecidos ambientes de interface gráfica do usuário para o MS-DOS e o grande consenso na indústria de computadores pessoais [PET93].

Para o usuário, o Windows cria um ambiente gráfico de multitarefa com janelas. A interface oferecida pelos aplicativos Windows facilita o trabalho do usuário, no sentido de que todos geralmente têm a mesma aparência e modo de operação fundamental [PET93]. Geralmente o aplicativo ocupa uma janela, é identificado por uma barra de título, e a maioria das funções são iniciadas ou por meio do menu do aplicativo, ou através de uma barra de ferramentas. Dessa forma, fica mais simples para o usuário aprender a utilizar um aplicativo, depois de aprender o primeiro.

Para o programador, o Windows fornece rotinas internas que permitem o uso de menus, caixas de diálogo, barras de rolagem e outros componentes de uma interface amigável. Também permite ao programador tratar o teclado, o "mouse", o monitor de uma maneira independente do dispositivo [PET93]. Os aplicativos não acessam diretamente o "hardware" dos dispositivos gráficos como a impressora e o monitor, mas têm acesso a um grande e variado conjunto de operações gráficas independentes de dispositivo [MIC92a]. Windows oferece uma linguagem de programação de gráficos (chamada "Graphics Device Interface" - GDI) que permite a apresentação de gráficos e texto formatado. 
Esta seção apresenta alguns dos principais elementos fornecidos pelo Microsoft Windows versão 3.1, para desenvolver aplicativos voltados para facilitar o aprendizado e utilização por parte do usuário. Também faz um estudo sobre a GDI.

\subsubsection{Multitarefa e Gerenciamento de Memória}

O Windows é um sistema multitarefa, isto $\hat{e}$, pode executar mais de uma aplicação ao mesmo tempo [MIC92a]. O sistema operacional MS-DOS não é multitarefa, e toda aplicação para o mesmo opera com o controle exclusivo sobre os recursos do computador, como dispositivos de entrada e saída, a unidade central de processamento, e a memória. Já uma aplicação Windows deve compartilhar esses recursos com todas as outras aplicações que estão em execução.

Uma aplicação MS-DOS tem acesso a toda a memória disponível na máquina. Já no Windows, a memória é um recurso compartilhado, e como mais de uma aplicação pode estar executando ao mesmo tempo, essas devem compartilhar a memória disponível, para evitar exaurir o recurso. O Windows gerencia a memória disponível para garantir que todos os aplicativos tenham acesso a ela, e para tornar seu uso o mais eficiente possível [MIC92a].

Toda a área de memória que o Windows controla é denominada memória global ou "heap" global. Todo bloco alocado na memória global é um segmento. O Windows aloca a memória que necessita, e o restante está disponível a todas as aplicaçōes e bibliotecas.

No sistema de gerenciamento de memória do Windows, uma aplicação pode alocar blocos da memória local, além da memória global. A memória local pode ser referenciada apenas pelo aplicativo. Cada segmento na memória é marcado com atributos que informam ao Windows como gerenciá-lo [PET93], podendo ser fixo ou móvel. O Windows pode movimentar os segmentos móveis na memória, se isso for necessário para criar espaço para outras alocações de memória. Um segmento fixo sempre reside no mesmo endereço fixo onde foi inicialmente alocado.

Os segmentos móveis podem também ser marcados como descartáveis, ou seja, quando o Windows necessita de memória adicional, ele pode liberar a área ocupada pelo segmento (utiliza o algoritmo Menos Recentemente Usado para determinar que 
segmento descartar). Segmentos descartáveis são normalmente utilizados para os dados que podem ser facilmente regenerados [PET93]. Por exemplo, manter em um bloco descartável as informações de um texto de ajuda.

As funçōes de alocação de memória do Windows não retornam diretamente ponteiros que a aplicação pode usar. Em vez disso, elas retornam "handles". Esse "handle" identifica a memoria alocada, e deve ser usado para obter o endereço corrente do bloco quando é necessário referenciar o mesmo. Isso pode ser feito travando o bloco (através de funções específicas), operação que retorna um ponteiro para seu início. Enquanto o bloco está travado, o Windows não pode movê-lo ou descartá-lo. Ao terminar de utilizar a memória, o "handle" deve ser destravado, para que o Windows possa mover (ou descartar) o bloco, se necessário.

\subsubsection{Programação Orientada a Eventos e Mensagens}

Desenvolver aplicativos para o ambiente gráfico do Windows exige a absorção do conceito de programação orientada a eventos e dominar os detalhes da interface gráfica.

A programação orientada a evento não é o mesmo que programação orientada a objetos e também é diferente da programação procedural tradicional [SIM94]. Na programação tradicional o programador tem total controle do programa. E sempre possível determinar o próximo passo a ser executado, isto é, os programas são executados em uma seqüência de comandos. Com a orientação a eventos, o programador tem ferramentas para criar aplicativos que năo seguem uma ordem rígida de execução (é o usuário quem determina quais serão as próximas etapas a serem executadas). $O$ Windows trabalha cooperativamente com o aplicativo, enviando mensagens para cada evento ocorrido, como por exemplo o movimento do "mouse" ou uma tecla pressionada. Cada mensagem é tratada como um evento pelo programa aplicativo.

O Windows gera uma mensagem de entrada para cada evento de entrada, como quando o usuário movimenta o "mouse" ou pressiona uma tecla. Essas são armazenadas na fila de mensagens do sistema, e depois inseridas na fila de mensagem da aplicação (cada aplicação tem a sua própria fila de mensagens) [MIC92a, PIE93]. 
Desde que uma aplicação recebe entradas através da sua fila de aplicação, uma característica importante de qualquer aplicação Windows é seu "laço de mensagem". A rotina principal de uma aplicação Windows resume-se a um laço para retirar mensagens da fila de eventos, identificar a mensagem e, em seguida, despachá-la ao procedimento que irá tratá-la. Ele retira mensagens de entrada da fila da aplicação, enviando-as para as janelas apropriadas [MIC92a] (figura 4.1). As mensagens representam eventos, e correspondem a estruturas que contêm um identificador e os parâmetros da mensagem.

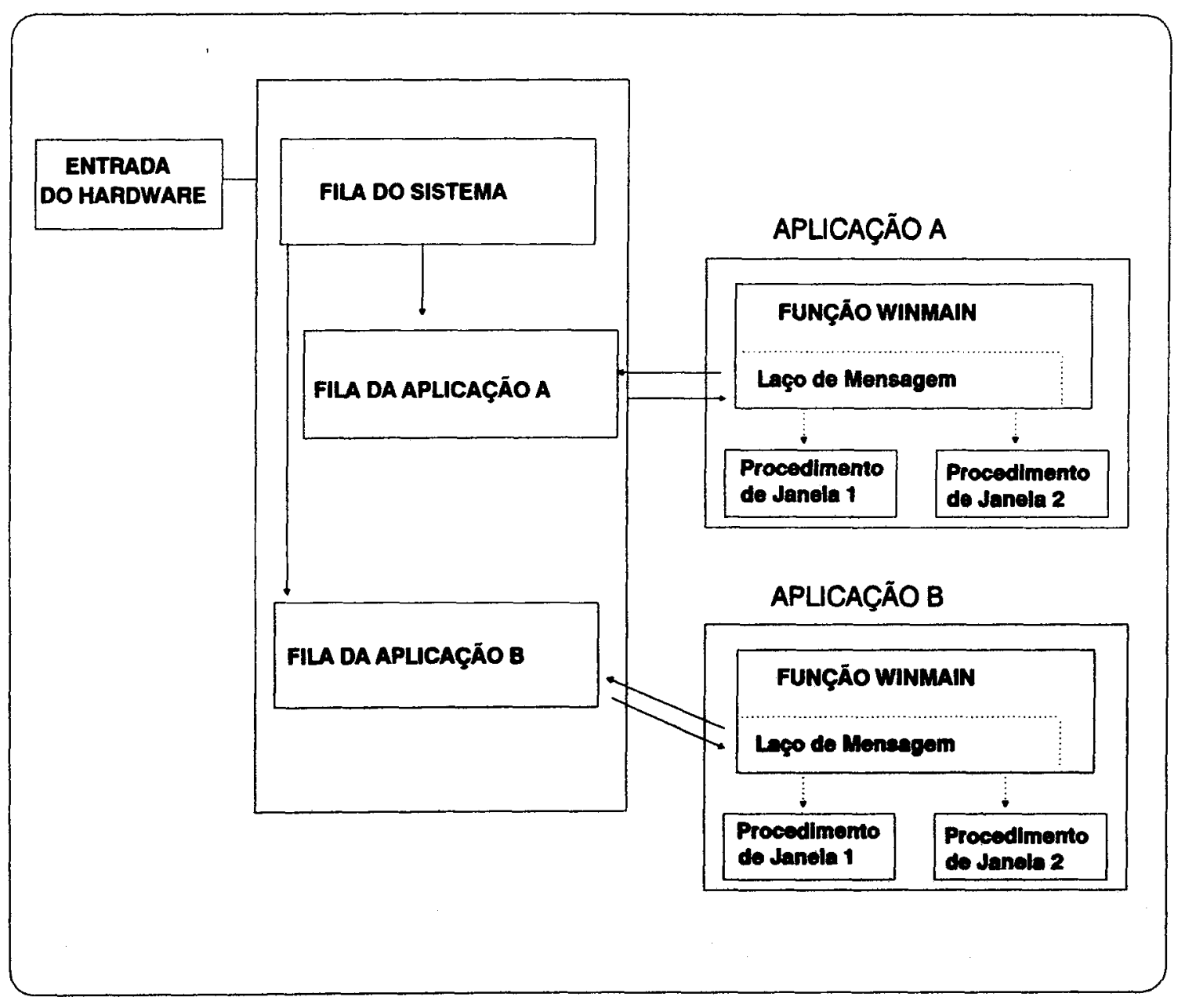

Figura 4.1: Laços de Mensagem 


\subsubsection{Elementos de Uma Aplicação Windows}

As aplicações desenvolvidas para Windows fazem uso de diversos recursos, que dão forma aos elementos que compõem a interface com o usuário. Alguns desses recursos são descritos a seguir.

\section{Janelas}

Uma janela consiste no dispositivo primário de entrada e saída para qualquer aplicativo Windows (figura 4.2). Uma janela de aplicativo normalmente contém uma barra de título, menus, possivelmente algumas barras de rolagem, molduras de tamanho e outras características que ocupam um retângulo na tela. A barra de título pode conter um título (que identifica a mesma ou a aplicação), a caixa do menu do sistema (com comandos para manipular a janela principal da aplicação), e botões para maximizar ou minimizar o tamanho da janela. Elementos opcionais como a barra de mensagem podem também ser utilizados.

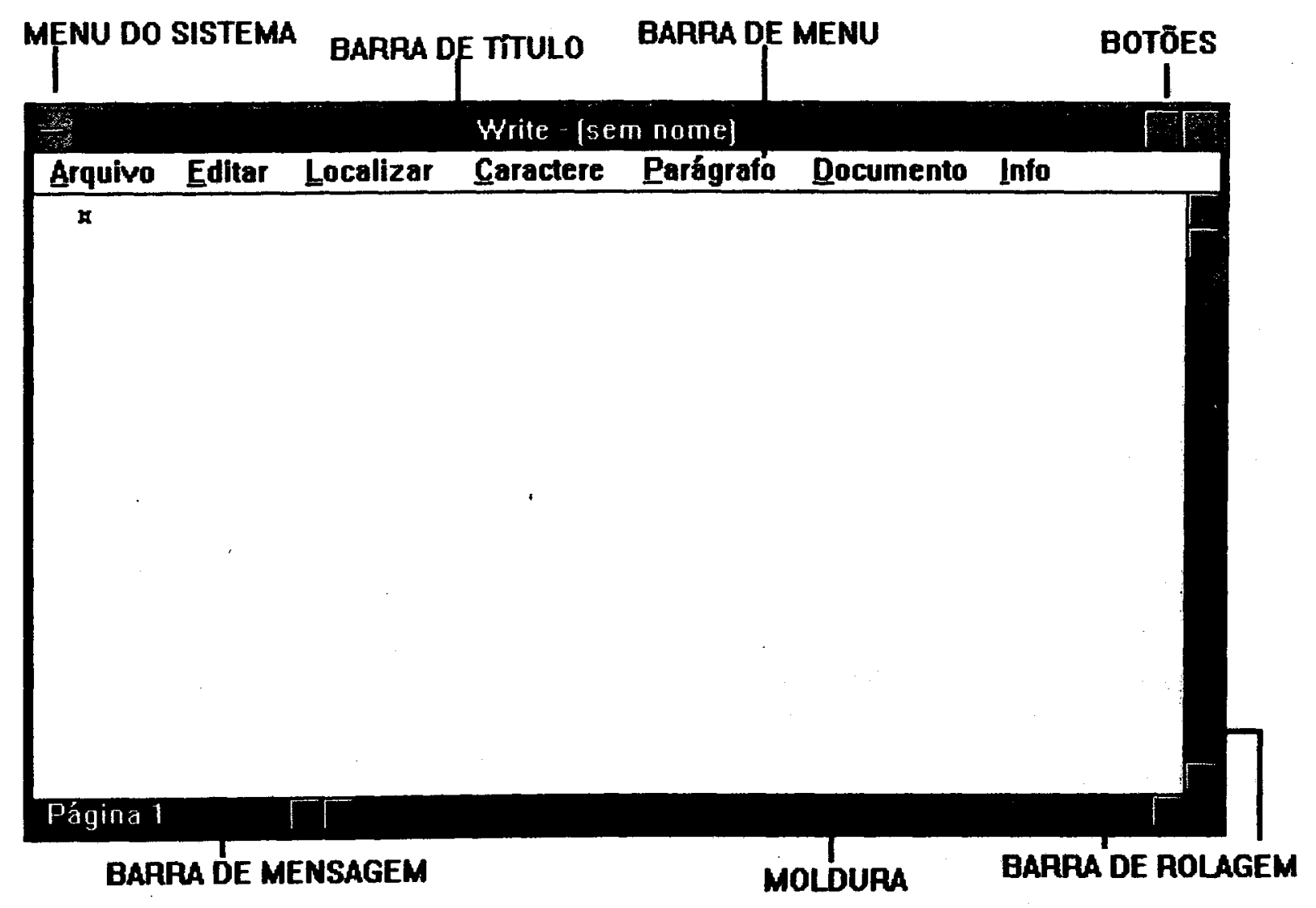

Figura 4.2 Janela 
Ao criar uma janela, uma aplicação especifica as características da mesma e então a desenha através de uma chamada a uma função do Windows. Embora a aplicação seja responsável por criar a janela, o Windows colabora para o seu gerenciamento. $O$ Windows mantém a posição e a aparência da janela, gerenciando as barras de rolagem (se tiver) e de título. A aplicação mantém e controla a aparência da área do cliente da janela (a porção dentro das bordas).

\section{Menus}

Menus constituem uma parte importante na interface oferecida pelo Windows [MIC92a, PET93]. Um menu consiste em um título (que deve revelar com clareza o propósito dos itens) e uma lista de itens, os quais o usuário pode visualizar e/ou escolher (com o uso do "mouse" ou mesmo através do teclado). Cada item representa um comando, seja explicitamente (como Sair) ou seja implicitamente (como Negrito, que em um editor de texto pode significar "aplica o formato Negrito"). O programador define os nomes e os itens dos menus, que são gerenciados pelo próprio Windows. Esse envia uma mensagem ao procedimento de janela quando o usuário faz uma escoha, para executar os comandos associados com o item escolhido.

A barra de menus de uma janela aparece logo abaixo da barra de título, sendo também chamada de menu principal ou menu de mais alto nível [PET93]. Os itens listados no menu principal quase sempre invocam um menu suspenso (ou instantâneo). Múltiplos níveis de menus podem ser definidos, isto é, um item em um menu pode invocar outro menu (os menus em cascata). Algumas vezes os itens dos menus podem invocar uma caixa de diálogo para obter algum tipo de informação do usuário.

Toda aplicação deve incluir um conjunto de menus padrão, para permitir aos usuários um ponto comum para facilitar o aprendizado de outros aplicativos [MIC92b]. Os menus padrão são o menu do sistema, menu arquivo, menu editar e ajuda. Geralmente o menu arquivo aparece primeiro na barra de menus, e ajuda aparece no final da barra. Na maioria das janelas principais dos aplicativos Windows e caixas de diálogo aparece, na extremidade esquerda da barra de título, um quadradinho que contém um pequeno traço. Nas janelas dos aplicativos esse quadradinho invoca o menu do sistema, que contém basicamente os itens relacionados a alterar o tamanho da janela (restaurar, minimizar, maximizar), mover de lugar, alternar para outro aplicativo e encerrar a execução do aplicativo. Já nas caixas de diálogo, estão itens 
relacionados a mover e encerrar a mesma.

\section{Caixas de Diálogo}

As caixas de diálogo sāo, na maioria das vezes, utilizadas para obter informações adicionais do usuário, além das que podem ser obtidas através dos menus [PET93, NOR92, MIC92b, NEW93]. Normalmente, um item de um menu que invoca uma caixa de diálogo apresenta reticências (...). Um exemplo de caixa de diálogo é a janela que aparece no monitor, quando um aplicativo solicita ao usuário para fornecer o nome de um arquivo a ser aberto (figura 4.3).

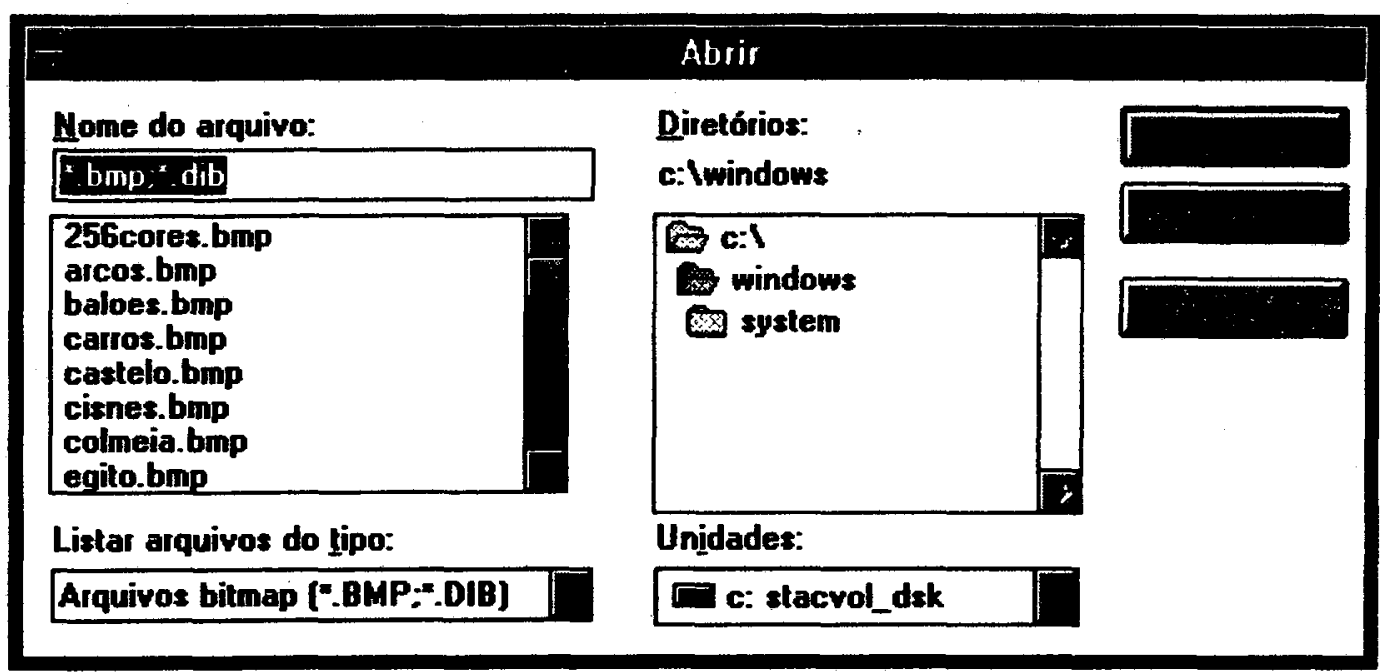

Figura 4.3 Caixa de Diálogo Abrir

Uma caixa de diálogo geralmente tem a forma de uma janela suspensa que contém várias janelas adicionais denominadas janelas-filhas (janelas que permitem criar controles, como botōes, quadradinhos de verificação, caixas de edição, de grupo e de lista, barras de rolagem). $O$ Windows é responsável pela criação da janela da caixa de diálogo, pelos controles das janelas-filhas e pelo procedimento que processa as mensagens da caixa de diálogo (incluindo toda entrada pelo teclado e "mouse"). $\mathrm{O}$ usuário interage diretamente com essas janelas, pressionando um botão ou deslocando uma barra de rolagem.

Os botões de apertar são retângulos que contém um texto especificado. São usados principalmente para acionar uma ação imediata sem reter qualquer tipo de 
indicação ligado/desligado (como exemplo pode-se citar o botão OK da caixa da figura 4.3).

Os quadradinhos de verificação normalmente têm um texto que aparece a sua direita (ou esquerda). São geralmente incorporados nos aplicativos para permitir que o usuário selecione opções. Funcionam como uma chave liga e desliga: pressionar uma vez faz com que um " $x$ " apareça sobre ele, e pressionar novamente faz com que 0 " $x$ " desapareça.

Botões de rádio são parecidos com os quadradinhos de verificação, com a diferença de que sua forma é circular. Um ponto cheio, dentro do círculo, indica que o botão de rádio foi selecionado. São utilizados para indicar opçoos mutuamente exclusivas e ao contrário dos quadradinhos de verificação, não funcionam como chaves, isto é, selecioná-lo uma segunda vez não muda seu estado.

As caixas de grupo não processam entradas do teclado e do "mouse". Uma caixa de grupo consiste em um contorno retangular com um título, e geralmente são usadas para envolver outros botões de controle.

As caixas de edição, como o nome diz, apresentam um retângulo, onde texto pode ser editado. Como exemplo tem-se a caixa através da qual o usuário indica o nome do arquivo a ser aberto (figura 4.3).

Uma caixa de lista é uma coleção de cadeias de caracteres, mostradas em colunas que podem ser roladas dentro de um retângulo, consistindo em opçōes de escolha para o usuário. São usadas com maior freqüência nas caixas de diálogo chamadas após o usuário selecionar o item abrir no menu arquivo (apresentando opçōes de escolha para o usuário). A figura 4.3 apresenta dois tipos de caixas de lista, um no qual relaciona os arquivos do diretório corrente e outros subdiretórios, e outro que mostra as unidades de disco.

Para facilitar a utilização das caixas de diálogo, o Windows 3.1 inclui um aprimoramento chamado de "biblioteca de caixa de diálogo comum". Essa biblioteca consiste em várias funções que invocam caixas de diálogo padrões para abrir e gravar arquivos, pesquisa e substituição, escolha de cores, de fontes e impressão [PET93, MIC92a, NOR92]. 
Uma caixa de diálogo comum é uma caixa de diálogo que uma aplicação mostra chamando funções que criam e apresentam a caixa de diálogo (padrão). A utilização dessas caixas de diálogo oferece ao usuário um elevado nível de consistência entre os aplicativos Windows. Além de simplificar o desenvolvimento de aplicaçōes Windows, essas caixas de diálogo fornecem ao usuário um conjunto padrão de controles para executar certas operações. A caixa Abrir Arquivo da figura 4.3 é um exemplo de caixa de diálogo comum.

\section{Caixas de Mensagem}

A caixa de mensagem (figura 4.4) é uma alternativa à caixa de diálogo, podendo ser utilizada quando o aplicativo precisa de uma resposta simples do usuário. Essa caixa tem um título, uma ou mais linhas de texto, um ou mais botões e (opcionalmente) um ícone. Pode ser utilizada também para fornecer informações da mesma forma que a função printf utilizada nos programas escritos em linguagem C para o MS-DOS.

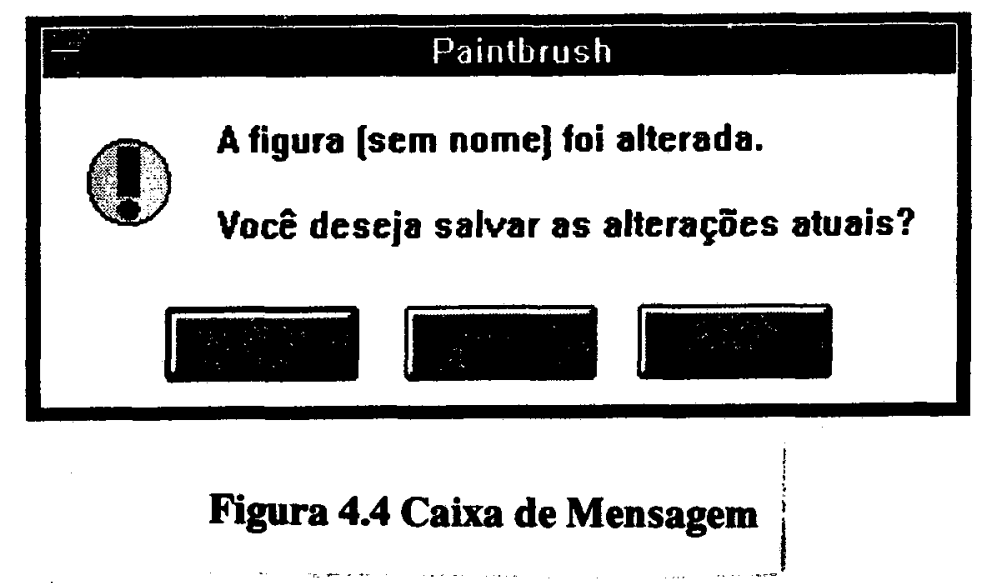

\section{fcones, Cursores e Mapas de Bits}

Um ícone é uma pequena imagem gráfica que representa, por exemplo, uma aplicação quando sua janela principal é minimizada. $O$ Windows fornece ao programador vários ícones pré-definidos, e também permite o projeto de novos ícones. Os ícones são usados também em caixas de diálogo e de mensagem, como o ícone de exclamação da figura 4.4.

Os mapas de bits são usados para desenhar figuras na tela, como por exemplo os utilizados para desenhar as setas das barras de rolagem, o quadradinho do menu do sistema etc. 
Cursor é um mapa de bits especial que mostra ao usuário a movimentação do "mouse" (ou, quando este não está disponível, as ações do teclado). Windows permite a aplicação alterar a forma do cursor, para adequar aos requisitos da mesma (o cursor pode ter o formato de uma seta, uma pequena mão, etc). Como os ícones, existem cursores pre-definidos, além da possibilidade de se projetar novos cursores que representam diferentes operações.

\subsubsection{Uma Introdução a GDI}

A GDI ("Graphics Device Interface") é a biblioteca de saída gráfica do Windows [NOR92]. O sistema da GDI é construído de forma que o Windows possa determinar o que um controlador pode fazer sozinho e em que ele precisa de ajuda [PET93]. Por exemplo, se o "hardware" da placa de vídeo inclui um co-processador gráfico que pode desenhar círculos, a GDI o aproveita, caso contrário a própria GDI precisa calcular os pontos do círculo e passá-los ao controlador.

Devido ao grande número de diferentes dispositivos gráficos que podem ser conectados ao IBM-PC e compatíveis, um dos objetivos da GDI é suportar gráficos independentes do dispositivo em periféricos de saída, como vídeos, impressoras e traçadores gráficos. Isso é obtido isolando os programas das características particulares dos diferentes dispositivos de saída.

Qualquer aplicação Windows pode usar as funções da GDI para ter acesso a um dispositivo de saída. Este acesso é feito utilizando o contexto do dispositivo e um "driver" específico para a saída a ser considerada (por exemplo "plotter", impressora, vídeo etc).

As chamadas para as funções da GDI, executadas pelo aplicativo, são totalmente independentes do dispositivo de saída. Essas funções são executadas baseando-se em atributos definidos pelo contexto do dispositivo.

Os atributos do contexto de dispositivo descrevem objetos selecionados para desenho (canetas para desenhar linhas, pincéis para preencher áreas, fonte para desenhar texto e cores para determinar as cores dos desenhos e texto), o modo pelo qual os desenhos são mapeados para o dispositivo, e outras informaçōes. Esses atributos permitem que os parâmetros para as funções da GDI incluam somente 
coordenadas iniciais ou tamanhos, não todas as informaçōes que o Windows precisa como fonte e cor, que são parte do contexto do dispositivo, de onde o Windows tira as informaçōes que precisa. Para alterar qualquer atributo, basta utilizar as funçōes adequadas [PET93]. Cada objeto tem um contexto, que poderá ser recuperado quando necessário.

Baseada no contexto do dispositivo, a GDI gera uma saída, que será enviada ao "driver" do dispositivo de saída a ser utilizado. O "driver" translada a chamada em operações dependentes do dispositivo de saída considerado.

Assim, conforme ilustrado na figura 4.5, o contexto do dispositivo e o "driver" funcionam como uma ligação entre a aplicação Windows e o dispositivo de saída [MIC92c].

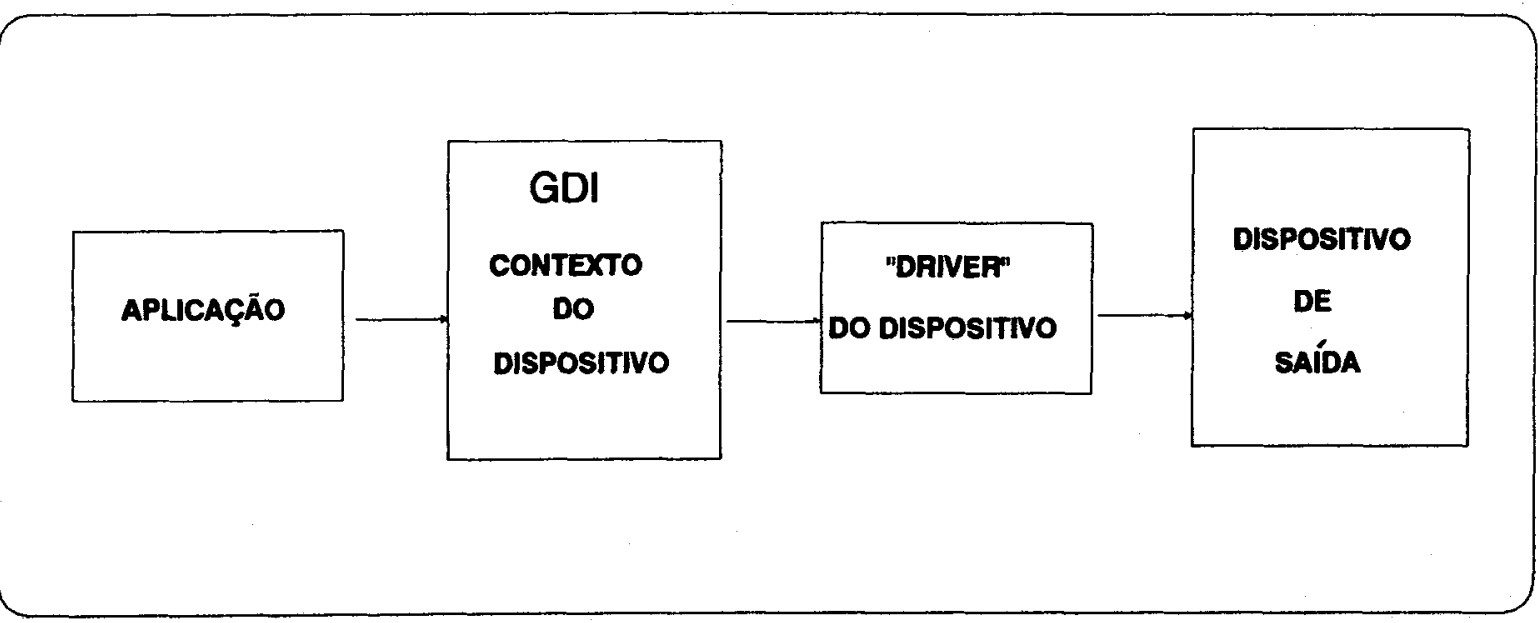

Figura 4.5: Fluxo de Informação Aplicação/"Driver" 


\subsection{Conclusão}

Interfaces homem-máquina tem se tornado cada vez mais importantes com o aumento do número de usuários e aplicações. Seu propósito é facilitar o diálogo entre o usuário e a máquina.

Durante a fase de projeto, torna-se importante o uso de protótipos, que irão permitir maior participação do usuário no desenvolvimento da interface. Shneiderman [SHN87] e Norman [NOR86] defendem o desenvolvimento do projeto tendo como centro o usuário final, pois métodos para projeto interativo e o uso de protótipos são necessários para se construir um sistema com sucesso. $O$ projeto de interfaces com o usuário é um processo complexo e criativo que combina intuição, experiência e estudo sobre a comunidade de usuários, etc.

Para o desenvolvimento de interfaces gráficas com o usuário, diferentes sistemas e ferramentas estão disponíveis. Um sistema que vem sendo amplamente utilizado e que apresenta uma interface gráfica padronizada é o Microsoft Windows. Este sistema oferece ao programador todas as ferramentas necessárias para o desenvolvimento de uma interface com o usuário amigável. Por outro lado, um aplicativo Windows facilita o aprendizado e utillização do "software" por parte do usuário, uma vez que é mantido um padrão entre diferentes aplicações desenvolvidas para o sistema em questão.

Assim, devido a essas características, adotou-se o Microsoft Windows versão 3.1 neste trabalho. Neste capítulo foram discutidos os principais elementos da inteface oferecida pelo sistema e noçōes sobre a programação e o gerenciamento de memória realizado neste sistema. 


\section{Capítulo 5}

\section{Sistemas de Simulação Automáticos}

Neste capítulo são apresentados exemplos de sistemas que permitem a especificação de modelos de simulação graficamente, e a geração automática do programa de simulação. A partir desses exemplos identificam-se e são discutidas as principais características de um sistema de simulaçāo automático.

\subsection{Introdução}

O capítulo 2 discutiu as vantagens da simulação como uma ferramenta para avaliação de desempenho. Apesar de todas as características atrativas da simulação, simular pode ser uma tarefa difícil para pessoas não experientes em programação. Além disso, os métodos tradicionais para codificação de um modelo (utilizando linguagens ou extensões) requerem que o programa de simulação seja abstraído de um modelo, o qual é conceitualizado em um nível mais alto do que aquele utilizado na programaçāo.

Atualmente, o uso de estações de trabalho, equipadas com monitores de vídeo de alta resolução, tem possibilitado uma nova aproximação para modelagem por simulação: a simulação visual. O usuário pode modelar o sistema graficamente, e observar seu comportamento através de animação [MEL85, BEL87, SHA92]. A programação visual é particularmente desejável e vantajosa para a modelagem de sistemas, já que o homem pode manipular informações de um modo mais eficiente se estas forem apresentadas graficamente [MEL85, DAV89]. 
Neste capítulo são apresentados alguns sistemas existentes que seguem essas idéias. A partir deles, identificam-se as principais características e funções de um sistema que permite a especificação gráfica de um modelo de simulação e a geração automática do correspondente programa de simulação.

\subsection{Sistemas Existentes}

Um grande número de ferramentas para simulação com capacidades gráficas vem sendo desenvolvidas [BEL87]. Em um ambiente desse tipo, o usuário desenha o modelo do sistema a ser simulado, entra com os valores numéricos dos parâmetros através do teclado e instrumenta a simulação definindo pontos de coleta de estatísticas. Alguns também apresentam uma animação da execução do programa de simulação.

A seguir são apresentadas algumas ferramentas nas quais pode-se identificar algumas dessas características.

\section{QMG [RAC90]}

QMG (Queueing Model Generator) é um módulo do ambiente de simulação PASION (PAScal SimulatION, extensão da linguagem Pascal). Contém um editor que permite ao usuário definir graficamente a estrutura do modelo, e um programa gerador que produz o código correspondente em PASION.

A interface com o usuário de QMG $\epsilon$ independente da linguagem, podendo ser adaptada a qualquer linguagem de simulação. QMG se parece a um editor de programas, mas o usuário edita um diagrama de blocos que representa um modelo de filas. Os blocos mostram os eventos possíveis, e as linhas de interconexão indicam a estrutura do modelo.

Diferentes símbolos são utilizados para descrever cada elemento de um modelo de simulação (figura 5.1).

O gerador (símbolo 1) produz as entidades do modelo (os clientes que entram em uma agência bancária, por exemplo). As entidades podem ser geradas com uma dada distribuição de probabilidades para o tempo entre-chegadas. Os demais blocos descrevem a "vida" da entidade dentro do sistema. Quando uma entidade entra em um bloco terminal (símbolo 2), ela encerra suas ações e desaparece. 


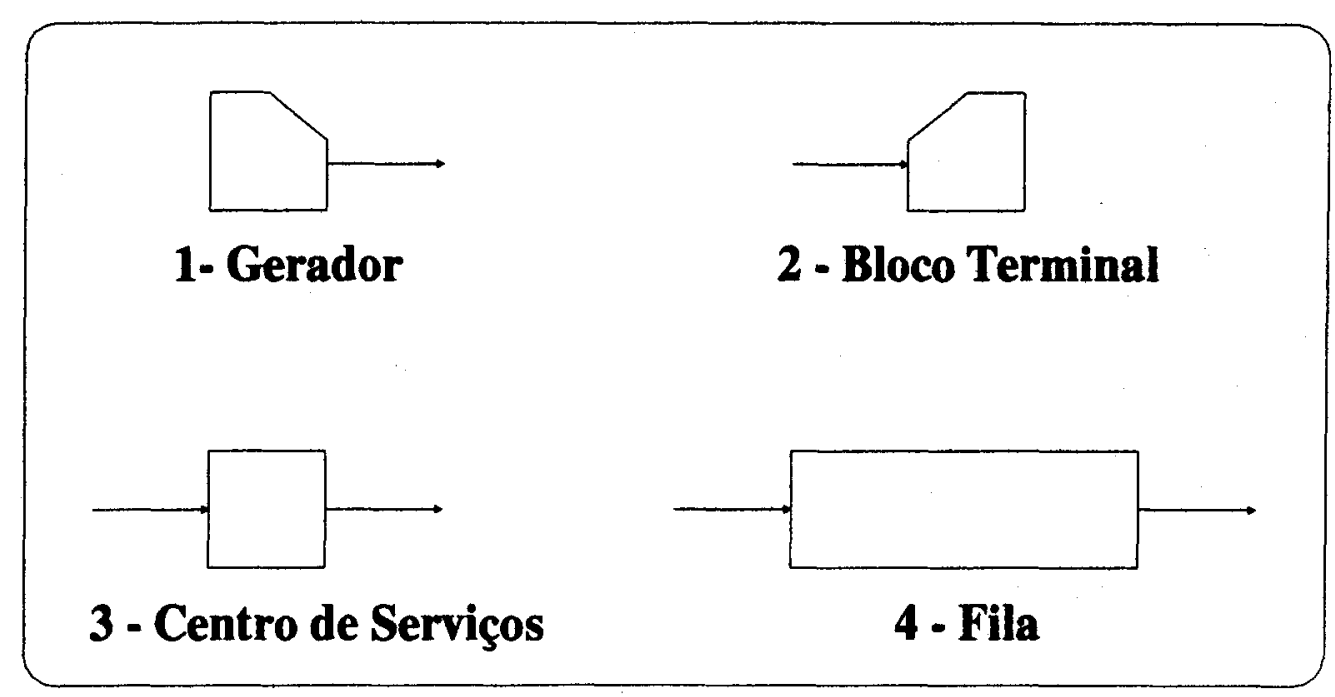

Figura 5.1: Símbolos Gráficos Utilizados pelo QMG

O símbolo 3 representa um centro de serviços, o qual pode ter um ou mais servidores. O tempo de serviço de uma entidade pode seguir uma das distribuições de probabilidade disponíveis.

Uma fila de espera é indicada pelo símbolo 4, podendo seguir uma das disciplinas: FIFO, LIFO ou aleatório.

O editor de QMG permite ao usuário determinar a estrutura do modelo, e não permite inconsistências óbvias, como por exemplo uma fila que não é seguida por um servidor, ou um modelo que não inicie com um gerador.

Definido o diagrama que representa o modelo, $Q M G$ pede pelos parâmetros de entrada. $\mathrm{O}$ usuário tem a sua disposição "helps" que apresentam as opçōes possíveis para cada caso (como os tipos de distribuiçoos disponíveis, as disciplinas de fila) e mensagens de erro. $O$ modelo pode ser gravado em um arquivo, recuperado e alterado.

O restante do trabalho $\varepsilon$ feito automaticamente pelo gerador, que produz um programa de simulação em PASION. O ambiente PASION permite também a apresentação dos resultados obtidos através de gráficos e histogramas.

\section{GraphSIM [OZD91]}

GraphSIM (Graphical SImulation Modeling) é um protótipo construído na linguagem Smalltalk, e permite a descrição de um modelo de simulação graficamente, 
através de diagramas. A parametrização do modelo é efetuada através de menus, os quais também apresentam ao usuário as diferentes possibilidades de escolha entre distribuiçōes disponíveis. A execução da simulação pode ser efetuada diretamente do ambiente GraphSIM. Quando a simulação termina, os resultados podem ser apresentados através de histogramas.

Segundo o autor, o sistema deve incluir um editor gráfico orientado a objetos e um pacote para apresentar as saídas graficamente na tela.

$$
\text { Q+ [FUN91] }
$$

E uma ferramenta interativa para modelagem, cuja idéia consiste em permitir ao usuário descrever um modelo da maneira mais simples possível, através de desenhos. Esta ferramenta permite também a observação do comportamento do sistema, através de animação. Assim, o usuário especifica um modelo utilizando operações gráficas e executa a simulação observando o comportamento do sistema simulado.

A interface com o usuário é baseada em menus, e o usuário cria os elementos que compõem o modelo com o uso do "mouse" (utilizando um editor gráfico). A parametrização é efetuada através de um editor de textos.

Os sistemas apresentados foram desenvolvidos com o propósito de facilitar o trabalho de modelagem através de simulaçāo, permitindo que pessoas com melhor conhecimento do sistema a ser estudado possam participar do processo de modelagem. $Q+$ permite, além da especificação gráfica do modelo (de filas), que se observe uma animaçāo da simulação. Embora também permita a especificação gráfica do modelo, GraphSIM utiliza-se de diagramas, ao invés de filas. QMG permite definir um modelo de filas sem qualquer programação, porém os símbolos utilizados podem causar confusão, como o símbolo que representa uma fila e o símbolo do centro de serviços.

Além dos sistemas discutidos, vale citar outros exemplos como BONeS [SHA92] (Block Oriented NEtwork Simulator, específico para simulação de redes) e ASiA (Ambiente de Simulação Automático), em desenvolvimento no grupo de Sistemas Distribuídos e Programação Concorrente do Departamento de Computação e Estatística do ICMSC-USP. O ambiente ASiA é discutido na seção seguinte. 


\subsection{ASiA - Ambiente de Simulação Automático [SAN94]}

ASiA é um sistema que permite que os usuários descrevam seus modelos através de um editor gráfico, definam os pontos de coleta de estatísticas, selecionem os tipos de gráficos a serem apresentados no relatório final e escolham qual sistema de simulação será utilizado (o ambiente automático pode oferecer diversos sistemas para a escolha do usuário). $O$ sistema de simulação, automaticamente, compila todas as informações contidas no modelo do sistema em estudo, inclue as opções definidas pelo usuário e gera (através de um gerador de aplicações) o programa de simulação correspondente. Dentro do mesmo ambiente, o usuário compila e executa o programa gerado.

\subsubsection{Estrutura Geral do ASiA}

O ASiA tem por objetivo afastar o usuário da tarefa de transcrição do modelo em um programa de simulação. O usuário fornece o modelo do sistema considerado, os parâmetros necessários para a simulação e os pontos de observação (onde haverá coletas de dados para a análise estatística) através de um editor gráfico. As demais tarefas serão executadas automaticamente pelo sistema proposto.

Quatro estágios básicos são necessários para a obtenção dos resultados no sistema de simulação automático (figura 5.2)

.editor gráfico: fornece uma interface amigável;

.gerador de aplicações: responsável pela geração do programa de simulação;

.execução da simulação: obtenção dos resultados;

.estágio de saída: análise dos dados e saída gráfica.

A função do editor gráfico é afastar o usuário da tarefa de transcrição do modelo discreto em um programa de simulação.

A segunda fase do sistema de simulação automática não depende da interferência direta do usuário. As informações coletadas e organizadas pelo editor gráfico em estruturas de dados previamente definidas, alimentam um gerador de aplicações que

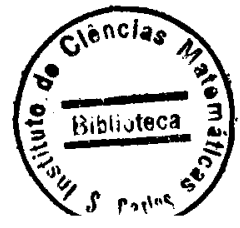


fornecerá como saída o programa de simulação. Esse programa é descrito de acordo com a linguagem de simulação adotada (podendo ser uma das abordagens discutidas no capítulo 2).

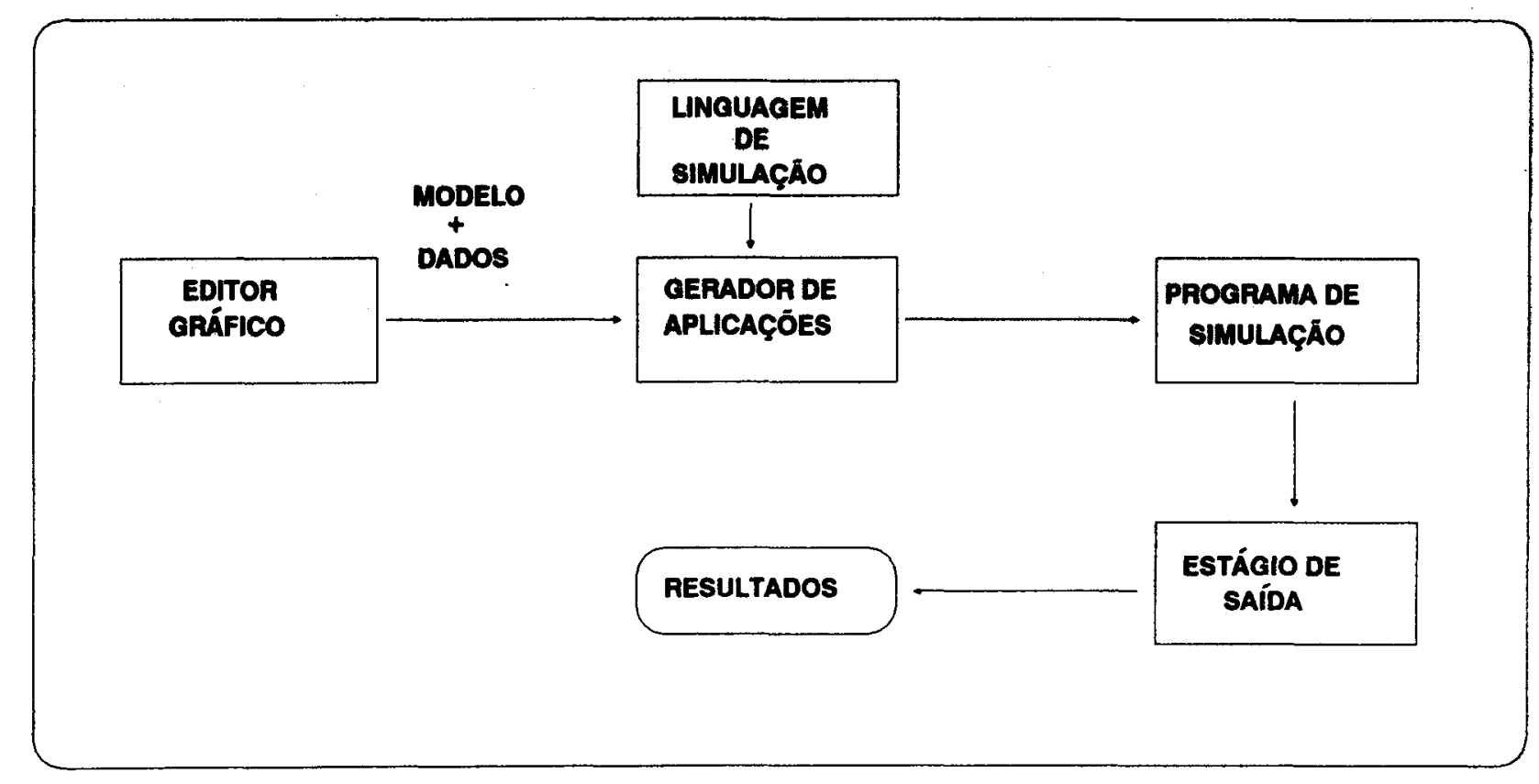

Figura 5.2: Visão Geral do ASiA

A terceira fase consiste na execução do programa de simulação gerado. Em princípio, qualquer sistema de simulação pode ser utilizado, sendo possível até mesmo oferecer ao usuário diversas opções.

O último estágio do sistema de simulação automático oferece ao usuário a possibilidade de visualização gráfica dos resultados obtidos na simulação.

\subsubsection{Editor Gráfico}

O editor gráfico compōe na tela de um monitor, os elementos do modelo que representam um sistema discreto (basicamente um modelo de redes de filas) apresentado pelo usuário, permitindo modificações imediatas. Uma vez definido o modelo, o editor requisita do usuário os parâmetros necessários para a simulação e os pontos de coleta de dados. As demais tarefas são executadas automaticamente pelo 
sistema.

Como o propósito é facilitar o processo de modelagem, a interface do editor segue os objetivos destacados no capítulo 4 para o projeto de uma interface, apresentando ao usuário um ambiente de fácil utilização.

\subsubsection{Geradores de Aplicação}

A crescente disponibilidade dos computadores nos últimos anos vem transformando-os em uma ferramenta de trabalho não apenas de usuários familiarizados com sua utilização (como acontecia no passado) mas também com pessoas sem um conhecimento razoável da máquina que está utilizando. Para atender principalmente a esse tipo de usuário e ainda para facilitar o trabalho de programadores, podem-se utilizar os geradores de aplicação ou geradores de programa [CLE88, LUK86].

Geradores de aplicação são ferramentas de apoio por computador ao desenvolvimento de "software" que, além de reduzir os custos e aumentar a produtividade, ajudam a melhorar a qualidade dos sistemas produzidos. Essencialmente, um gerador de aplicação é um utilitário que, a partir de uma especificação em alto nível de um problema, transforma automaticamente esta especificação na implementação do problema. O objetivo é automatizar a produção de "software", tirando o processo de implementação das mãos dos projetistas de sistemas e deixando-o a cargo do computador [CLE88].

Geradores de aplicação oferecem muitas vantagens, dentre as quais estão o aumento da produtividade na fase de desenvolvimento de "software" e na facilidade na fase de manutenção, além de facilitar na escrita da especificação. Por não conter detalhes de implementação, a especificação torna-se mais fácil de ser escrita, lida e modificada.

Geradores de aplicação operam de maneira semelhante a um compilador, traduzindo informaçōes de alto nível para informaçōes de mais baixo nível. As especificações descrevem o problema ou tarefa a ser feita pela aplicação. Essas especificações podem estar em uma das formas: um diálogo interativo (onde selecionam-se as opções de uma série de menus); na forma gráfica (através de 
diagramas) ou numa linguagem textual [CLE88].

Os geradores de aplicação são normalmente compostos por três módulos básicos: um módulo de interface, um módulo analisador de especificaçōes e um módulo gerador de produtos [LUK86]. A figura 5.3 mostra como os módulos se relacionam [MEI91a].

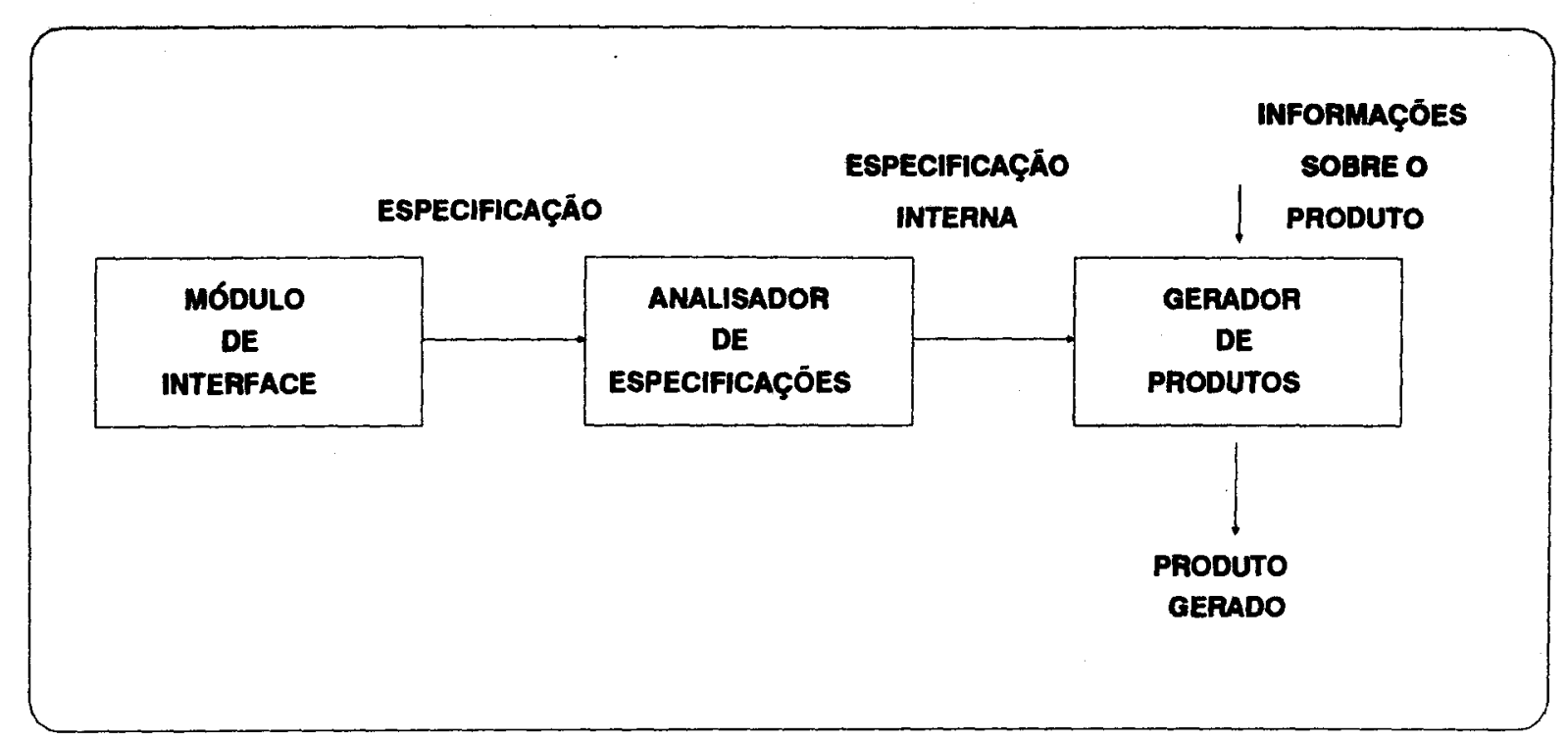

Figura 5.3: Estrutura de um Gerador de Aplicação

O módulo de interface com o usuário pode não aparecer explicitamente em todos os geradores e, nesse caso, a especificação de entrada é textual, podendo ser fornecida num arquivo preparado por algum editor de texto. Quando ele existe, torna mais amigável o uso do gerador, escondendo dificuldades da linguagem de especificação.

O analisador de especificaçōes é responsável pelas análises sintática e semântica das entradas e deve produzir como resultado estruturas de dados intermediárias, que são utilizadas pelo módulo seguinte.

O módulo gerador de produtos é encarregado de gerar o produto desejado pelo usuário. Para isso, ele possui um conjunto de rotinas para acesso às estruturas de dados geradas pelo analisador de especificaçôes e reconhece descriçōes de produtos em uma linguagem própria, que deve indicar as manipulaçōes necessárias na estrutura de dados intermediária e o formato final do produto. 
Uma vez conclúdo, o gerador pode ser utilizado pelo analista ou até mesmo por um usuário final. O processo básico necessário para o desenvolvimento de um sistema usando um gerador de aplicação (figura 5.4), começa com a especificação (que descreve o que o programa deve fazer). Essa é fornecida para o gerador de aplicação, que cria o produto da aplicação na linguagem de programação alvo. Finalmente, o produto, juntamente com o código produzido manualmente pelo projetista de sistemas (se necessário), é compilado para produzir o sistema executável [MEI91b].

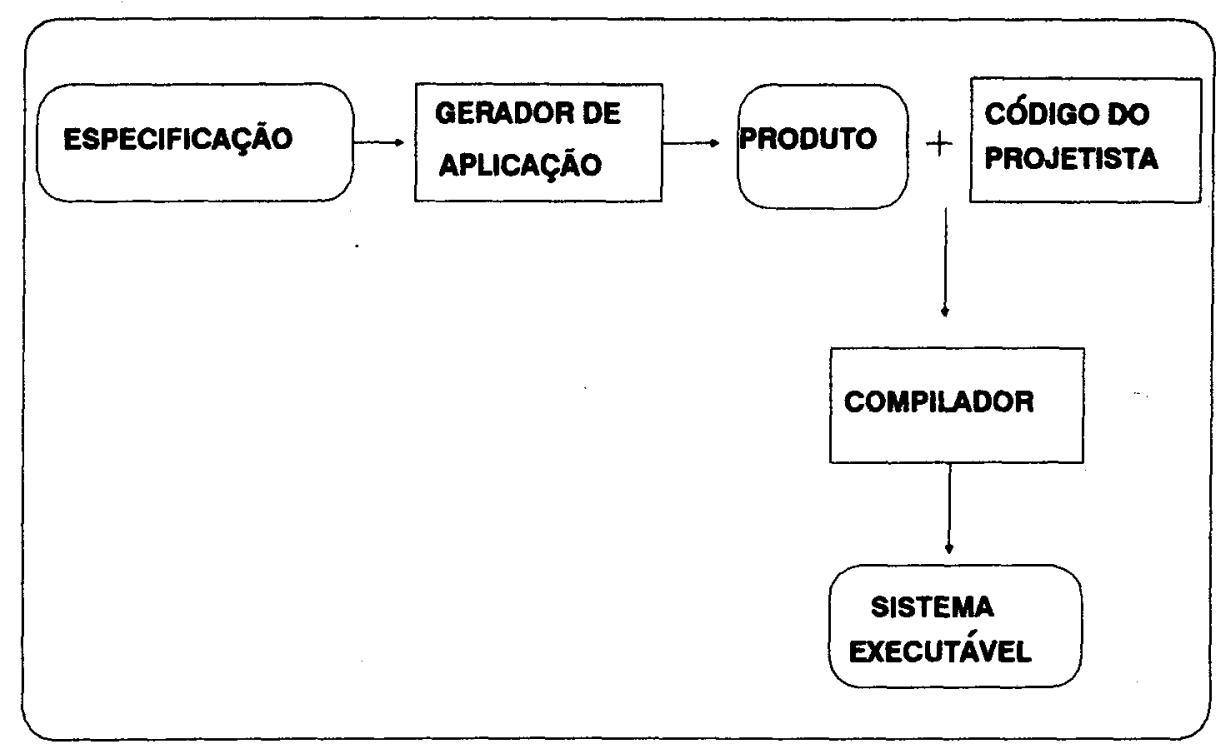

Figura 5.4: Utilização de um Gerador de Aplicação

No sistema de simulação automático, o gerador de aplicações produz um programa de simulação baseado na tabela fornecida pelo editor gráfico e no conjunto de regras definidas pela linguagem de simulação adotada. $O$ gerador de aplicaçōes analisa a tabela gerada pelo editor gráfico e, para cada componente da tabela, provoca a geração dos comandos necessários para simulá-lo. Por exemplo, para cada recurso (facilidade) definido na tabela gerada pelo editor gráfico, o gerador de aplicaçōes deve gerar os seguintes comandos (os exemplos utilizam como linguagem de simulação SMPL - extensão da linguagem C [MAC87]):

.definição da facilidade: que cria e dá um nome para a facilidade, e deve ser executado antes que a facilidade seja utilizada. Por exemplo, o comando: cpu = facility("CPU",1) cria a facilidade CPU com um único servidor; 
requisição da facilidade: requisita que uma determinada facilidade seja reservada e deve ser executada toda vez que um cliente deseja utilizar uma facilidade. Por exemplo, no comando: $r=$ request(cpu,cl,pri) o cliente $c 1$ requisita a cpu com uma prioridade pri.

Cada item da tabela fornecida pelo editor gráfico deverá gerar uma série de comandos na linguagem de simulação considerada. Além desses, existe um conjunto de comandos que devem ser gerados, como por exemplo a definição das estruturas de dados que implementam cada recurso disponivel, comandos que definem as constantes do programa, etc. Assim, o programa de simulação vai sendo gerado de forma que após analisar toda a tabela, tem-se o programa praticamente pronto para ser executado pelo sistema de simulação.

\subsubsection{Sistema para Simulação}

Uma vez definido o modelo de uma simulação e seus parâmetros, deve-se escolher uma linguagem ou pacote de simulação que fornecerá para o gerador de aplicação o conjunto de regras para a geração do programa de simulação. Para a escolha, algumas possibilidades podem ser analisadas:

.linguagens convencionais;

.linguagens de simulação;

.pacotes com propósito específico;

.extensões.

No ASiA adota-se a utilização de extensões para simulações orientadas a evento e a processo. Nesse sentido três extensōes estão sendo consideradas:

.SMPL[MAC87]: extensāo da linguagem C que implementa uma simulação orientada a evento;

.EFC [SOU92]: extensão da linguagem C que implementa uma simulação orientada a processo;

.EFM2 [SPO92]: extensão da linguagem Modula 2 que implementa uma simulação orientada a processo. 


\subsubsection{Estágio de Saída}

O estágio de saída permite a visualização dos resultados obtidos. Oferece também um conjunto de ferramentas para a análise e validação, já que os resultados de uma simulação baseiam-se em um conjunto de números aleatórios, o que torna importante o controle da precisão dos resultados obtidos [MAC87]. Como visto no capítulo 3, uma série de testes estatísticos devem ser executados sobre os resultados para verificar se atingem a precisão desejada, envolvendo a utilização de métodos como "Batch Means", Replicação, etc.

\subsection{Conclusão}

Simulação visual e interativa é um importante avanço no processo de modelagem por simulação, já que a utilização de ambientes gráficos para a elaboração de sistemas de simulação pode simplificar o trabalho do projetista ou usuário final. Mesmo quando as pessoas têm conhecimento de programação e noções sobre simulação, um ambiente com entrada gráfica facilita a tarefa de modelagem.

Alguns exemplos de sistemas que seguem essas idéias foram apresentados, e a partir deles identificou-se os componentes básicos de um sistema de simulação automático, que permite ao usuário descrever graficamente o sistema a ser simulado. O sistema permite a geração automática do programa de simulação, através do uso de um gerador de aplicação.

Dentre esses componentes destaca-se o uso de um editor gráfico que faz a interface entre o projetista (ou usuário) e o sistema de simulação automático para a especificação de um modelo, e um gerador de aplicação que traduz a especificação em um programa de simulação. 


\section{Capítulo 6}

\section{Definição do Editor Gráfico}

Este capitulo discute a estrutura da interface oferecida pelo Editor Gráfico, a definiçāo das informaçōes necessárias para a geraçāo automática de um programa de simulação especificado graficamente, $e$ as operaçōes necessárias para produzir as tabelas a serem utilizadas pelo Gerador de Aplicação a fim de gerar o programa correspondente ao modelo definido pelo usuário.

\subsection{Introduçāo}

O EdGraf constitui o módulo de interface entre o usuário e o Gerador de Aplicação do ASiA (Ambiente de Simulação Automático) em desenvolvimento no Grupo de Sistemas Distribuídos e Programação Concorrente do Departamento de Computação e Estatística do ICMSC-USP [SPO93a, SPO93b].

O Editor Gráfico tem como objetivos: proporcionar ao usuário a interação com o ambiente ASiA, a manutenção da especificação gráfica, a captação de todos os parâmetros do modelo e a geração das tabelas que serão utilizadas pelos estágios seguintes do ASiA.

A interface do usuário oferece um ambiente gráfico para que o modelo do sistema em estudo e seus parâmetros sejam introduzidos no ASiA de uma forma amigável. A seção 6.2 apresenta os elementos dessa interface.

Todas as informações necessárias para a geração automática de um programa de simulação são organizadas em estruturas de dados ou tabelas. Através dessas tabelas, o Gerador de Aplicação cria o programa correspondente ao modelo definido pelo 
usuário. A seção 6.3 discute as informações necessárias ao Gerador.

Para produzir as tabelas, o Editor analisa a especificação gráfica e os parâmetros fornecidos pelo usuário, fazendo a verificação de consistência e evitando incoerências no modelo. Todos os dados podem ser gravados em arquivos, para que possam ser posteriormente editados e também alterados. A seção 6.4 discute como essas operaçōes são realizadas.

Dessa forma, Editor Gráfico esconde, através da interface amigável, os detalhes referentes à montagem da tabela de especificaçâo que vai alimentar o Gerador de Aplicação. Entre a interface e a tabela pronta, existe uma série de operações que o Editor executa, a fim de trabalhar as informações obtidas da especificação gráfica e da parametrização do modelo. O Editor faz a verificação de consistência (tanto da especificação gráfica quanto dos parâmetros fornecidos através dos menus e caixas de diálogo) e monta a tabela de especificação. Alguns arquivos são produzidos, armazenando as informações para o Gerador e também a especificação gráfica do modelo. A figura 6.1 apresenta uma visão geral da estrutura do Editor Gráfico. 


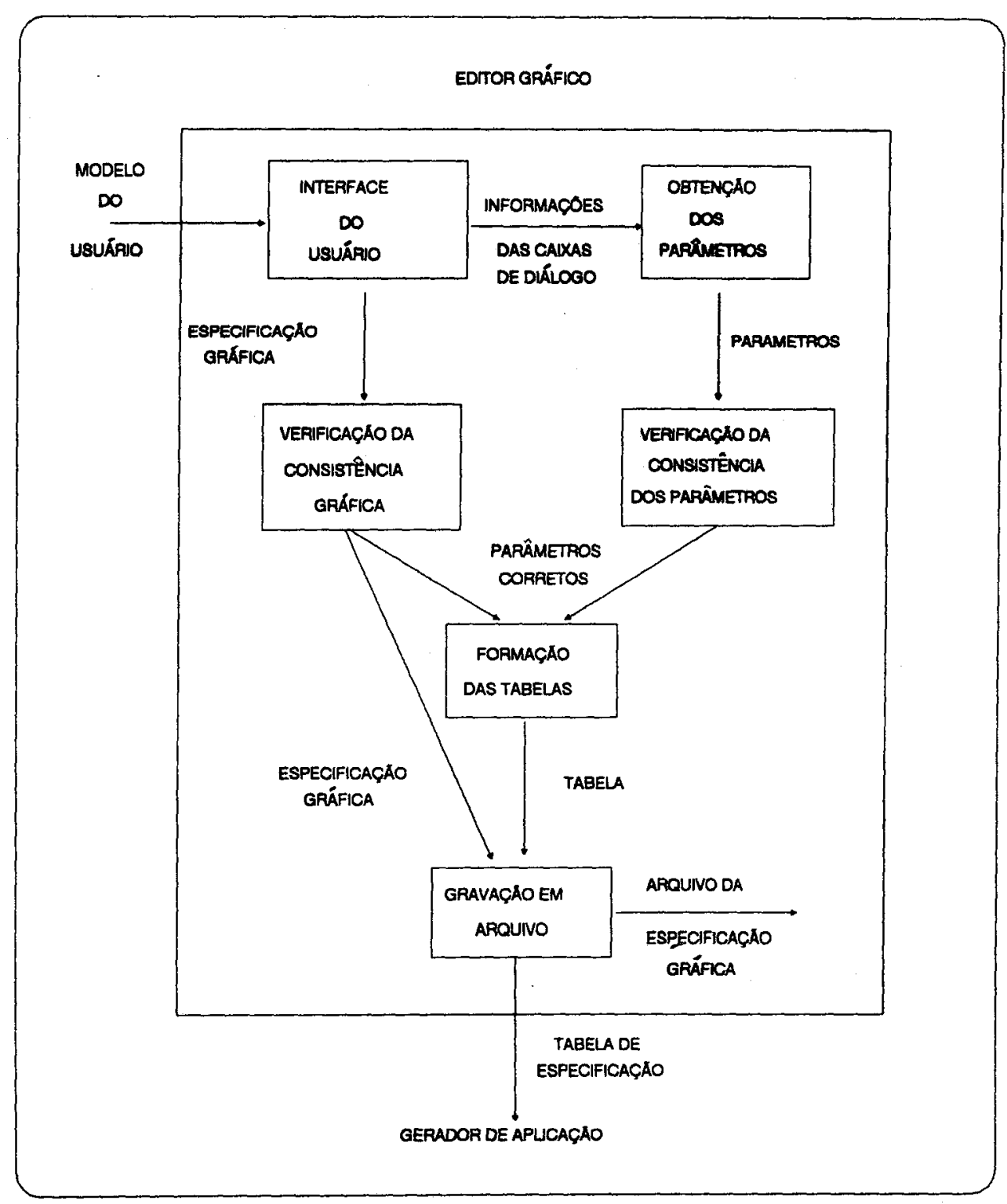

Figura 6.1: Uma Visão Geral do Editor Gráfico

\subsection{A Interface do Usuário}

O Editor Gráfiço é responsável por fornecer ao usuário uma interface de fácil aprendizado e utilização, e também pela manutenção da parte gráfica, possibilitando desenhar (com verificação automática de consistência), apagar elementos de um modelo, gravar arquivos e recuperar arquivos previamente definidos. 
O usuário tem à disposição todos os elementos de uma interface gráfica amigável. O uso do "mouse" facilita todas as operaçōes, e permite acionar a barra de ferramentas para desenhar os recursos do modelo em questão. Também através da barra de ferramentas, o usuário pode selecionar um recurso, unir dois recursos (indicando o caminho a ser seguido por um cliente do sistema sendo modelado) e apagar qualquer símbolo desenhado.

Com uma barra de menus, o Editor possibilita ao usuário executar operações como as relacionadas com arquivos, e fornecer os parâmetros do modelo. A barra de menus oferece as seguintes possibilidades:

.Sair;

.Especificação Gráfica;

.Modelo;

.Recursos;

.Outros;

Ajuda.

\subsection{Obtenção do Modelo e Parâmetros}

A especificaçāo completa de um modelo de simulação exige uma série de parâmetros, alguns relacionados ao modelo como um todo, e outros específicos para cada recurso definido.

Todas as informações necessárias para a geração automática de um programa de simulação são captadas pelo Editor Gráfico, através de uma análise da própria especificação gráfica (se o modelo é representação de um sistema fechado, a existência de ciclos, as conexōes entre os recursos, recursos formados por centros de serviço com uma fila e/ou um servidor) e da obtenção dos parâmetros do modelo fornecidos pelo usuário por meio dos menus e caixas da interface.

No capítulo 2 foram identificados os principais parâmetros referentes a diferentes tipos de centros de serviços, com uma (ou várias) fila(s), e um (ou vários) servidor(es). A partir das extensões funcionais SMPL, EFM2 e EFC, e da linguagem 
GPSS, procurou-se identificar todas as informações necessárias para a geração completa de um programa de simulação referente a um modelo de filas (o estudo foi feito em conjunto, entre as partes envolvidas no projeto do Editor Gráfico e do Gerador de Aplicação). Foram analisados modelos de diferentes níveis de complexidade, desde aqueles constituídos apenas por um centro de serviço formado por uma fila e um servidor, até modelos com vários centros de serviço, modelos fechados, modelos com vários pontos de entrada, modelos representando sistemas onde existam centros de serviço sem fila e também modelos onde exista sincronismo. À medida em que modelos mais complexos são considerados, torna-se necessário captar novas informações na especificação gráfica, ou mesmo solicitá-las ao usuário. Algumas dessas informações não estão sendo captadas pelo Editor Gráfico, porém já foram definidas [SPO94a, SPO94b, SPO94c, SPO94d].

O Gerador de Aplicação desenvolvido por Spolon [SPO93a, SPO94c, SPO94d] produz programas na extensão funcional SMPL. A interface oferecida pelo Editor Gráfico é o mais independente possível do sistema ou linguagem utilizada pelo Gerador e por isso foram analisadas outras extensōes.

Foram identificados alguns parâmetros e informações que se referem ao modelo como um todo e outros que dizem respeito a cada recurso definido através de um centro de serviço. Os primeiros são identificados como parâmetros gerais do modelo, e os últimos, como parâmetros específicos de cada recurso definido no modelo. Todos são descritos a seguir, destacando seu significado no contexto de um modelo de simulação e a sintaxe adequada em cada caso.

\section{Parâmetros Gerais do Modelo}

Nome do Modelo: nome do modelo definido. Deve ser uma cadeia alfanumérica;

.Trace: ativa o "trace" do SMPL [MAC87] (ou de outra linguagem de simulação adotada), podendo haver uma escolha por um dos seguintes tipos:

"trace" desativado;

ativa o "trace", e as mensagens são mostradas continuamente na tela do monitor ou na impressora, dependendo de qual seja o dispositivo padrão 
de saída;

.as mensagens do "trace" são enviadas para a tela, ocorrendo pausa a cada vez em que a mesma é totalmente preenchida;

.as mensagens do "trace" são enviadas para a tela, porém a pausa ocorre após a exibição de cada mensagem;

.atualiza contadores de linha e página e determina mudança de página ou pausa na tela, se necessário;

tempo de execuçāo: tempo que limita a execução da simulação. Deve ser um número real da forma x.y, ou 0.0 se a simulação não for limitada pelo tempo;

tempo de warmup: caso o usuário não queira utilizar "Batch Means" [MAC87], mas mesmo assim queira identificar um tempo na simulação para zerar todos os contadores e medidas obtidas no programa de simulação, deve usar esse campo. O tempo especificado passa a ser o início do intervalo de medida, e as medidas relatadas representam a atividade do modelo de simulação somente a partir daquele ponto no tempo, até o ponto que o relatório das medidas obtidas for produzido. Pode ser utilizado para descartar dados obtidos enquanto o modelo não atingiu estado estacionário. Deve ser um número real da forma x.y, e 0.0 se não for utilizado;

relatório final: determina se o relatório padrão do SMPL deve ou não ser gerado quando da execução do programa de simulação. Deve ser s/S ou $\mathbf{n} / \mathbf{N}$;

nome do arquivo de saida: nome do arquivo que armazena o programa de simulação a ser gerado. Deve ser uma cadeia alfanumérica;

tempo da primeira chegada: indica o tempo da chegada do primeiro cliente ao sistema simulado. Deve ser um número real da forma x.y;

interface: indica se o usuário deseja ou não ativar a interface mtr do SMPL, que fornece ao usuário a possibilidade de obter histogramas a partir dos resultados obtidos na execução do programa de simulação e diferentes tipos de relatórios. A interface é efetuada através de algumas teclas, que têm suas funções renomeadas durante a execução do programa [MAC87]. Deve 
ser $\mathrm{s} / \mathrm{S}$ ou $\mathrm{n} / \mathrm{N}$;

número máximo de entidades: limita a simulação pelo número de clientes que deixam o sistema. Deve ser um número inteiro positivo, e 0 (zero) se a simulação não for limitada pelo número de entidades (clientes);

número de distribuiçōes: indica o número de distribuiçōes do usuário a serem utilizadas no modelo. O usuário deve certificar-se de que todas as distribuições existem, ou digitálas e gravá-las em arquivo, para serem utilizadas pelo Gerador de Aplicação. Deve ser um número inteiro positivo;

número de ciclos: limita a simulação pelo número de ciclos, no caso de modelagem de um sistema fechado. Deve ser um número inteiro positivo, e 0 se a simulação for de um sistema aberto. Caso a especificação gráfica definida indique um sistema aberto (ou seja, o usuário definiu uma entrada), esse campo é apresentado como 0 automaticamente, caso contrário o usuário deve fornecer o número de ciclos diferente de 0 ;

tamanho do lote: indica o tamanho do lote, para aplicação do método "Batch Means". Deve ser um número inteiro positivo, e 0 se não for aplicado;

.valores desprezados: indica a quantidade de valores a serem desprezados antes de iniciar a coleta de dados, para aplicação do método "Batch Means". Deve ser um número inteiro positivo. Caso o valor do tamanho do lote for igual a 0 (indicando que o método não será utilizado), EdGraf avisa ao usuário que esse campo também deve ser igual a 0 (através de uma caixa de mensagem).

\section{Parâmetros Especíícos de Cada Recurso}

nome do recurso: identificação do recurso;

número de senvidores: número de servidores do centro de serviço que representa o recurso. Deve ser um número inteiro positivo;

número de filas: número de filas do centro de serviço que representa o recurso. Deve ser um número inteiro positivo; 
.estatística sobre o comprimento da fila: indica se o usuário deseja ou não obter estatísticas sobre o tamanho máximo e mínimo da fila. Deve ser usado somente quando se tratar de centro de serviço com uma fila. Os dados são apresentados ao final da execução da simulação, em forma de relatório, após o relatório padrão (se houver). Deve ser s/S ou n/N;

.estatística sobre fila vazia: indica se o usuário deseja ou não obter a porcentagem de vezes em que um cliente encontra fila vazia. Também deve ser utilizado para uma fila, como a estatística do comprimento. A estatística é apresentada ao final da simulação, após o relatório padrão. Deve ser s/S ou $\mathrm{n} / \mathrm{N}$;

escolha do próximo recurso: determina o modo de decisão para escolha do próximo recurso. Ou seja, caso a saída de um recurso esteja ligada a vários outros, deve haver uma decisão para escolher para qual recurso o cliente deve se dirigir. Essa escolha pode ser de um dos seguintes tipos:

intervalos de probabilidade. No caso do recurso estar ligado a apenas um outro, ou a vários outros e a escolha é feita através de probabilidade;

.ciclos, com número de voltas pré-estabelecido para o recurso em questão, e depois segue para o recurso seguinte. Nesse caso, os clientes para o recurso entram em sua fila, aguardam atendimento, e então retornam para a mesma fila. Repetem essa operação até atingirem o número especificado de vezes que um cliente deve passar pelo recurso;

.sistemas fechados, o que deve ser especificado para o primeiro recurso do modelo. Somente um recurso do modelo pode ter esse valor para 0 campo, EdGraf não permite que outros tenham esse valor;

distribuições de probabilidade: devem ser fornecidas as distribuições de probabilidade para o tempo entre-chegadas e para o tempo de serviço. Pode ser uma das distribuiçôes pré-definidas, ou então uma distribuiçâo definida pelo usuário. As distribuições pré-definidas são:

.exponencial;

.erlang;

.hiperexponencial; 
.uniforme;

.triangular.

tempos médios entre-chegadas e serviço: tempo médio entre-chegadas de novos clientes ao sistema, e tempo médio que um cliente leva para ser atendido no centro de serviço. Devem ser números reais, da forma x.y;

desvio padrāo dos tempos entre-chegadas e de serviço: desvio-padrāo do tempo entre-chegadas e de serviço. Devem ser números reais, da forma x.y;

seqüência para a geração de números aleatórios: deve ser especificada para o tempo entre-chegadas e para o tempo de serviço. Deve ser um número inteiro, entre 1 e 15 ;

ponto mais provável da distribuiçāo triangular: ponto de maior probabilidade de ocorrência da distribuição triangular, deve ser especificado para o tempo entre-chegadas e para o tempo de serviço. Deve ser um número real da forma x.y;

disciplina da fila: indica a disciplina da(s) fila(s) de espera, através de algoritmos de escalonamento, usados para decidir a formação da fila e qual usuário deve entrar em serviço quando um servidor de um centro de serviço se encontra disponível. SMPL utiliza somente a fila padrão (FCFS - "First Come First Served"), e por isso esse campo não é utilizado. E mantido para futuras expansōes do ASiA a outros sistemas de simulação;

escolha da fila: quando um servidor de um centro de serviço se torna disponível, deve-se determinar de qual fila retirar o próximo cliente a ser atendido. Nāo está sendo utilizado, é mantido para expansões do ASiA;

escolha do cliente: determina a opção do cliente por uma fila de espera, quando mais de uma está disponível. Não está sendo utilizado no momento. E mantido para expansões do ASiA;

escolha do servidor: quando um cliente requisita serviço e mais de um servidor do centro de serviço está disponivel, deve-se escolher qual deles irá atender ao pedido. Não está sendo utilizado no momento. É mantido para expansões do ASiA; 
.conexāo entre os recursos definidos no modelo: esta informação é captada a partir da especificação gráfica do modelo, indicando a maneira pela qual os diversos centros de serviço estão relacionados;

número de passagens no ciclo: número de vezes que um usuário deve passar por um ciclo, se existir. Deve ser um número inteiro;

intervalos de probabilidade: usados para escolha do próximo recurso a ser visitado pelo cliente do sistema em estudo, se for o caso. Devem ser números inteiros;

número de recursos com os quais um determinado recurso está sincronizado (ser houver sincronismo): o sincronismo deve ocorrer quando existe a posse simultânea de recursos. Valor não utilizado no momento;

indicação se deve liberar um recurso passivo logo após a sincronização com outros recursos: um recurso passivo é aquele que não oferece serviço, mas deve ser alocado a um cliente quando este está utilizando os serviços de outro recurso [SOA90]. Deve conter o o valor 0 quando o recurso passivo não é liberado ou 1 em caso contrário. Não utilizado no momento;

indicação que o recurso não tem fila: não utilizado pelo Editor.

\section{Distribuições Definidas Pelo Usuário}

Além de possibilitar ao usuário fornecer os parâmetros do modelo, o Editor Gráfico também permite definir novas distribuiçōes de probabilidade. $O$ Editor Gráfico calcula a distribuiçāo de freqüência correspondente, que vai ser utilizada pelo Gerador de Aplicação. Os valores a serem obtidos são:

.valor de obsenvação: valor de interesse, cujo número de ocorrências foi observado;

número de ocorrências: número de ocorrências do valor em questão, dentre o total de observaçōes.

\section{Eventos Definidos Pelo Usuário}

Pode ser necessário, em um modelo, definir eventos que devam ser escalonados antes do início da simulação. Nesse caso, os parâmetros necessários são: 
tempo de ocorrência: tempo de ocorrência do evento, deve ser um número real da forma x.y;

identificação do recurso em questāo: o Editor Gráfico analisa a especificação gráfica para obter a identificação do recurso.

\subsection{Consistência, Armazenamento e Manutenção}

O Editor Gráfico transforma todas as informaçōes vindas do modelo de simulação, que foi especificado utilizando uma interface agradável, em um conjunto de dados consistente e organizado de forma que possa ser utilizado pelo Gerador de Aplicação.

Existe uma série de operaçôes que deve ser realizada pelo Editor Gráfico, a fim de obter todas as informações corretas. A verificação de consistência ocorre tanto durante o desenho da especificação gráfica, com mensagens que avisam ao usuário quando esse tenta executar alguma ação proibida, como durante a parametrizaçāo do modelo, onde cada informação é analisada conforme os tipos, valores e intervalos apresentados na seção 6.3. Por exemplo, no caso da especificação gráfica, EdGraf não permite recursos com definiçāo incompleta, avisando ao usuário através de caixas de mensagem. No caso da parametrização, por exemplo, se o usuário escolher uma sequiência para geração de números aleatórios que não exista, ou ainda digitar caracteres em vez de um valor numérico, EdGraf apresenta uma caixa de mensagem que informa os possíveis valores corretos. Para cada um dos parâmetros a serem fornecidos tal procedimento é efetuado, em caso de erro por parte do usuário. Dessa forma, o Editor não permite que um modelo inconsistente seja definido. Todos os recursos definidos no modelo devem ter entrada e saída também definidos. EdGraf pede também pela entrada e saída (ou saídas) do modelo, a menos que o modelo seja a representação de um sistema fechado.

À medida que os símbolos gráficos vão compondo o modelo, vão sendo armazenados em memória. $O$ mesmo ocorre com todas os parâmetros fornecidos. $O$ usuário pode gravar todas as informações em arquivos, o que possibilita a recuperação de modelos para simples verificação ou mesmo alteração. E na forma de arquivos que as tabelas contendo a especificação do modelo definido pelo usuário são transferidas 
para o Gerador de Aplicação. EdGraf sempre pergunta, ao final do trabalho do usuário, se o mesmo deseja salvar o trabalho desenvolvido.

\subsection{Conclusão}

A interface do ASiA, responsabilidade do Editor Gráfico, é constituída por elementos que a tornam agradável e simples de ser utilizada, como menus e janelas. O projeto do Editor Gráfico envolveu não apenas definir uma interface agradável para o usuário, mas também identificar todas as informações necessárias para produzir um programa de simulação a partir da representação gráfica de um modelo.

Além dos parâmetros identificados no capítulo 2, outros parâmetros e informações foram identificados a partir de uma análise das extensões funcionais SMPL, EFM2, EFC e da linguagem GPSS. Dessa forma, deixou-se o Editor Gráfico o mais independente possível da linguagem de simulaçāo utilizada.

O Editor Gráfico permite ao usuário definir sua própria distribuição de probabilidade para utilizar no modelo, e também definir eventos que devam ser escalonados antes do início da execução da simulação. Os dados relativos à nova distribuição e aos eventos também são captados pelo Editor Gráfico.

Tendo obtido da especificação gráfica e do usuário as informações necessárias, o Editor Gráfico produz a tabela que o Gerador de Aplicação vai utilizar para constituir o programa de simulação. 


\section{Capítulo 7}

\section{Implementação do Editor Gráfico}

Este capítulo apresenta as partes do sistema ao nivel de implementaçāo, descrevendo a interface oferecida ao usuário e as estruturas de dados utilizadas para armazenar as informaçōes necessárias para a geração automática do programa de simulação. No decorrer deste capítulo, o editor recebe o nome de EdGraf (Editor Gráfico para o ASiA).

\subsection{Introdução}

O Editor Gráfico definido no capítulo 6 foi implementado utilizando-se o compilador Borland $\mathrm{C}++\mathrm{e}$ os recursos oferecidos pelo Microsoft Windows 3.1. Neste capítulo são apresentados os aspectos relacionados com essa implementação.

A seção 7.2 apresenta algumas considerações feitas visando obter um produto de "software" de boa qualidade. A seçâo 7.3 apresenta os principais elementos que compõem a interface oferecida pelo EdGraf. A seção 7.4 descreve as estruturas de dados utilizadas para armazenar as informaçōes necessárias e os principais aspectos relacionados à implementação.

\subsection{Considerações Sobre o Projeto}

No desenvolvimento do EdGraf foram utilizados alguns conceitos gerais da Engenharia de Software, visando obter um produto de boa qualidade [PRE87]: 
.modularidade: o sistema foi implementado em uma estrutura modular, o que facilita as tarefas de desenvolver, manter, modificar e estender o mesmo;

.manutebilidade: durante a elaboração do sistema, algumas decisōes foram tomadas para permitir atividades de manutençăo no decorrer do tempo de vida útil do sistema. A documentação, tanto interna ao código fonte quanto externa (Descrição da Implementação e Manual do Usuário [SPO94a, SPO94b]), foi desenvolvida com o intuito de facilitar a manutenção e futuras alteraçōes no EdGraf.

As necessidades dos usuário dominaram o projeto da interface, como sugerido por Norman [NOR86], e todas as mensagens de erro foram organizadas de forma a não confundir o usuário [NOR86, SHN87]. Ainda seguindo os objetivos de projeto de interfaces homem-máquina (apresentados no capítulo 4), procurou-se desenvolver um aplicativo que facilitasse o trabalho do usuário na tarefa de especificar um modelo de simulação. A consistência com outros aplicativos para Windows aparece na utilização de caixas padrão como Abrir e Salvar Arquivos.

\subsection{A Interface do Usuário}

O Editor Gráfico EdGraf foi desenvolvido visando facilitar o trabalho do usuário na especificação de um modelo de simulação. Desse modo, a interface gráfica procura oferecer, através de janelas, menus e a utilizaçāo do "mouse", os elementos necessários para captar do usuário todas as informações do modelo, desde a representação gráfica até os parâmetros do mesmo. Com isso, capacita o usuário para especificar modelos de filas, utilizando centros de serviço constituídos por uma (várias) fila(s) e um (vários) servidor(res). $O$ apêndice $A$ exemplifica a utilização do EdGraf.

A tela principal do EdGraf apresenta uma barra de título, uma barra de menus (com menu do sistema e menus do editor), uma barra de ferramentas e uma janela de edição gráfica (figura 7.1). A barra de título informa ao usuário o nome do sistema, com a frase "EdGraf - Editor Gráfico ASiA". As barras de menus, ferramentas e a janela de edição gráfica permitem ao usuário a definição e parametrização de um modelo de simulação. 


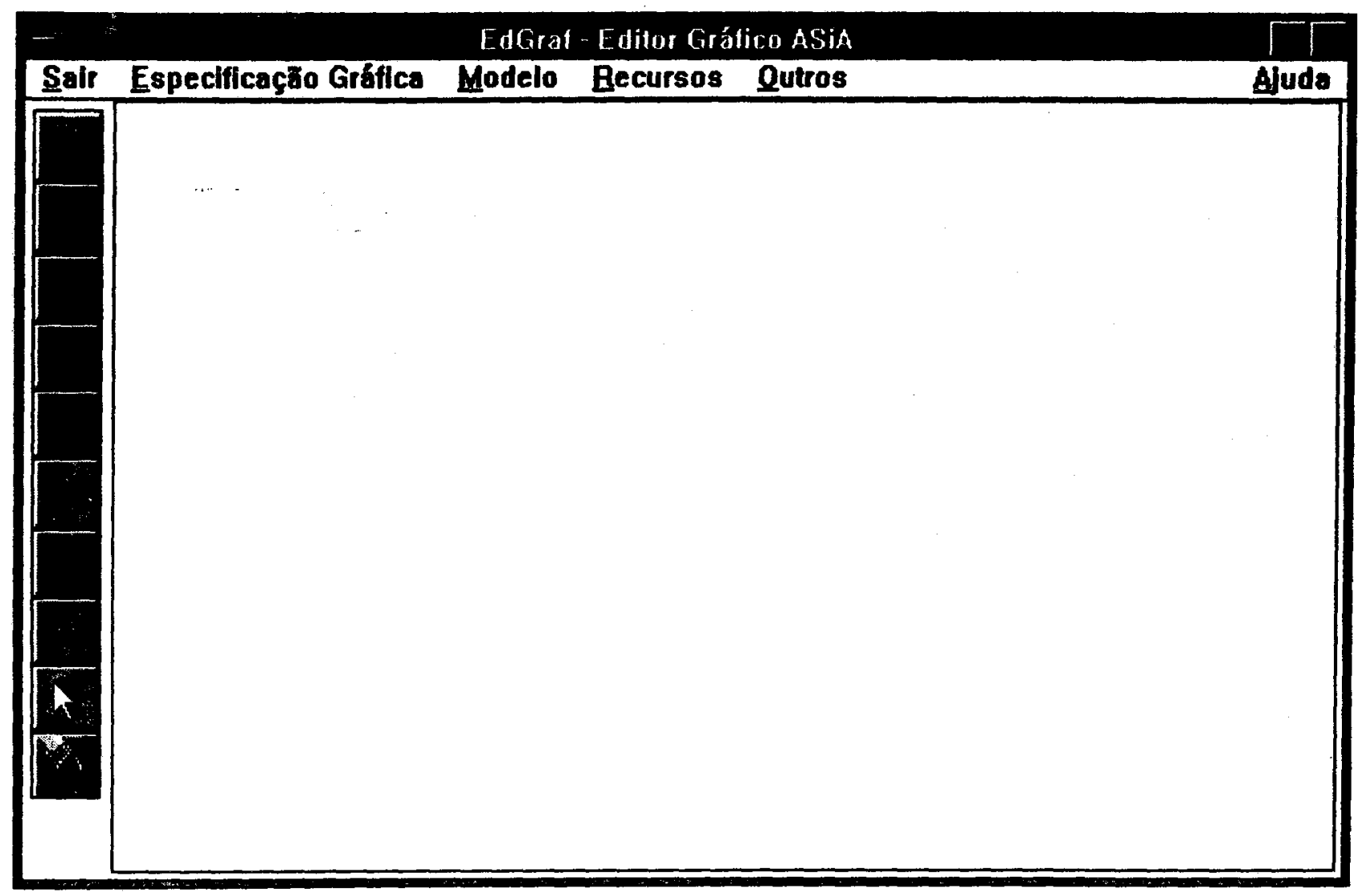

Figura 7.1: Tela Principal do EdGraf

\subsubsection{Janela de Edição Gráfica}

A janela de edição gráfica (retângulo maior à direita da barra de ferramentas, na figura 7.1) ocupa a maior parte da tela, e nesta área o usuário pode desenhar a especificação do modelo. Através de manipulação direta da tela, com o uso do "mouse", o usuário tem acesso à barra de ferramentas para compor seu modelo. 


\subsubsection{Barra de Ferramentas}

A barra de ferramentas (janela de ícones), situada a esquerda da janela de edição, apresenta dez ícones que representam as primitivas de desenho e seleção de símbolos na janela de edição gráfica (figura 7.2). Através dos ícones, o usuário pode compor a especificação gráfica do modelo.

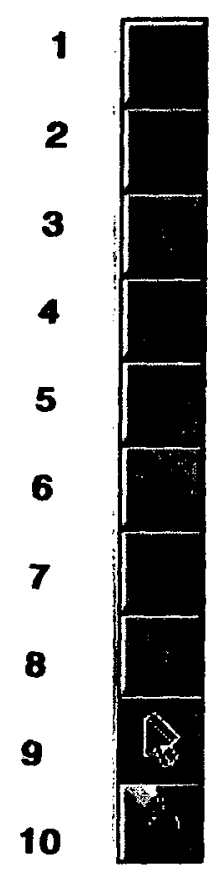

Figura7.2 : Barra de Ferramentas

\section{fcones 1, 2, 3, 4:}

Os quatro primeiros ícones representam os tipos possíveis de centros de serviço que podem ser utilizados pelo usuário para definir os recursos de um modelo de simulação. Dessa forma, o usuário pode desenhar um recurso com uma fila e um servidor, uma fila e vários servidores, várias filas e um servidor, ou ainda várias filas e vários servidores. Ressalta-se que o número de filas e de servidores do centro de serviço deve ser fornecido pelo usuário no momento da parametrização do modelo. 


\section{fcones 5, 6:}

O usuário tem à disposição, na janela de ícones, as setas que indicam entrada ou saída de um recurso. Podem ser usadas para especificar a entrada e a(s) saída(s) do modelo.

\section{fcones 7, 8:}

Esses ícones possibilitam estabelecer uma ligação entre dois recursos, e ramificaçōes das mesmas. Todas as ramificações devem ser desenhadas a partir de uma ligação.

\section{Icone 9:}

O nono ícone da janela deve ser utilizado na seleção de um recurso para parametrização ou na definição de um evento para o mesmo, e desenha na janela de edição uma seta que indica qual o recurso selecionado.

\section{Ícone 10:}

O último ícone da barra de ferramentas permite apagar qualquer símbolo desenhado. E importante destacar que, quando um símbolo de um centro de serviço for apagado, todas as ramificações e ligações que chegam e partem do mesmo também são apagadas, isto é, EdGraf não deixa inconsistências na especificação gráfica.

\subsubsection{Barra de Menus}

A barra de menus (também chamada de menu principal) aparece logo abaixo da barra de título (figura 7.1) e apresenta os seguintes menus:

Sair

.Especificação Gráfica

.Modelo

.Recursos

.Outros

.Ajuda 
Visando facilitar o aprendizado do usuário, todas as caixas de diálogo para abrir e salvar arquivo são as caixas padrāo do Windows (as caixas de diálogo comum descritas no capítulo 4), utilizadas nos aplicativos desenvolvidos para o mesmo.

Menu Sair

O menu Sair apresenta os seguintes itens:

.Limpar

.Abrir Tudo

Salvar Tudo

.Salvar Tudo Como

.Sair

Menu Especificação Gráfica

O menu Especificação Gráfica apresenta os itens:

.Nova

.Abrir

.Salvar

Salvar Como

Menu Modelo

O menu Modelo apresenta os itens:

.Parametrizar

.Mostrar

.Abrir

.Salvar

Salvar Como

Menu Recursos

O menu Recursos apresenta os itens: 
.Parametrizar

.Alterar

.Mostrar

.Cancelar

Abrir

Salvar

Salvar Como

\section{Menu Outros}

O menu Outros contém dois itens e cada um constitui, por sua vez, um submenu:

.Distribuição Tabelada

.Evento

\section{Distribuição Tabelada}

Distribuição Tabelada permite ao usuário a definição de distribuiçōes de probabilidade [MAC87, SPO93b]. Apresenta os itens:

.Nova

.Mostrar

Abrir

Salvar

Salvar Como

\section{Evento}

Evento possibilita ao usuário definir eventos para recursos definidos no modelo. Esses eventos são escalonados antes do início da simulação, por isso o usuário deve indicar o tempo para sua ocorrência. Esse submenu apresenta os seguintes itens:

.Definir

.Mostrar

.Cancelar 
.Novo

.Abrir

Salvar

Salvar Como

Menu Ajuda

O menu Ajuda contém os itens:

.Ajuda

Sobre

Dos itens citados acima, todos estão implementados, com excessão de Mostrar (menu Recursos) que está parcialmente implementado, e Ajuda (menu Ajuda) que está sendo implementado em um trabalho de Iniciaçāo Científica.

Alguns dos itens dos menus apresentam ainda vários sub-itens ou caixas de diálogo quando são ativados. Esse é o caso, por exemplo, dos itens Parametrizar nos menus Modelo e Recursos que serão detalhados na próxima seção.

\subsubsection{Elementos Utilizados para a Captação dos Parâmetros} Necessários a Um Modelo de Simulação

A especificação completa de um modelo de simulação exige uma série de parâmetros relacionados ao modelo como um todo, e também outros específicos para cada recurso definido no mesmo. Esses parâmetros, abordados no capítulo 6, são requisitados pelo EdGraf, através de caixas de diálogo, ativadas pelos itens dos menus. Tais caixas são apresentadas a seguir. 


\section{Parâmetros Gerais do Modelo}

\section{Caixa de Dí́logo "Modelo"}

Todos os parâmetros que refletem as características gerais do modelo são fornecidos através do menu Modelo, item Parametrizar, por meio da caixa de diálogo Modelo (figura 7.3). O capítulo 6 apresentou a definição de todos os parâmetros que aparecem nessa caixa.

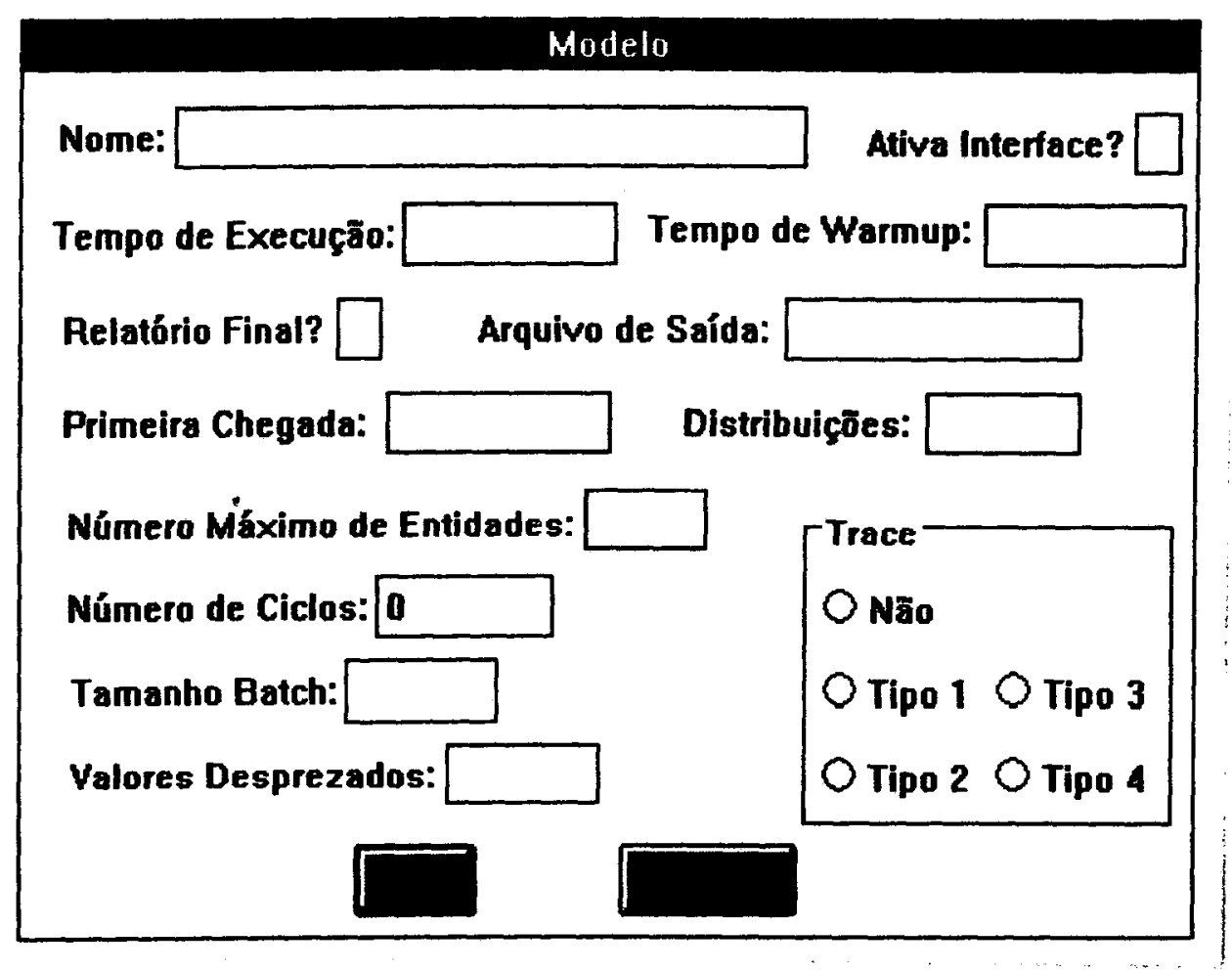

Figura7.3: Caixa Modelo

\section{Parâmetros Específicos de Cada Recurso do Modelo}

Cada recurso definido no modelo de simulação necessita de uma série de parâmetros. Tais parâmetros, específicos de cada recurso, são fornecidos através do menu Recursos. Para facilitar o trabalho do usuário, os parâmetros são solicitados por 
diferentes itens do menu, através de caixas de diálogo. Ressalta-se que essas caixas são utilizadas também quando o usuário vai alterar os parâmetros de um recurso. Todos os parâmetros requisitados pelas caixas foram discutidos no capítulo 6 .

\section{Caixa de Diálogos "Dados do Recurso"}

O item Recursos, do item Parametrizar, apresenta a caixa de diálogo Dados do Recurso (figura 7.4) referentes à identificação do recurso. Quando o usuário utiliza ciclos no recurso (significando que o cliente deve passar um número de vezes pelo recurso em questão e depois se deslocar para o recurso seguinte), os clientes entram na fila, recebem atendimento, e então retornam para a mesma fila. Repetem essa operação até atingirem o número especificado de vezes que um cliente deve passar pelo recurso. Esse número é solicitado pelo EdGraf através da caixa de mensagem Ciclo (figura 7.5). Quando a escolha é feita probabilisticamente, as caixas das figuras 7.6 e 7.7 requisitam os valores necessários para cada ponto de escolha, isto é, as saídas do recurso para outros recursos definidos no modelo.

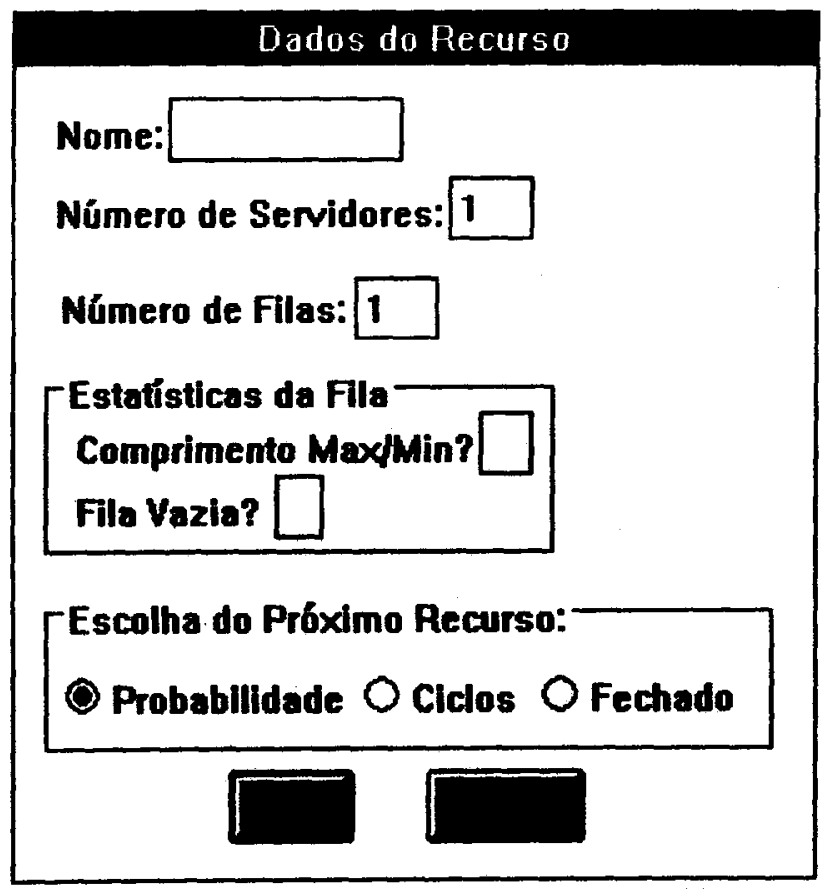

Figura 7.4: Caixa Dados do Recurso 


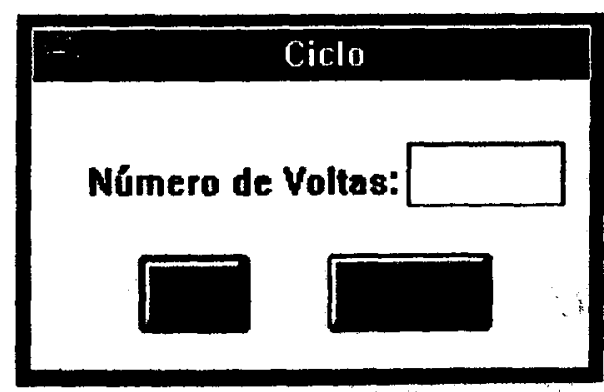

Figura 7.5: Caixa Ciclo

Ramificação

Probabilidade:
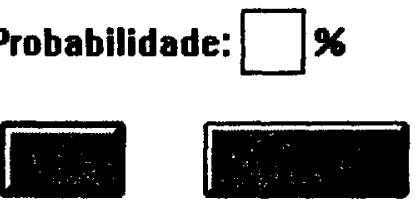

Figura 7.6: Caixa Ramificação

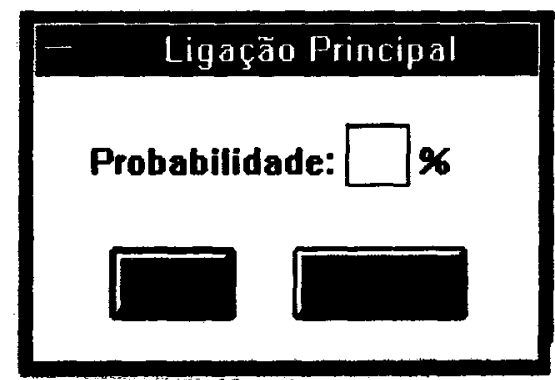

Figura 7.7: Caixa Ligação Principal

\section{Caixa de Diálogo "Chegada"}

O item Chegada, do item Parametrizar, apresenta a caixa de diálogo Chegada (figura 7.8) que pede pelos parâmetros relacionados ao tempo entre-chegadas para o recurso. 


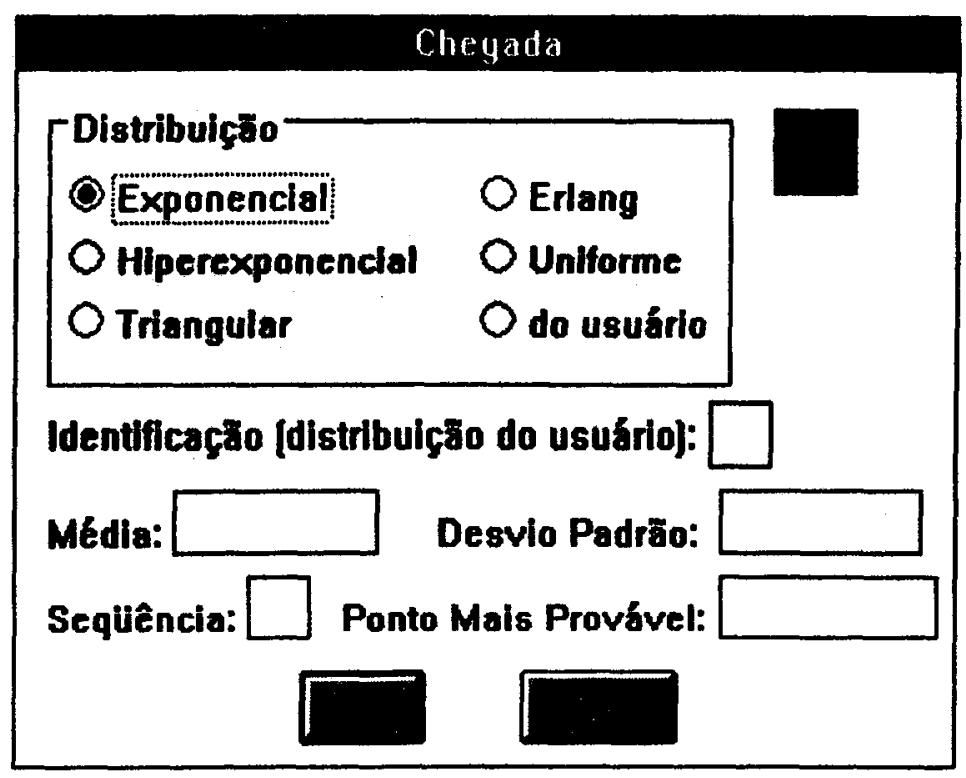

Figura 7.8: Caixa Chegada

\section{Caixa de Diálogo "Fila"}

O item Fila, do item Parametrizar, apresenta a caixa de diálogo Fila (figura 7.9), que solicita os parâmetros relacionados à(s) fila(s) do recurso.

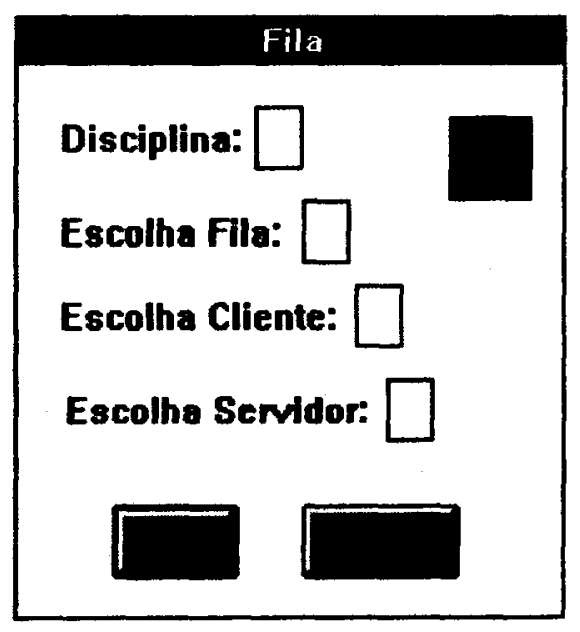

Figura 7.9: Caixa Fila 


\section{Caixa de Diálogo "Serviço"}

O item Serviço, do item Parametrizar, apresenta a caixa de diálogo Serviço (figura 7.10), que solicita pelos parâmetros relacionados ao tempo de serviço do recurso.

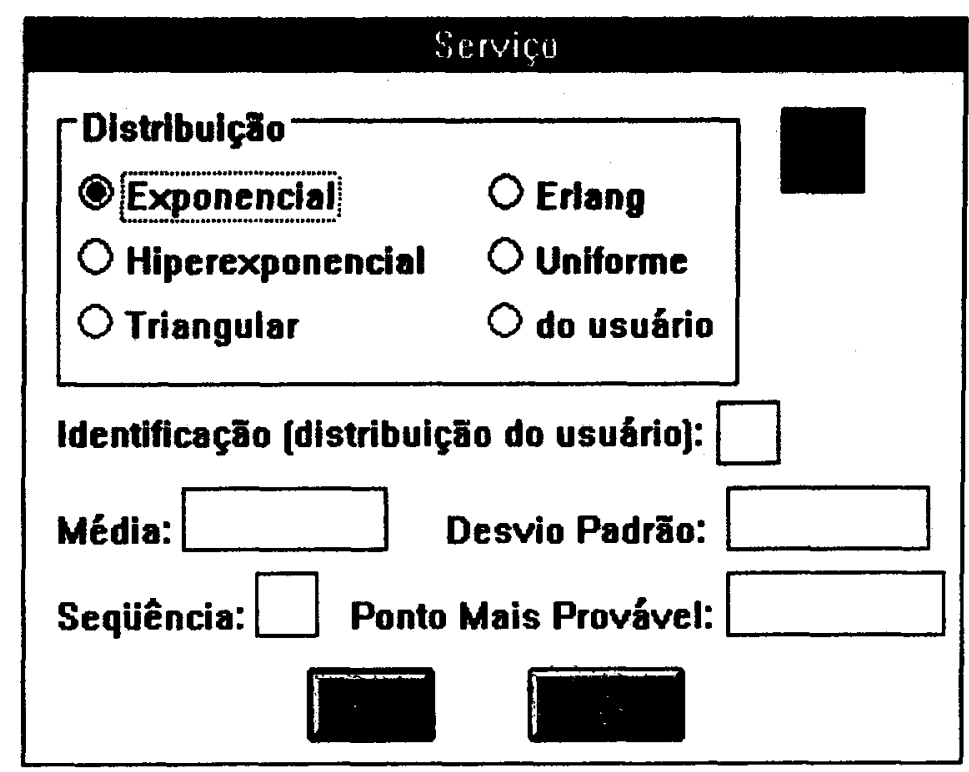

Figura 7.10: Caixa Serviço

\subsubsection{Distribuições Definidas Pelo Usuário}

Um usuário pode querer utilizar uma distribuição de probabilidade definida a partir de suas observaçōes. Nesse caso, EdGraf capta do usuário os valores de observações e o número de ocorrências para cada valor e produz a distribuição de freqüência correspondente.

Para definir uma nova distribuição, o usuário deve utilizar o submenu Distribuição Tabelada (menu Outros da barra de menus). Essa opção apresenta a caixa de diálogo Distribuição Tabelada (figura 7.11). 


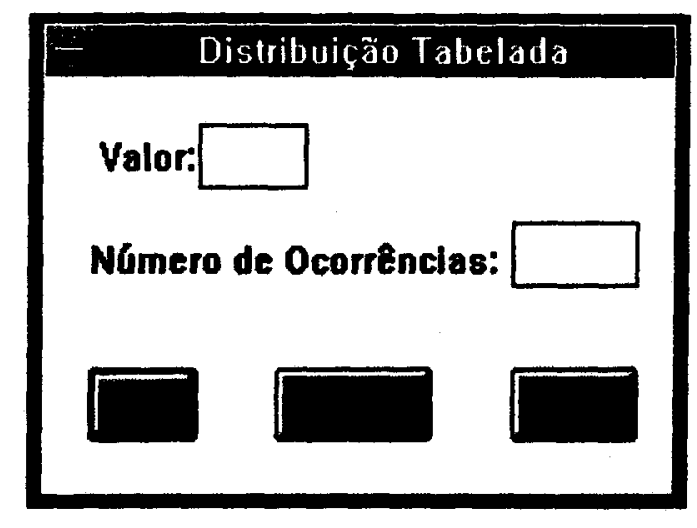

Figura 7.11 Caixa Distribuição Tabelada

\subsubsection{Como Definir Eventos}

Pode ser necessário iniciar uma simulação com clientes já aguardando na fila de um dado recurso. Nesse caso, alguns eventos devem ser escalonados antes do início da simulação. EdGraf permite ao usuário indicar o recurso envolvido, e o tempo de ocorrência do evento.

Para definir eventos para recursos definidos no modelo, o usuário deve utilizar o submenu Evento (menu Outros da barra de menus). A caixa Evento solicita o tempo de ocorrência (figura 7.12).

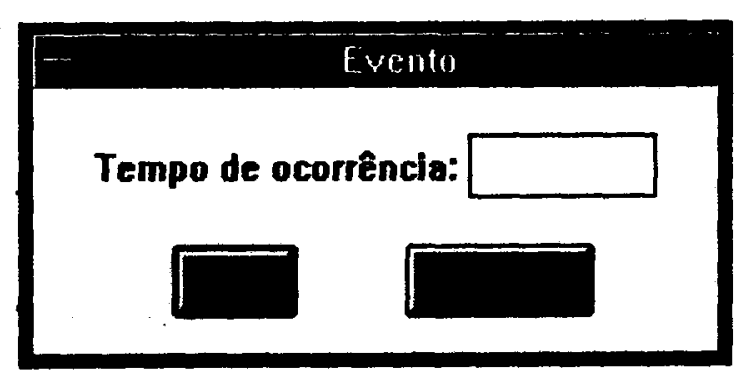

Figura 7.12: Caixa Evento 


\subsection{A Implementação do EdGraf}

O EdGraf foi desenvolvido utilizando-se a linguagem de programação $\mathrm{C}$, com o compilador Borland $\mathrm{C}++$ versão 3.1, em microcomputador tipo IBM-PC 386 . O código fonte tem aproximadamente 15000 linhas, incluindo os comentários. Foi desenvolvido um manual que descreve detalhadamente a implementação do Editor [SPO94a].

Para a interface ser mais amigável, fêz-se uso dos recursos oferecidos pelo Microsoft Windows 3.1. Como discutido no capítulo 4, o Windows fornece rotinas que permitem o uso de menus, caixas de diálogo, ícones, cursores e outros componentes de uma interface gráfica. Todas as caixas de diálogos, menus e ícones utilizados no EdGraf foram projetados com o auxílio do Resource Workshop [RES91]. O Resource Workshop é uma ferramenta que possibilita, através de editores gráficos, projetar caixas de diálogo, menus, ícones, cursores, mapas de bits e outros recursos oferecidos pelo Windows e que facilitam a interface com o usuário. Através dos editores pode-se visualizar exatamente como cada elemento de interface vai ser apresentado no aplicativo Windows.

Todas as caixas de diálogo relacionadas com a manipulação de arquivos são padrão do Windows, mantendo-se assim consistência com os demais aplicativos desenvolvidos para este ambiente. Isso facilita a utilização e aprendizado por parte do usuário.

O "software" do Editor Gráfico foi desenvolvido em 4 grupos principais, cada um composto de vários módulos (figura 7.13):

.o grupo dos módulos responsáveis pela interface propriamente dita;

.o grupo dos módulos que manipulam as informações referentes aos parâmetros e à especificação gráfica do modelo;

.o grupo responsável por todo o tratamento de arquivos;

.o grupo de módulos responsáveis pela verificação de consistência dos parâmetros fornecidos pelo usuário. 


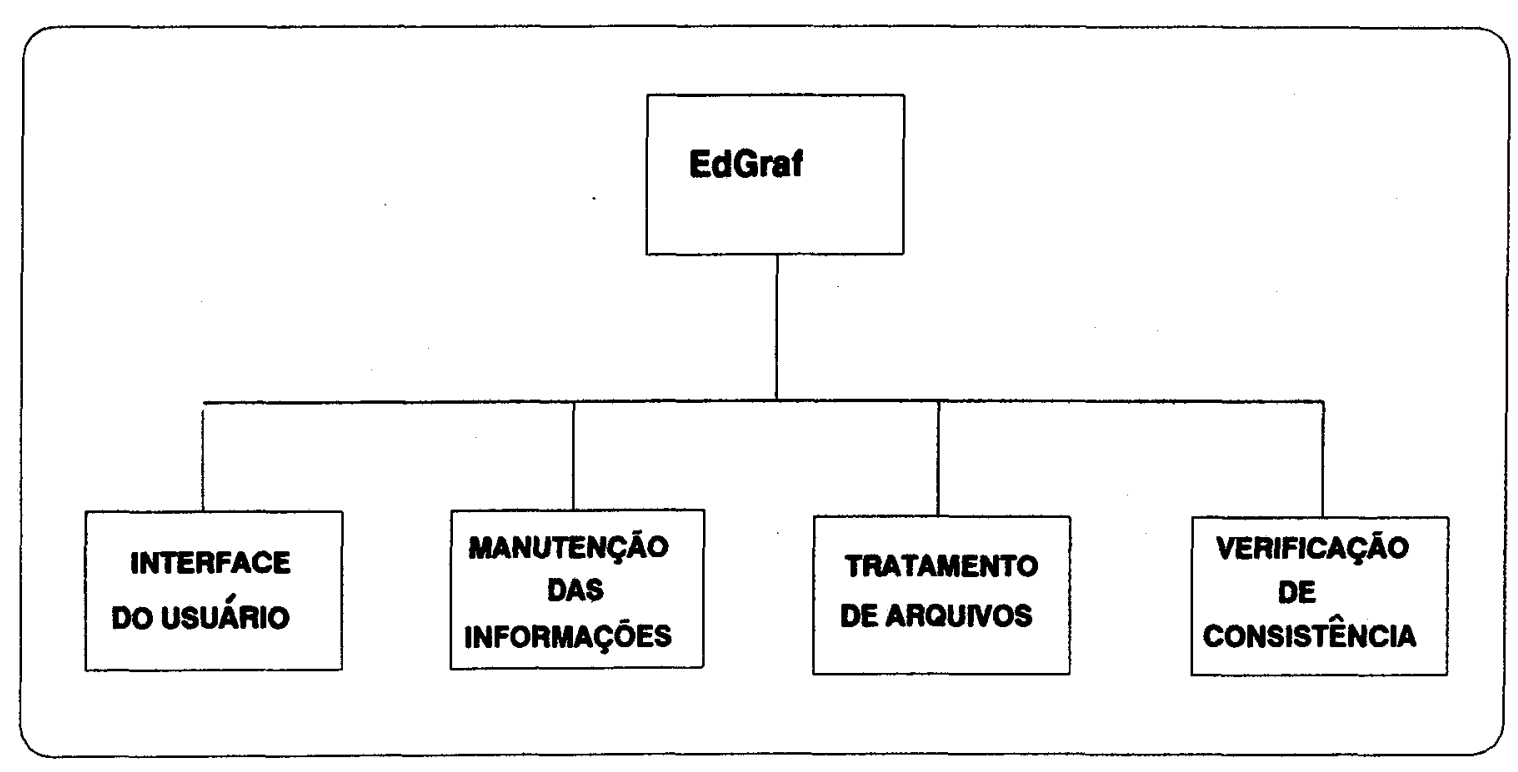

Figura 7.13: Grupos de Módulos do EdGraf

As seções seguintes apresentam as principais características de cada um dos grupos.

\subsubsection{Interface do Usuário}

A interface oferecida pelo EdGraf é baseada no uso de janelas e menus, manipuladas através do "mouse". As caixas de diálogo (tipos de janelas) são mantidas através de procedimentos padrão, que recebem as mensagens do teclado e "mouse".

Este grupo contém os seguintes módulos (figura 7.14):

.os responsáveis pelo tratamento das mensagens endereçadas a cada janela; .o que trata das caixas de diálogo;

.o responsável pela verificação de consistência da especificação gráfica; .o que contém a definição dos recursos.

A função de cada um desses módulos é descrita a seguir. 


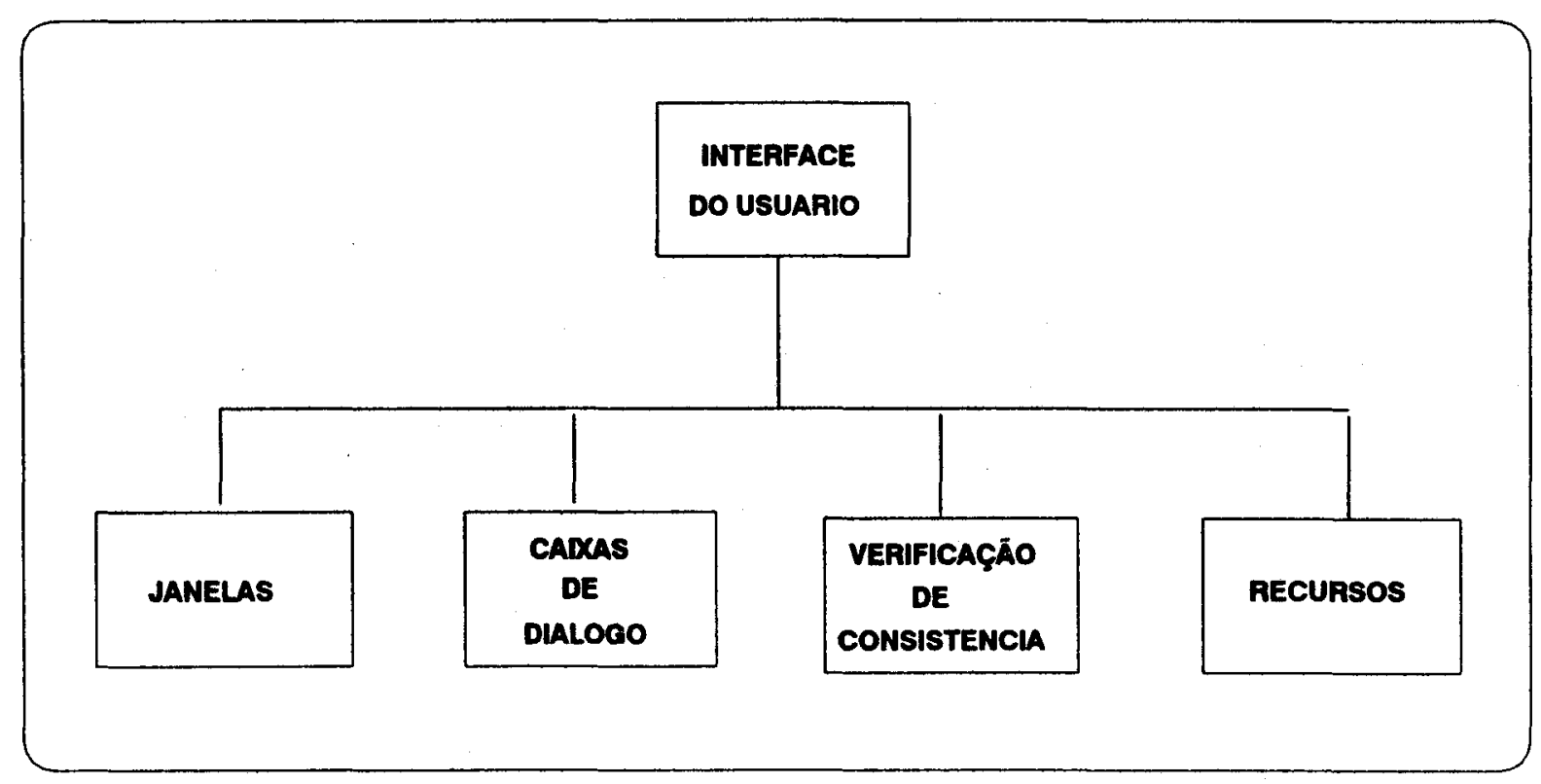

Figura 7.14: Módulos da Interface do Usuário

\section{Janelas}

Compreende três módulos, responsáveis pelas mensagens relativas às janelas principal, de edição gráfica e a que contém a barra de ferramentas.

No módulo responsável pela janela principal são criadas as janelas de edição e de ferramentas, como janelas filhas da primeira. Esse módulo também processa as mensagens referentes a cada item dos menus, início e finalização do EdGraf. No tratamento dos menus, todas vez que um deles é ativado, EdGraf verifica quais os itens que podem ser ativados. Por exemplo, o usuário não pode visualizar a parametrização do modelo, se esta não for fornecida.

No módulo responsável pela janela de edição gráfica são processadas as mensagens referentes ao botão do "mouse" e à pintura da janela, como quando o usuário desenha um novo símbolo ou altera o tamanho da mesma. Quando um símbolo é desenhado ou apagado, EdGraf pede ao Windows que atualize apenas a região envolvida, na janela de edição gráfica. Dessa forma, não é necessário repintar toda a área da janela, mas apenas a porção alterada. Também verifica a posição do cursor do "mouse" na janela, quando ocorre seleçāo de símbolo para apagar ou parametrizar recurso. Outra função executada por este módulo é o desenho de uma 
pequena seta na janela de edição, que indica o recurso selecionado para parametrização. Também nesse caso apenas a região da janela de edição gráfica onde a seta é desenhada é atualizada, evitando-se assim a repintura de toda a janela.

Para a janela que contém a barra de ferramentas, o módulo é responsável pelas mensagens referentes à criação, pressão do botão do "mouse" e pintura. EdGraf identifica o ícone escolhido verificando a posição do cursor do "mouse" dentro da janela. Quando um ícone é selecionado, utiliza a função InvertRect para inverter as cores do mesmo, permitindo que o usuário saiba qual opção está selecionada.

\section{Caixas de Diálogo}

Estão neste módulo todos os procedimento responsáveis pelo tratamento das caixas de diálogo (apresentadas na seção 7.3): caixa de Apresentação, caixa Sobre, e todas as caixas responsáveis por obter do usuário os parâmetros do modelo especificado, informaçōes sobre distribuiçōes e eventos definidos. Manipulam as mensagens enviadas de e para cada uma das caixas (como a pressão dos botões $\mathrm{OK}$ e CANCELA, com o uso do "mouse", ou uma tecla).

\section{Verificação de Consistência}

EdGraf analisa a especificação gráfica do modelo, conforme este é desenhado pelo usuário. Dessa forma, não permite inconsistências como recursos sem entrada ou saída definidas. Quando o usuário apaga um símbolo, automaticamente são apagados todas as entradas e saídas que chegam e partem do mesmo, evitando-se dessa forma que setas perdidas na janela atrapalhem o trabalho de especificação.

Este módulo também é responsável por verificar se a especificação do modelo está completa, no momento em que o usuário inicia a parametrização. Caso isso ocorra, o usuário recebe uma notificação através de uma caixa de mensagem.

\section{Recursos}

Este módulo contém a definição dos recursos (os elementos fornecidos pelo Windows, como as caixas de diálogo, os menus e os ícones) utilizados na interface oferecida pelo EdGraf e projetados com o auxílio do Resource Workshop. 


\subsubsection{Manutenção das Informações}

Todos os parâmetros fornecidos pelo usuário, as informaçōes captadas pelo EdGraf a partir da especificação gráfica, e a própria estrutura da especificação são mantidos em memória e posteriormente armazenados em arquivos. Dessa forma, o usuário pode recuperar (e modificar) qualquer modelo já definido com o EdGraf.

Este grupo é responsável pela manutenção das listas que mantém as informações fornecidas pelo usuário (transferir as informações das caixas de diálogo para a lista). A manipulação de listas encadeadas no Windows requer a utilização de "handles", os nós armazenam "handles" ao invés de ponteiros (como discutido no capítulo 4). A seguir são descritos os módulos que compõem esse grupo (figura 7.15). As informaçōes que devem ser mantidas são relacionadas com os módulos:

.parâmetros gerais do modelo;

.símbolos da especificação gráfica;

.parâmetros dos recursos;

.as conexões (ligações) entre os símbolos;

.ciclos;

.distribuições do usuário;

.eventos definidos pelo usuário 


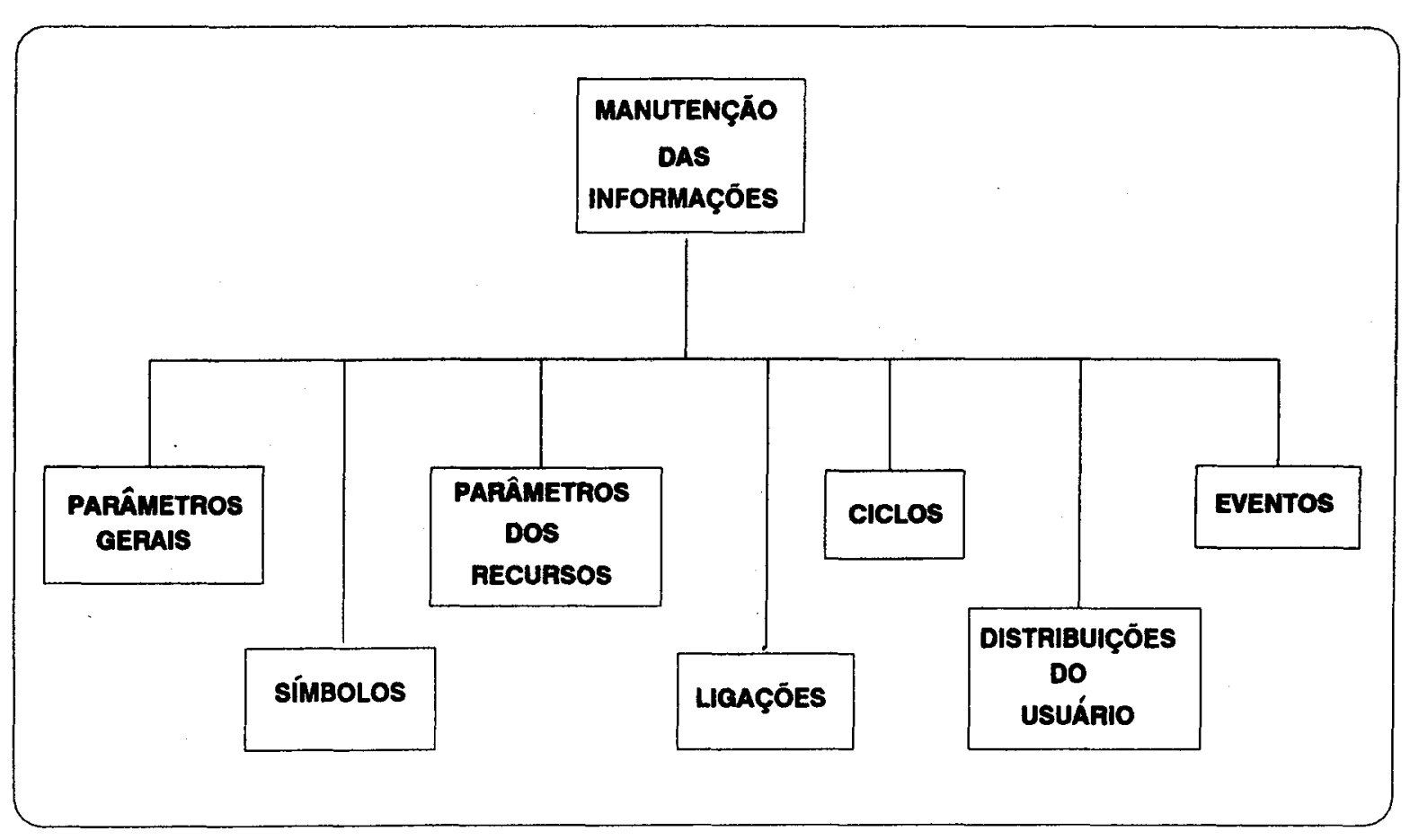

Figura 7.15: Módulos da Manutenção das Informações

\section{Parâmetros Gerais do Modelo}

A estrutura a seguir guarda todas as informaçōes gerais referentes ao modelo de simulação, fornecidas pelo usuário através da caixa Modelo. Todos os campos da estrutura foram discutidos no capítulo 6.

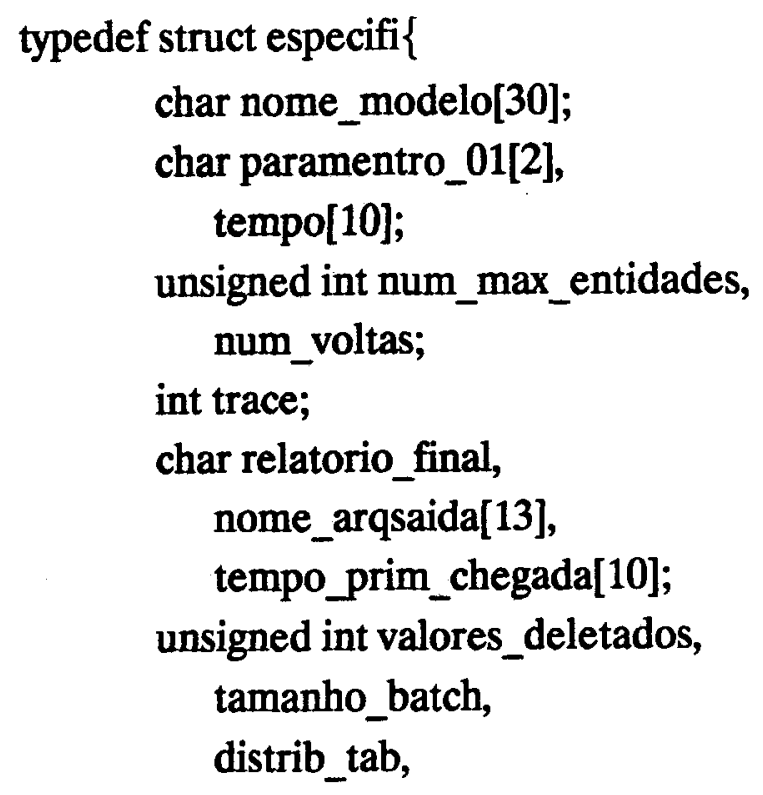




\section{reesc; \\ double warm_up; \\ \} Especificacao}

\section{Símbolos}

Os símbolos que compõem a especificacão grafica do modelo de simulação são armazenados em uma lista com a seguinte estrutura:

typedef struct lista_de_simbolos \{

int $\mathrm{x}$, y;

char tipo;

int identrec;

LOCALHANDLE prox;

\} lista_simbolos;

$. x, y:$ identificam o canto superior esquerdo do desenho;

.tipo: identifica o tipo do centro de serviço desenhado, que pode ser com uma fila e um servidor, uma fila e vários servidores, várias filas e um servidor, ou várias filas e vários servidores;

identrec: identificação do recurso, usada também na parametrização;

prox: "handle" para o próximo nó da lista.

Para cada símbolo desenhado (centros de serviços ou setas) tem-se um retângulo imaginário cujo canto superior esquerdo correspondente exatamente ao canto superior esquerdo do desenho. E esse o ponto identificado pelas coordenadas x,y que seguem a orientação da figura 7.16. Esse tratamento facilita a definição dos comandos necessários para efetuar o desenho, e a pesquisa necessária quando um símbolo é selecionado.

Neste módulo também estão definidas as rotinas de desenho, acionadas quando o usuário utiliza a barra de ferramentas para definir um recurso no modelo, e também quando ocorre alteração no tamanho da janela de edição. Essas rotinas utilizam 
basicamente as primitivas da GDI ("Graphics Device Interface") de desenho de linhas, elipses e pontos para desenhar os símbolos na janela de edição.

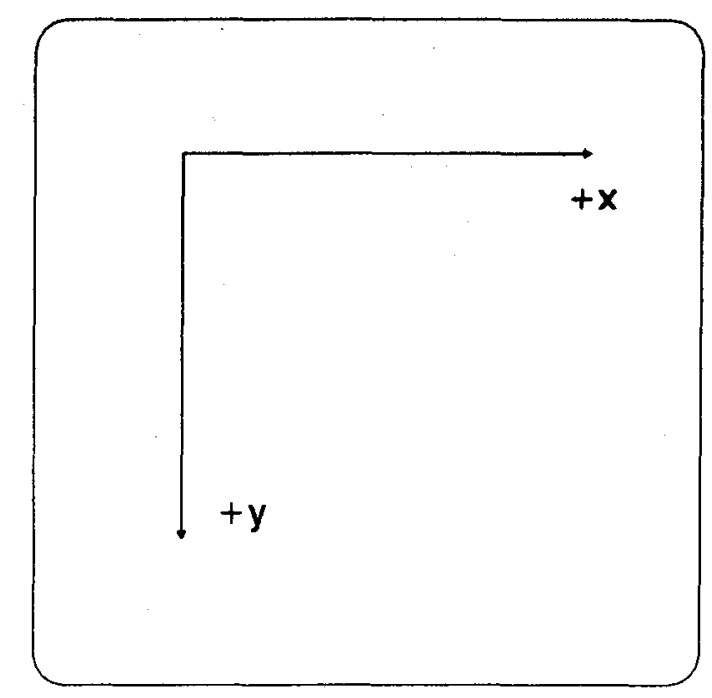

Figura 7.16: Orientação dos Eixos x e y

\section{Parâmetros dos Recursos}

Para cada recurso parametrizado pelo usuário, um nó na lista de recursos é criado. Essa lista armazena todas as informaçōes referentes aos recurso. A lista é mantida em memória por três "handles", sendo ordenada de forma a facilitar sua utilizaçāo pelo Gerador de Aplicação. O recurso que consiste no ponto de entrada do sistema sendo simulado tem o nó correspondente inserido sempre na primeira posição da lista, e os que apresentam saída do sistema, no fim. Os demais são inseridos entre esses. Dessa forma mantem-se três estruturas de lista na mesma estrutura física.

Cada nó da lista tem a seguinte estrutura:

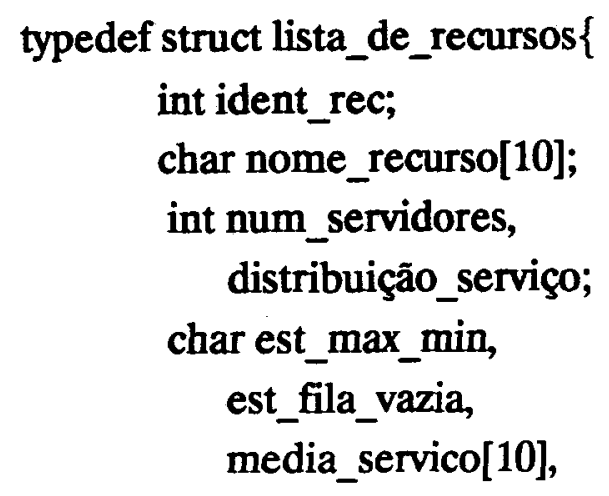




\author{
pto_triang_servico[10]; \\ int seq_num_aleat_servico, \\ disciplina, \\ escolha_fila, \\ escolha_cliente, \\ escolha_servidor, \\ escolha_prox_rec, \\ distribuição_chegada; \\ char media_chegada[10], \\ desvio_padrao_chegada[10], \\ pto_triang_chegada[10]; \\ int seq_num_aleat_chegada; \\ char entradas_saidas[41], \\ sem_fila; \\ unsigned int num_filas, \\ flag_sinc; \\ char libera_recurso; \\ LOCALHANDLE prox; \\ \} lista_recursos;
}

Os campos da estrutura correspondem aos parâmetros identificados no capítulo 6, exceto o campo ident_rec, que armazena o mesmo identificador utilizado na lista de símbolos.

\title{
Ligações
}

Este módulo contém a lista que armazena a maneira como os recursos estão relacionados, isto é, a saída de um ligada à entrada de outro. Cada nó da lista tem a estrutura a seguir:

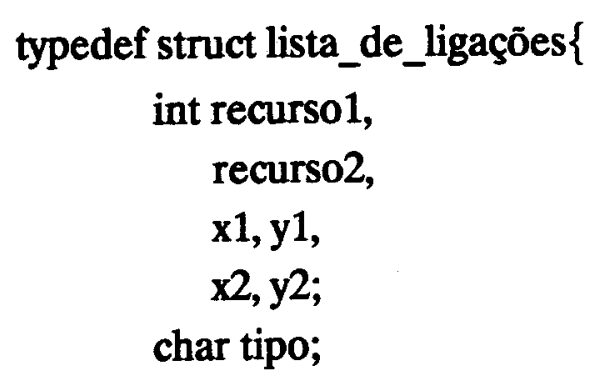

\} lista_ligações; 
recursol, recurso2: identificaçāo dos recursos;

$x 1, y 1$ : ponto inicial;

$x 2, y 2$ : ponto final;

tipo: indica o tipo da ligação;

prox: "handle" para o próximo nó da lista.

\section{Ciclos}

Responsável pela lista de ciclos, que contém as informações relativas aos ciclos que o usuário define no modelo. Também é mantida por três "handles", como a lista de recursos. Dessa forma, fica facilitado o trabalho do Gerador de Aplicação, pois a lista fica ordenada tal que o recurso que tem a entrada do modelo é o primeiro, e os que tem a(s) saída(s), os últimos. Cada nó tem a seguinte estrutura:

typedef struct lista_de_tot_loop\{

char n_rec[10];

unsigned int $n \_$loop;

LOCALHANDLE prox;

\} list_tot_loop;

n_rec: identificação do recurso, é utilizado pelo Gerador de Aplicação para identificar uma variável contadora do número de vezes que um cliente deve passar pelo ciclo;

.n_loop: número de vezes que um cliente deve passar pelo ciclo;

.prox: "handle" para o próximo nó da lista.

\section{Distribuições do Usuário}

Este módulo é responsável pela lista que armazena os dados fornecidos pelo usuário para definição de uma nova distribuição. Cada nó da lista tem a seguinte estutura:

typedef lista_de_dist_tab \{

char valor[5]; 
char prob[6];

LOCALHANDLE prox;

\} lista_dist_tab;

.valor: valor cujo número de ocorrência é observado;

prob: número de ocorrências do valor observado;

prox: "handle" para o próximo nó.

\section{Eventos}

Todos os eventos definidos pelo usuário para o modelo em questão são inseridos em uma lista manipulada por este módulo. Cada nó da lista tem a seguinte estrutura:

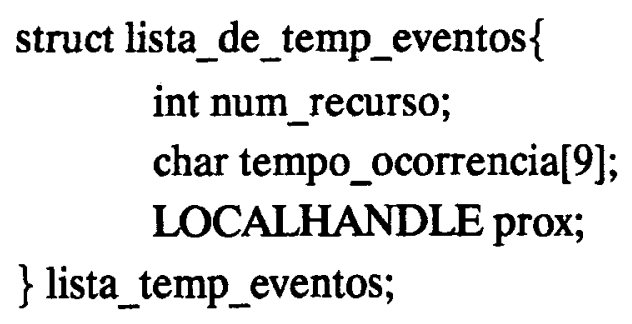

num_recurso: número do recurso para o qual um evento deve ser escalonado, como a chegada de um cliente ou a utilização deste recurso;

.tempo_ocorrencia: tempo para o qual o evento especificado será escalonado;

.prox: "handle" para o próximo recurso.

\subsubsection{Tratamento de Arquivos}

Como o trabalho do EdGraf consiste em captar os dados que serão utilizados pelo Gerador de Aplicação para produzir o programa de simulação, tornou-se necessário definir como armazenar esses dados e transferílos ao Gerador. Optou-se por armazenar esses dados em arquivos, constituindo uma base de dados (Base de Dados do ASiA) a qual permite que o Gerador de Aplicação tenha acesso aos parâmetros. Ressalta-se que o termo Base de Dados não é utilizado, neste trabalho, no sentido de haver um Sistema de Gerenciamento de Banco de Dados. A Base de Dados 
do ASiA consiste em um conjunto de arquivos contendo os parâmetros e outras informações referentes ao modelo.

Além dos parâmetros, a especificação gráfica do modelo também é armazenada em arquivo. Para cada arquivo produzido pelo EdGraf está associada uma estrutura OPENFILENAME [MIC92b]. Essa estrutura contém informaçōes que o sistema utiliza para iniciar as caixas de diálogo para abrir e salvar arquivos, como por exempo o nome do arquivo e o diretório correspondente.

Dessa forma, o grupo de Tratamento de Arquivos é dividido em dois módulos (figura 7.17):

.um módulo que manipula dados relativos à especificação gráfica; .um módulo responsável pela manutenção dos arquivos de parâmetros.

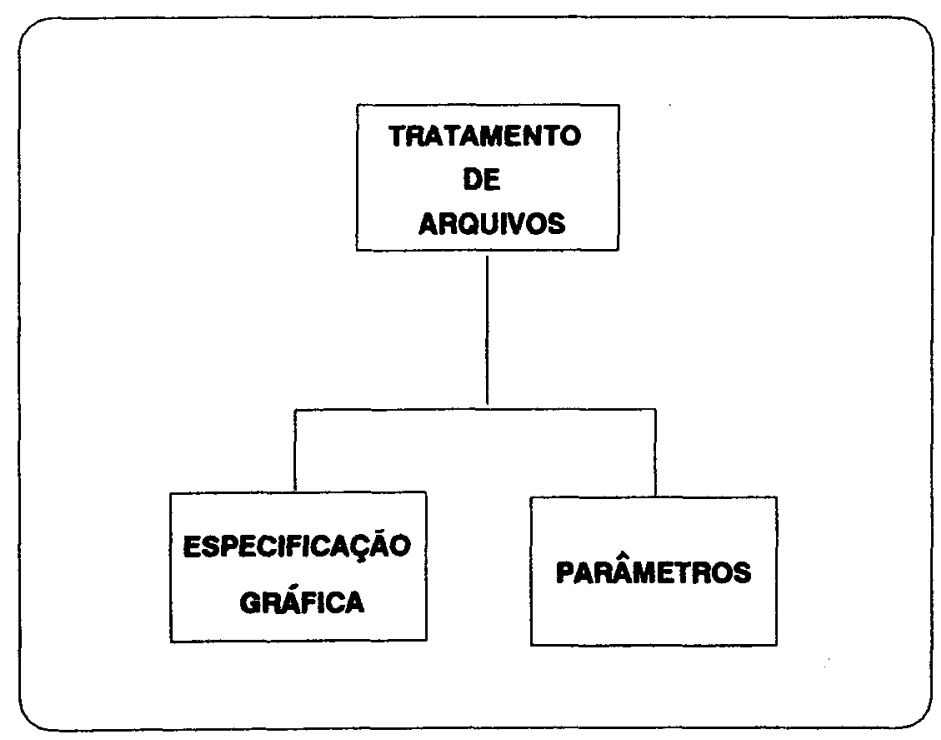

Figura 7.17: Módulos do Tratamento de Arquivos

A funçāo de cada um dos módulos é descrita a seguir.

\section{Especifícação Gráfica}

A especificação gráfica é armazenada em dois arquivos, que têm as extensōes .esp e lig. $\mathrm{O}$ arquivo esp armazena os nós da lista encadeada que contém os símbolos 
desenhados pelo usuário, e o arquivo com extensão .lig armazena os nós da lista que indica as ligaçōes entre os recursos definidos no modelo.

\section{Parâmetros}

Para armazenar os parâmetros do modelo especificado, este módulo do EdGraf produz cinco arquivos, que contém as informações necessárias para o Gerador de Aplicação. Os arquivos são relativos a:

.Parâmetros Gerais do Modelo: os parâmetros gerais do modelo definido são gravados em arquivo com a extensão padrão .mod. Por exemplo, se o usuário chamar seu modelo de exemp1, o nome utilizado para o arquivo será exemp1.mod;

.Parâmetros Específicos de Cada Recurso: os parâmetros relativos aos recursos definidos no modelo, armazenados nos nós da lista de recursos, são gravados neste arquivo. $\mathrm{O}$ arquivo produzido tem a extensão padrão .rec. Caso o recurso tenha algum ciclo, as informações referentes a este são armazenadas no arquivo com extensão .lop (as informações da lista de ciclos);

.Distribuição Definida pelo Usuário: cada distribuição definida pelo usuário pode ser armazenada em arquivo, com a extensão padrão .dis. São gravados os dados da lista de distribuição;

.Eventos Definidos Pelo Usuário: os eventos definidos pelo usuário e armazenados na lista de eventos podem ser gravados em arquivo com a extensão padrão .eve.

\subsubsection{Verificação de Consistência}

Além de fornecer ao usuário uma interface consistente para a especificação de modelos de simulação, EdGraf deve cuidar para que todas as informações fornecidas pelo usuário sejam corretas.

Neste módulo estão definidas todas as rotinas de verificação de consistência dos parâmetros fornecidos pelo usuário através das caixas de diálogo. Caso algum dado de 
alguma das caixas esteja errado, uma mensagem é apresentada, identificando o erro e mostrando ao usuário a maneira correta de fornecer a informação em questão.

Todos os valores numéricos são lidos como cadeias de caracteres, e depois transformados para números inteiros ou reais.

Como exemplo da verificação de consistência efetuada pelo EdGraf tem-se o caso do fornecimento do número de vezes em que um cliente deve passar por um ciclo definido no modelo. Caso o usuário digite um caracter ao invés de um número, este módulo do EdGraf avisa e solicita pelo valor correto. Outrar situação ocorre no caso de alguns parâmetros, como a seqüência para geração de números aleatórios. Somente alguns valores inteiros são permitidos para a sequiência, e o módulo avisa quando esses valores são ultrapassados.

\subsection{Conclusão}

Este capítulo apresentou os aspectos relativos à implementação do EdGraf. Uma preocupação no desenvolvimento do Editor Gráfico foi a construção de uma interface que facilitasse o trabalho do usuário no processo de especificar um modelo de simulação.

Nesse sentido, a implementação do Editor na linguagem $C$ utilizando o ambiente Windows contribuiu para que esse objetivo fosse atingido, ao criar condições para introduzir na interface elementos como janelas, menus, caixas de diálogo, ícones e outros, abordados no capítulo 4.

Através de manipulação direta da tela com o uso do "mouse", o usuário escolhe os símbolos para serem desenhados, símbolos que devam ser apagados, e ainda faz a seleção de símbolos para serem parametrizados. Itens de menus apresentam caixas de diálogo solicitando os parâmetros do modelo. A troca de mensagens com o usuário é efetuada sempre que alguma informação incorreta é fornecida. EdGraf a recusa, informando o motivo provável do erro. 


\section{Capítulo 8}

\section{Conclusões}

Este capítulo conclui a dissertação destacando as contribuiçōes alcançadas $e$ apresentando as conclusöes finais, sugestōes para a continuidade do trabalhdo e a crítica bibliográfica.

\subsection{Crítica Bibliográfica}

\section{Simulação de Sistemas}

O capítulo 2 desta dissertacão apresentou uma revisão sobre simulação, salientando sua importância, características gerais, etc. Diversos autores destacam a simulação como uma ferramenta para validação de projetos $e$ avaliação de desempenho, aplicável em diferentes áreas e em particular na área de sistemas computacionais [MAC87, KOB78, GRA78, NUT78, SOA90, PEG91].

Diferentes ferramentas podem ser utilizadas para análise de desempenho, envolvendo instrumentação, modelagem ou o uso de "benchmarks". A avaliação de desempenho baseado em modelagem requer a solução do modelo, que pode ser obtida através de técnicas analíticas ou simulação. Valores médios para os parâmetros também podem ser utilizados, porém erros podem ser introduzidos já que considera-se pequena a variância destes parâmetros. Os modelos analíticos produzem resultados com um esforço computacional muito menor. Porém, oferecem pouca flexibilidade e a medida que aumenta a complexidade do sistema a ser estudado podem se tornar inviáveis. Além disso, podem não apresentar solução para muitos problemas práticos, e uma alteração no projeto pode significar a reformulação de todo o modelo. Simulação compreende uma ferramenta mais flexível do que as técnicas analíticas, 
porém modelos de simulação são difíceis de validar e em alguns casos o esforço computacional necessário pode ser muito grande.

Em muitas situações instrumentar o sistema real é difícil e pode perturbar sua utilização por outros usuários. Segundo Nutt [NUT78] a utilização de protótipos pode não ser viável, devido aos custos na sua construção e modificação.

A utilização de "benchmarks" necessita do sistema real [REI90, ABU88, NIC88] e é interessante para a comparaçāo de diferentes arquiteturas.

A avaliação de desempenho pode se beneficiar de qualquer uma das técnicas discutidas, porém simulação se destaca pela sua flexibilidade. Simulação pode ser considerada tanto para avaliaçāo de sistemas que nāo existem como para os casos em que a instrumentação do sistema poderá perturbar sua utilizaçāo ou os dados obtidos. Pode-se ainda considerar a utilização de simulação quando a solução analítica torna-se inviável.

No desenvolvimento de modelos de simulação pode-se optar por uma abordagem discreta ou contínua [MAC75, MAR80, SOA90, PEG91, DAV89]. Embora a simulação contínua venha sendo largamente utilizada em diferentes áreas (como em estudos de dissipação de calor, na área médica, etc) o estudo de sistemas computacionais é normalmente desenvolvido através de modelos discretos, uma vez que a operação destes sistemas é composta por um conjunto de atividades ocorrendo em intervalos regulares. Simulação discreta pode ser organizada seguindo orientações a evento, processo ou atividade [MAC75, MAC87, SOA90, TAN94]. A orientação a atividades tem sido pouco utilizada, merecendo pouco destaque na literatura. A orientação a evento pode levar a um programa de simulação mais simples, porém na simulação de sistemas complexos o programa pode se tornar obscuro. A orientação a processos permite uma representação mais natural do modelo, estabelecendo maior identidade com o sistema a ser simulado.

MacDougall [MAC87] descreve os passos necessários ao processo de modelagem via simulaçāo, compreendendo desenvolvimento, teste e análise. No desenvolvimento abstrai-se as características do sistema em um modelo, o qual deve ser codificado utilizando alguma linguagem. Santana [SAN89a] e Santana [SAN89b] apresentam como possibilidades o uso de linguagens convencionais, pacotes de uso específico, linguagens de simulação de uso geral ou extensões funcionais. A utilização de 
extensões funcionais tem se destacado por unir os aspectos de uma linguagem de programação convencional ao caráter específico de uma linguagem de simulação [MAC87].

Maryanski [MAR80], Pegden [PEG91], Davies [DAV89] e MacDougall [MAC87] ressaltam a importância da validação no processo de simulação, para garantir credibilidade ao modelo. Esse é um dos passos mais críticos no processo de modelagem através de simulação [MAC87, SOA90, NUT78, PEG91].

Sargent [SAR84] apresenta um tutorial sobre verificação e validação de simulaçāo, apresentando procedimentos para efetuá- las.

\section{Parâmetros de Entrada e Análise Estatística de Resultados}

O capítulo 3 apresentou uma revisāo sobre os parâmetros de um modelo de simulação e a análise de resultados.

Diversos autores [SOA90, PEG91, MAC87, DAV89] ressaltam a importância de fornecer parâmetros de entrada precisos para o modelo, a influência das condições iniciais da simulação e uso de métodos estatísticos para a obtenção dos resultados finais da simulação.

Para abstrair as características do sistema, são utilizados modelos baseados em redes de filas, formados por filas e servidores [SOA90]. A partir do estudo dos modelos básicos, constituídos por uma ou várias filas associadas a servidores, identificaram-se os parâmetros necessários a simulação, como o tempo de serviço, tempo entre-chegadas e disciplina da fila.

Identificados os parâmetros, pode-se obtê-los a partir do sistema real ou estimativas. Os dados obtidos são organizados em forma de tabelas ou ajustados a distribuições teóricas, a partir das quais são gerados valores aleatórios para representar o comportamento do sistema.

Atenção especial deve ser voltada a como parar o programa de simulação. $O$ uso de resultados de uma única execução ou tempo de simulação insuficiente pode levar a resultados imprecisos, daí a necessidade de métodos estatísticos baseados no cálculo de intervalos de confiança. 


\section{Interface Gráfica com o Usuário}

O capítulo 4 discutiu os conceitos básicos para o desenvolvimento de uma interface homem-máquina amigável, e interfaces gráficas utilizando o Microsoft Windows.

Foley [FOL87] e Shneiderman [SHN87] destacam que o projeto de uma interface homem-máquina deve se preocupar com o usuário, facilitando o diálogo deste com a máquina. Também relacionam como alguns dos principais objetivos de uma interface a velocidade de aprendizagem e utilização, e as baixas taxas de erros por parte do usuário.

Foley [FOL87] e Norman [NOR86] relacionam alguns estilos utilizados em interfaces: WYSIWYG, manipulação direta, menus, e diálogos utilizando linguages natural, comandos e pergunta-resposta. Dentre esses estilos, WYSIWYG, manipulação direta e menus se destacam por serem gráficas.

A literatura referente ao Windows é vasta. Petzold [PET93] apresenta os principais elementos da interface gráfica oferecida pelo Windows, explicando também a programação orientada a evento, gerenciamento e alocação de memória [SIM94, MIC92a, MIC92b, MIC92c]. Em [NOR92, PET93, MIC92c] encontra-se descrita a biblioteca de saída gráfica do Windows, a GDI.

\section{Sistemas de Simulação Automáticos}

No capítulo 5 foram apresentados exemplos de sistemas que permitem a geração automática do programa de simulação, através da especificação gráfica do modelo.

Melamed [MEL85] e Bell [BEL87] ressaltam o uso de sistemas de simulação com entradas e saídas gráficas como de grande importância no processo de modelagem por simulaçāo.

Basicamente, esse tipo de sistema apresenta ao usuário uma interface que permite especificar um modelo de simulação através de primitivas gráficas, a geração automática do programa de simulação e a visualização das saídas obtidas, como visto nos sistemas descritos por Raczynski [RAC90] (QMG), Funka-Lea [FUN91] (Q+), Ozden [OZD91] (GraphSIM) e Santana [SAN9.4] (ASiA). Do estudo desses sistemas, destaca-se que a simbologia utilizada no QMG pode ser confusa para o usuário, e Q + tem a vantagem de possibilitar também uma animação da simulação. No ASiA 
procura-se oferecer um sistema a baixo custo, executando em máquinas tipo IBM-PC e utilizando uma simbologia que facilita o usuário (representando redes de filas).

Raczynski [RAC90] ressalta o uso de geradores de aplicação em simulação. Do estudo sobre geradores de aplicação, Cleaveland [CLE88] e Luker [LUK86] sugerem o uso de geradores de aplicação para facilitar o trabalho do projetista, além de aumentar a produtividade dos mesmos.

Luker [LUK86] destaca que programadores experientes podem usar geradores de aplicação e adicionar ao código produzido outras funções. Assim é importante que o programa produzido pelo gerador seja bem estruturado, comentado adequadamente e legível.

\subsection{Contribuições do Trabalho}

Com o desenvolvimento do EdGraf foram alcançadas várias contribuições, que são destacadas a seguir:

implementação do módulo de interface do ASiA, com uma interface básica que facilita o trabalho do usuário na utilização do Ambiente;

a construção dos módulos do EdGraf permitiu obter total domínio do sistema desenvolvido, o que resultou na produção de uma documentação completa sobre a implementação e utilização do mesmo [SPO94a, SPO94b]. Isso possibilitará a fácil integração de novas características que ampliem a funcionalidade oferecida pelo EdGraf;

.devido ao fato do EdGraf ser independente da linguagem ou pacote de simulação utilizado pelo. Gerador de Aplicação, a interface desenvolvida para o ASiA pode ser considerada genérica, permitindo a especificação gráfica de modelos em qualquer orientação (evento, processo ou atividade). A condição necessária é que o sistema de interesse possa ser representado através de um modelo de rede de filas;

.especificação das informações e parâmetros necessários para a definição completa de um modelo de simulação, o que facilita a expansão do ambiente ASiA para outros sistemas de simulação. 


\subsection{Conclusões}

As conclusōes do trabalho são:

.visando facilitar a manutenção e futuras expansões do EdGraf foi desenvolvida documentação completa e detalhada, versando sobre os aspectos relacionados com a implementação. O usuário final também dispōe de um manual, com instruções mostrando todos os passos necessários para especificar um modelo de simulação;

.a interface fornecida pelo EdGraf constitui um ponto fundamental no desenvolvimento do $\mathrm{ASiA}$, pois dela depende a aceitação do sistema de simulação automático por parte do usuário. Assim, todos os esforços se concentraram para criar um ambiente agradável e de fácil utilização. Este objetivo foi alcançado com o uso do Microsoft Windows 3.1;

.este trabalho apresentou também a viabilidade de se desenvolver um sistema de simulação automático, com especificação gráfica do modelo de simulaçāo. Dessa forma, o trabalho de quem não tem todos os requisitos para desenvolver todos os passos necessários a uma simulação, e mesmo dos mais capacitados, fica facilitado;

.a utilização dos elementos fornecidos pelo Microsoft Windows, para elaborar a interface oferecida pelo EdGraf, facilita o aprendizado por parte do usuário. Aquele que já está acostumado a utilizar aplicativos desenvolvidos para o Windows pode aplicar seus conhecimentos na interface do ASiA, uma vez que foram utilizados elementos padrões como as caixas de tratamento de arquivos. Além disso, o uso do Windows para desenvolver aplicativos vem aumentando a cada dia.

\subsection{Sugestões Para Trabalhos Futuros}

A seguir são listadas algumas sugestōes para dar continuidade a este trabalho:

.EdGraf e o Gerador de Aplicação [SPO94c] devem ser integrados, de tal forma que através de uma simples opção na barra de menus, o código 
relativo ao modelo definido no Editor possa ser imediatamente produzido pelo Gerador;

pode-se acrescentar ao EdGraf a capacidade de permitir ao usuário visualizar a porção de código relacionada a um determinado ponto do modelo, indicado pelo usuário com a ajuda do "mouse";

.EdGraf pode permitir a rolagem da tela, não limitando assim a quantidade de símbolos desenhados ao que o usuário consegue visualizar na janela de edição gráfica;

.como a interface oferecida pelo EdGraf é bem independente da linguagem, pacote ou extensão utilizada pelo Gerador de Aplicação, pode-se apresentar ao usuário, através de janelas, as distribuições e estatísticas disponíveis em cada um desses sistemas de simulação, suportados por diferentes geradores de aplicação;

.pode-se permitir ao usuário definir novas estatísticas, que não estejam disponíveis no sistema de simulação utilizado para gerar o programa de simulação correspondente ao modelo definido;

pode-se extender o EdGraf acrescentando uma opção na barra de menus que permita visualizar e inserir trechos de código relacionado a um determinado ponto do modelo, a partir do programa produzido pelo Gerador de Aplicação;

.em cada caixa de diálogo, um botão do tipo "help" pode ser inserido, auxiliando o usuário a compreender, com rapidez e eficiência, o significado de cada informação requisitada. A ajuda do menu principal também deve ser implementada (um sistema de ajuda ao usuário já está sendo desenvolvido em um outro trabalho);

.uma característica importante a ser acrescentada é o suporte a modelos com múltiplas entradas;

.com relação ao desenho na janela de edição gráfica, pode ser implementado o "desenho inteligente", isto $\varepsilon$, fazer a análise das linhas para buscar o melhor caminho entre dois recursos e que não sobreponha nenhum desenho. 


\section{Referências Bibliográficas}

[ABU88] ABURTO Jr.; A. A. Benchmarks: Problems and Pitfalls. Byte, v.13, n.6, p.207-224, Junho 1988.

[BEL87] BELL, P. C.; O'KEEFE, R. M.. Visual Interactive Simulation - History, Recent Developments, and Major Issues. Simulation, v.49, n.3, p.109-116, 1987.

[CLE88] CLEAVELAND, J.C.. Building Application Generators. IEEE Software, v.5, n.4, p.25-33, 1988.

[DAV89] DAVIES, R.; O'KEEFE, R.. Simulation Modeling With Pascal. Prentice-Hall International Ltda., 1989.

[EDW92] EDWARDS, G.; SANKAR, R.. Modeling and Simulation of Networks using CSIM. Simulation, v.58, n.2, p.131-136, Fevereiro 1992.

[FOL87] FOLEY, J. D.; van DAM, A.; FEINER, S. K; HEIGHES, J. F.. Computer Graphics - Principles and Practice. Addison-Wesley Publishing Company, cap.9, p.391-433, 1987.

[FUN91] FUNKA-LEA, C.A. et al. Interactive Visual Modeling for Performace. IEEE Software, v.8, n.5, p.58-68, Setembro 1991.

[GRA78] GRAHAM, G. S.. Queueing Network Models of Computer System Performance. ACM Computing Surveys, v.10, n.3, p.219-224, Setembro 1978.

[KOB78] KOBAYASHI, H.. Modeling and Analisys - An Introduction to System Performance Evaluation Methodology. Addison-Wesley Publishing Company, 1978.

[LUC71] LUCAS Jr., H. C.. Perfomance Evaluation and Monitoring. ACM Computing Surveys, v.3, n.3, p.79-91, Setembro 1971.

[LUK86] LUKER, P.A.. Program Generators and Generation Software. The Computer Journal, v.29, n.4, p.315-321, 1986. 
[MAC75] MACDOUGALL, M.H.. System Level Simulation. em Digital System Design Automation: Languages, Simulation \& Data Base, Cap. 1, Computer Science Press, Inc., p.1-115, 1975.

[MAC87] MACDOUGALL, M.H.. Simulating Computer Systems, Techniques and Tools. The MIT Press, 1987.

[MAR80] MARYANSKY, F. J.. Digital Computer Simulation. Hayden Book Company, Inc. 1980.

[MAR91] MARCUS, A.; van DAM, A. User-Interface Developments for the Nineties. IEEE Computer, v.24, n.9, p.49-57, Setembro 1991.

[MAR92] MARCUS, A.. Graphics Design for Eletronic Documents and User Interfaces. Addison-Wesley, 1992.

[MEI91a] MEIRA, C. A.A. Sobre Geradores de Aplicação. Dissertação (Mestrado) - ICMSC, USP. Setembro 1991.

[MEI91b] MEIRA, C. A.A.; MASIERO, P.C.. Um Gerador de Aplicaçōes para Sistemas Reativos. V SIMPÓSIO BRASILEIRO DE ENGENHARIA DE SOFTWARE, Ouro Preto, Minas Gerais, Outubro 1991. Anais.

[MEL85] MELAMED, B.; MORRIS, R.J.T.. Visual Simulation: The Performance Analysis Workstation. IEEE Computer, v.18, n.8, p.87-94, Agosto 1985.

[MIC92a] MICROSOFT Windows Software Development Kit - Guide to Programming. Microsoft Corporation, 1992.

[MIC92b] MICROSOFT Windows Software Development Kit - The Windows Interface: An Application Design Guide. Microsoft Corporation, 1992.

[MIC92c] MICROSOFT Windows Software Development Kit - Programmer's Reference, Volume 1: Overview. Microsoft Corporation, 1992.

[NEW93] NEWCOMER, J. M.. Modeless Dialog Boxes for Windows. Dr. Dobb's Journal, n. 200, p.26-30, Maio 1993.

[NIC88] NICHOLS, B.. Benchmarks: That's "B" Word. Byte, v.13, n.6, p.207-216, Junho 1988.

[NOR86] NORMAN, D. A.; DRAPER, S. W.. User Centered System Design. Lawrence Erlbaum Associates, Publishers, 1986. 
[NOR92] NORTON, P.; YAO, P.. Programando em Borland C + + Para Windows. Berkeley Brasil Editora, 1992

[NUT78] NUTT, G. J.. A Case Study of Simulation as a Computer System Design Tool. IEEE Computer, p.31-36, Outubro 1978.

[OZD91] OZDEN, M.H.. Graphical Programming of Simulation Models in an Object-Oriented Environment. Simulation, v.56, n.2, p.104-116, Fevereiro 1991.

[PEG91] PEGDEN, C. D. et al. Introduction to Simulation Using SIMAN. MacGraw-Hill International Editions, 1991.

[PET93] PETZOLD, C.. Programando Para Windows 3.1. Makron Books, 1993.

[PIE93] PIETREK, M.. Inside the Windows Messaging System. Dr. Dobb's Journal, n. 197, p.72-80, Fevereiro 1993.

[PRE87] PRESSMAN, R. S.. Software Engineering - A Practicioner's Approach. MacGraw-Hill, 1987.

[RAC90] RACZYNSKI, S.. Graphical Description and a Program Generator for Queuing Models. Simulation, v.55, n.3, p.147-152, Setembro 1990.

[REI90] REINHOLD, P. W.. An Overview of Common Benchmarks. IEEE Computer, v.23, n.12, p. 65-75, Dezembro 1990.

[RES91] Resource Workshop User's Guide. Borland International, 1991.

[ROB83] ROBERTS, N.; ANDERSEN, D. F.; DEAL, R. M.; GARET, M. S.; SHAFFER; W. A.. Introduction to Computer Simulation: The System Dynamics Approach. Addison-Wesley Publishing Company, 1983.

[ROT92] ROTH, P. F.; ILGAS, M.; MOUFTAH, H, T.. Simulation: A Powerful Tool for Prototyping Telecommunications Networks. Simulation, v.58, n.2, p.78-92, Fevereiro 1992.

[SAN89a] SANTANA,R.H.C.. Performance Evaluation of Lan-Based File-Servers. Tese (Doutorado), cap.4, p.74-84. University of Southampton, Outubro 1989.

[SAN89b] SANTANA, M.J.. An Advanced Filestore Architecture for a Multiple-Lan Distributed Computing System. Tese (Doutorado), p41-48. University of Southampton, Outubro 1989. 
[SAN94] SANTANA, R.H.C.; SANTANA, M.J.; CALÔNEGO JR, N.. Sistema de Simulação Automático. Trabalho a ser submetido, 1994.

[SAR84] SARGENT, R. G.. A Tutorial on Verification and Validation of Simulation Models. Proceedings of the 1984 Winter Simulation Conference, p. 115-121, 1984.

[SAY85] SAYDAM, T.. Process-Oriented Simulation Languages. Simuletter. v.16, n.2, p.8-13, Abril 1985.

[SHA88] SHARMA, R.; LAUWRENCE, L. R.. Modular Design for Simulation. Software-Pratice and Experience, v.18, n.10, p.945- 966, Outubro 1988.

[SHA92] SHANMUGAN, K. S.; FROST, V. S; LaRUE, W.. A Block-Oriented Network Simulator. Simulation, v.58, n.2, p.83-94, Fevereiro 1992.

[SHN87] SHNEIDERMAN, B.. Designing the User Interface - Strategies for Effective Human-Computer Interaction. Addison-Wesley Publishing Company, 1987.

[SIM94] SIMÕES, L. J.. Programação Windows. PC Magazine Brasil, v.4, n.3, p.51-52, Março 1994.

[SOA90] SOARES, L. F. G.. Modelagem e Simulação Discreta de Sistemas. VII Escola de Computação, São Paulo, 1990.

[SOU92] SOUSA, R. C. G.. Extensão Funcional da Linguagem C para Simulação de Sistemas Discretos. Relatório ao CNPq, Fevereiro 1992.

[SPO92] SPOLON, Renata. Extensão Funcional de Modula 2 para Simulação de Sistemas Discretos. Relatório ao CNPq, Fevereiro 1992.

[SPO93a] SPOLON, Roberta. Um Gerador de Aplicação para um Ambiente de Simulação Automático. Minidissertação (Mestrado) - ICMSC-USP. Junho 1993.

[SPO93b] SPOLON, Renata. Editor Gráfico para Simulação de Sistemas Discretos. Minidissertação (Mestrado) - ICMSC-USP. Julho 1993.

[SPO94a] SPOLON, Renata; SPOLON, Roberta; SANTANA, R. H. C.; SANTANA, M. J.. EdGraf - Editor Gráfico para o ASiA - Descrição da Implementação. São Carlos, ICMSC-USP, julho 1994. (Relatórios Técnicos do ICMSC-USP, 020 - ISSN 0109-2569). 
[SPO94b] SPOLON, Renata; SPOLON, Roberta; SANTANA, R. H. C.; SANTANA, M. J.. EdGraf - Editor Gráfico para o ASiA - Manual do Usuário. São Carlos, ICMSC-USP, julho 1994. (Notas Didáticas do ICMSC-USP, 013 - ISSN 0103-2585).

[SPO94c] SPOLON, Roberta; SPOLON, Renata; SANTANA, M. J..; SANTANA, R. H. C.. Gerador de Aplicação para o ASiA - Descrição da Implementação. São Carlos, ICMSC-USP, julho 1994. (Relatórios Técnicos do ICMSC-USP, 021 - ISSN 0109-2569).

[SPO94d] SPOLON, Roberta; SPOLON, Renata; SANTANA, M. J.; SANTANA, R. H. C.. Desenvolvimento de Um Gerador de Aplicação para Simulação de Sistemas Discretos. São Carlos, ICMSC-USP, julho 1994. (Notas do ICMSC-USP - série Computação, 011 - ISSN 0103-2577).

[TAN94] TANIR, O.; SULEYMAN, S.. Defining Requirements for a Standard Simulation Environment. IEEE Computer, v.27, n.2, p.28-34, Fevereiro 1994. 


\section{Bibliografia}

BORLAND C + + Tools and Utilities Guide. Borland International, Inc. 1991.

BORLAND C + + User's Guide. Borland International, Inc. 1991.

BORLAND C + + Programmer's Guide. Borland International, Inc. 1991.

BRUNNER, D.; CRAIN, R. C.. GPSS/H in the 1990's. The 1991 Winter Simulation Conference, p. 9-11, 1991.

KERNIGHAM, B.W. e RITCHIE, D.M.. C a Linguagem de Programação. 3 ed., Rio de Janeiro, Campus, 1987.

TENENBAUM, A.M.; LANGSAM, Y.; AUGENSTEIN, M.J.. Data Structures using C. Englewood Cliffs, Prentice-Hall, 1990. 


\section{Exemplo}

\section{Um Modelo Simples}

Este apêndice apresenta exemplos de utilização do EdGraf para a especificação completa de um modelo de simulação. São descritos os passos completos para especificar um modelo simples, e os outros passos necessários para modelos mais complexos.

O modelo da figura A.1 foi extraído do livro de MacDougall [MAC87] e descreve um sistema com uma fila e um servidor.

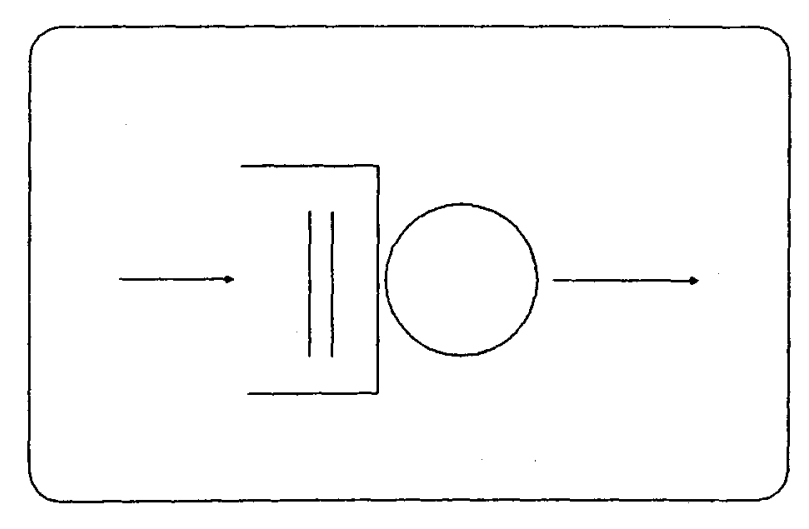

Figura A.1: Um Modelo Simples

As informações necessárias para a implementação do modelo são: 
.tempo médio entre-chegadas: 200.0 unidades de tempo;

.tempo médio de serviço: 100.0 unidades de tempo;

.tempo de execução do programa de simulação: 200000.0 unidades de tempo;

.disciplina da fila: ê utilizada a disciplina "First Come First Served";

distribuição de probabilidade: é utilizada a distribuição exponencial, para a geração dos tempos entre-chegadas e de atendimento dos clientes do sistema;

.número de filas e de servidores para o único centro de serviço definido: a utilização do símbolo adequado, de centro de serviço com uma fila e um servidor, automaticamente identifica o número de filas e de servidores com sendo igual a 1 .

Ao iniciar o EdGraf, uma caixa de mensagem apresenta o nome do sistema, autor e data (figura A.2). Após a apresentação, o usuário tem a sua disposição a tela principal do EdGraf (figura A.3).

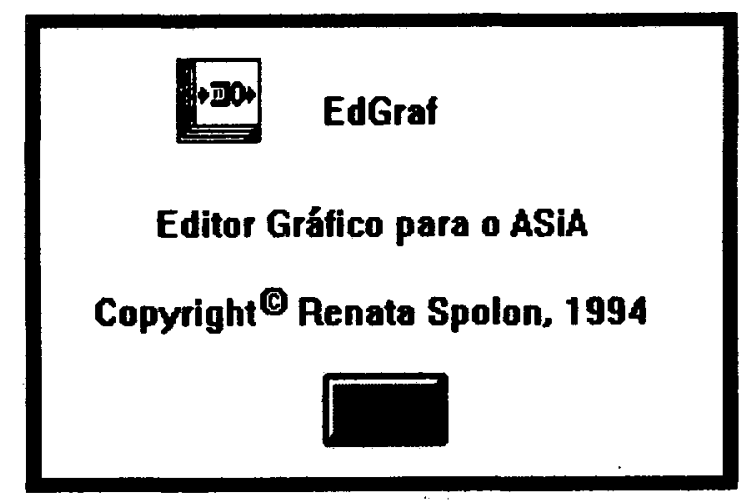

Figura A.2: Caixa de Apresentação do EdGraf

Para especificar o modelo da figura A.1, devem ser utilizados os ícones da barra de ferramentas (situada a esquerda, na figura A.3). O usuário pode utilizar o item Nova, do menu Especificação Gráfica, para ativar os itens de arquivo do menu, ou então começar a especificação sem se preocupar com os itens de arquivo de cada menu (utilizando os itens Salvar Tudo e Salvar Tudo Como do menu Sair). 


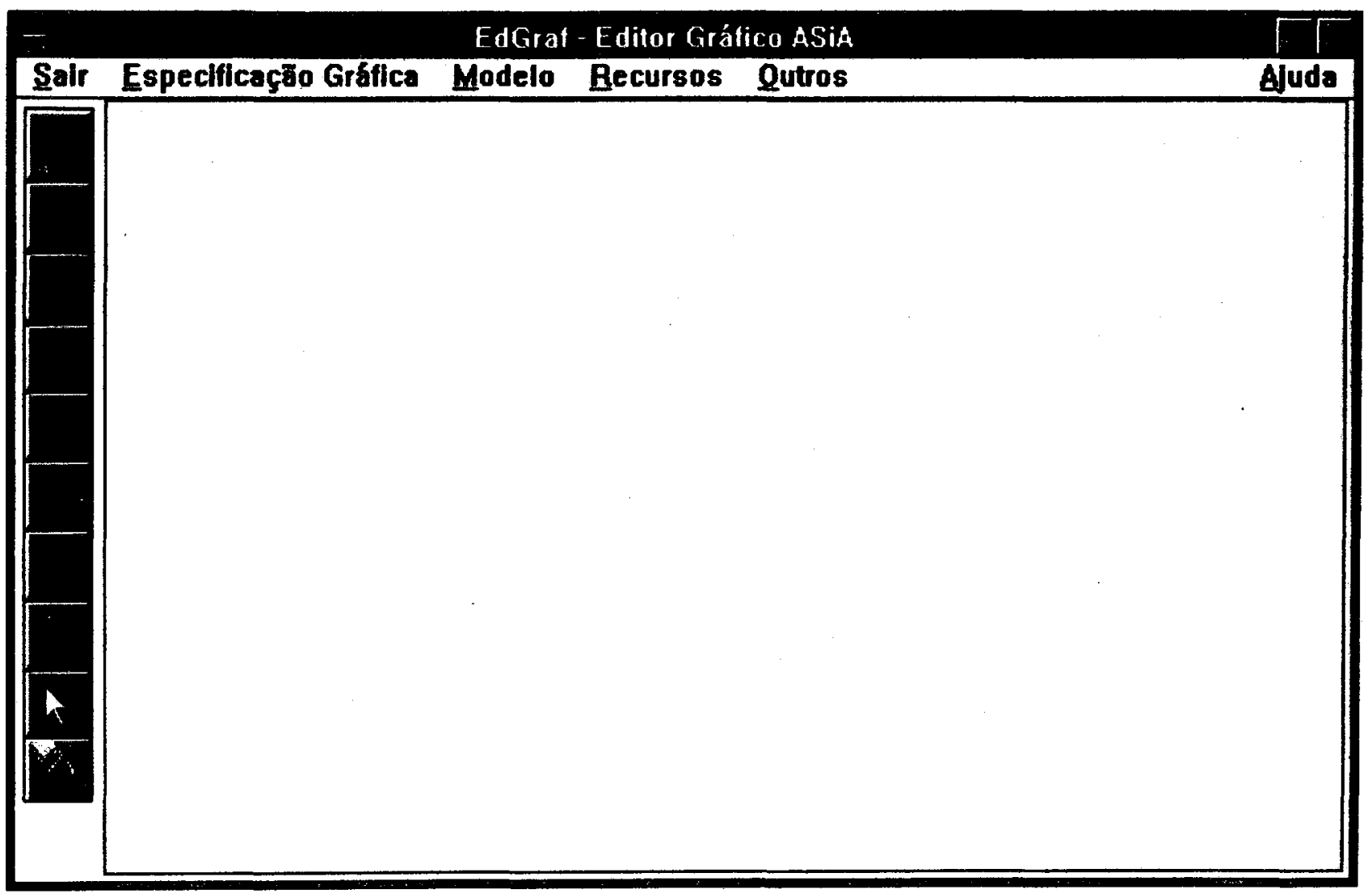

Figura A.3: Tela Principal do EdGraf

Para a especificação gráfica, o primeiro ícone da barra de ferramentas deve ser utilizado. Basta pressionar o botão do "mouse" sobre o mesmo, liberá-lo, e indicar também através do "mouse", a posição do desenho na janela de edição gráfica (figura A.4).

A seguir, devem ser especificados a entrada e a saída do modelo, utilizando os ícones de seta (quinto e sexto ícones da barra de ferramentas). Com o "mouse" deve-se indicar o símbolo de recurso que foi desenhado. (figuras A.5 e A.6). 


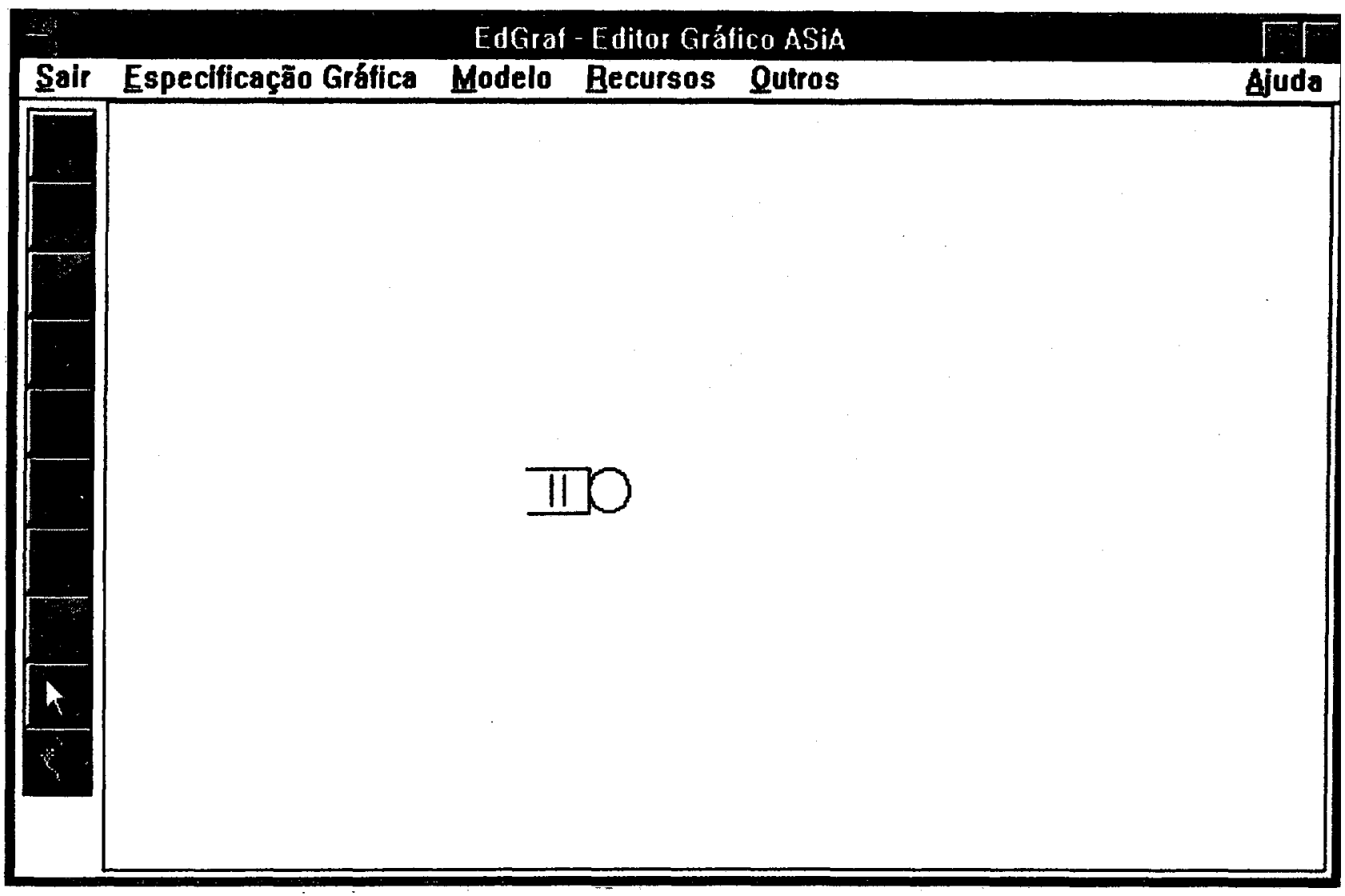

Figura A.4: Desenhando a Especificação Gráfica do Modelo

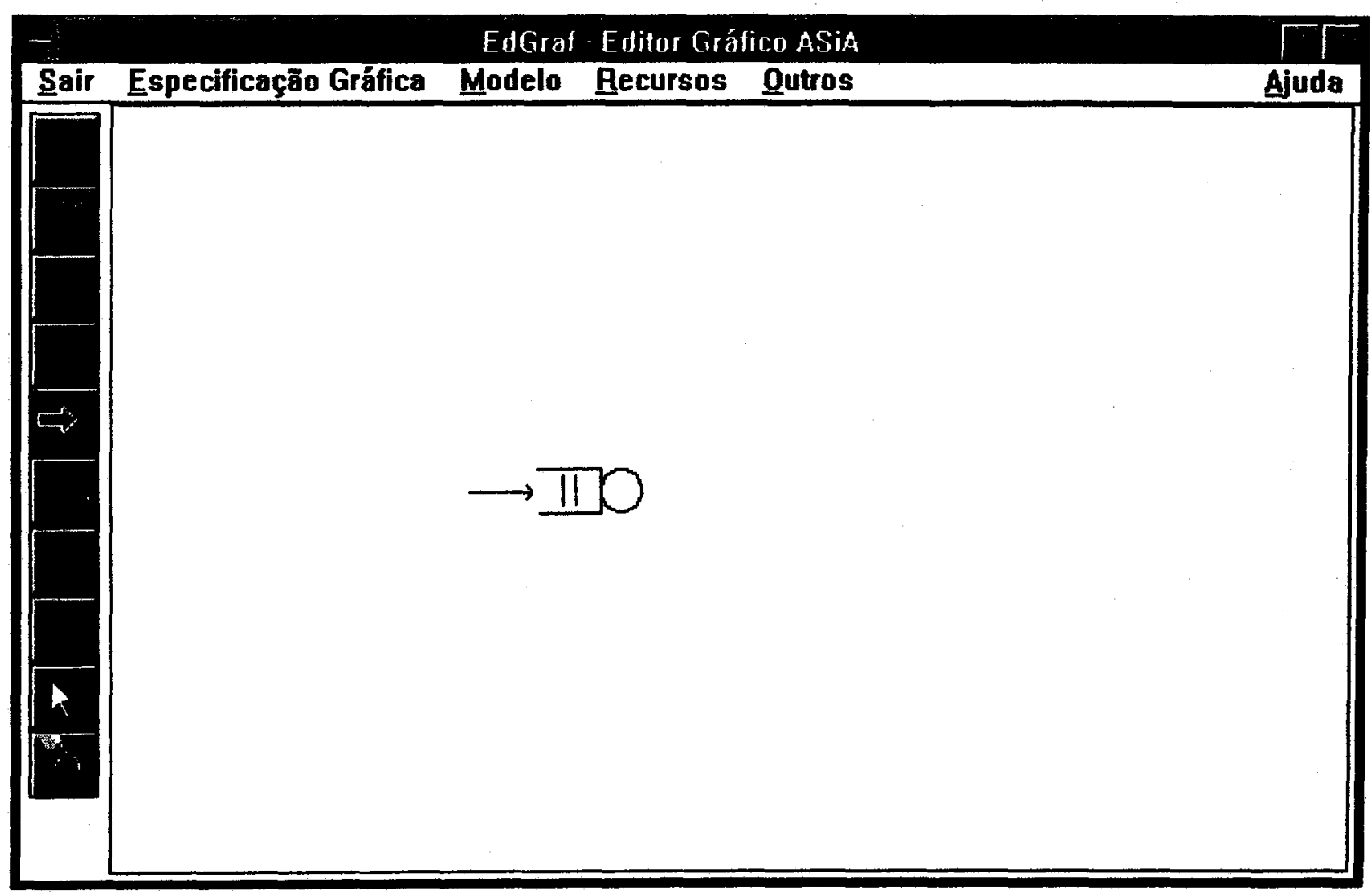




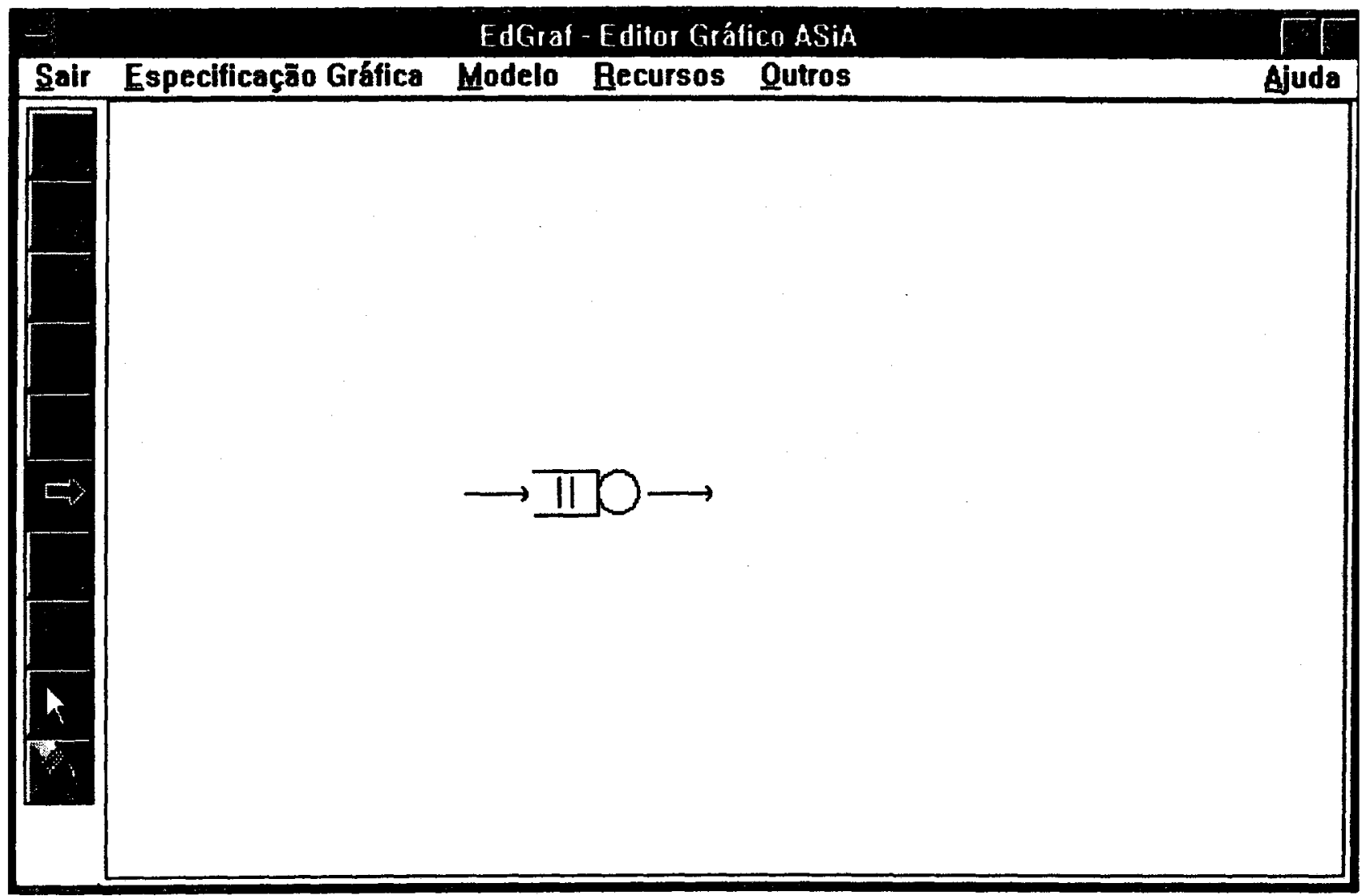

Figura A.6: Indicando a Saída do Modelo

Caso não indique o símbolo do recurso, o usuário recebe uma mensagem de erro (figura A.7).

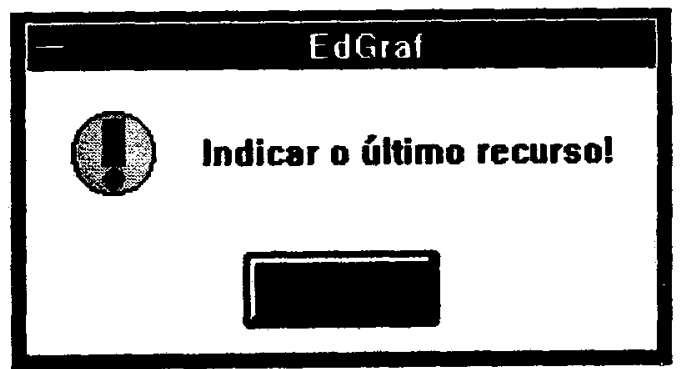

Figura A.7: Caixa Indicando Erro

Com isso, a especificação gráfica do modelo está completa. O próximo passo consiste em parametrizar o modelo. As informações gerais do modelo sāo fornecidas através da caixa de diálogo Modelo (figura A.8). O item Parametrizar, do menu Modelo, ativa essa caixa (figura A.9). 


\section{Dados do Modelo}

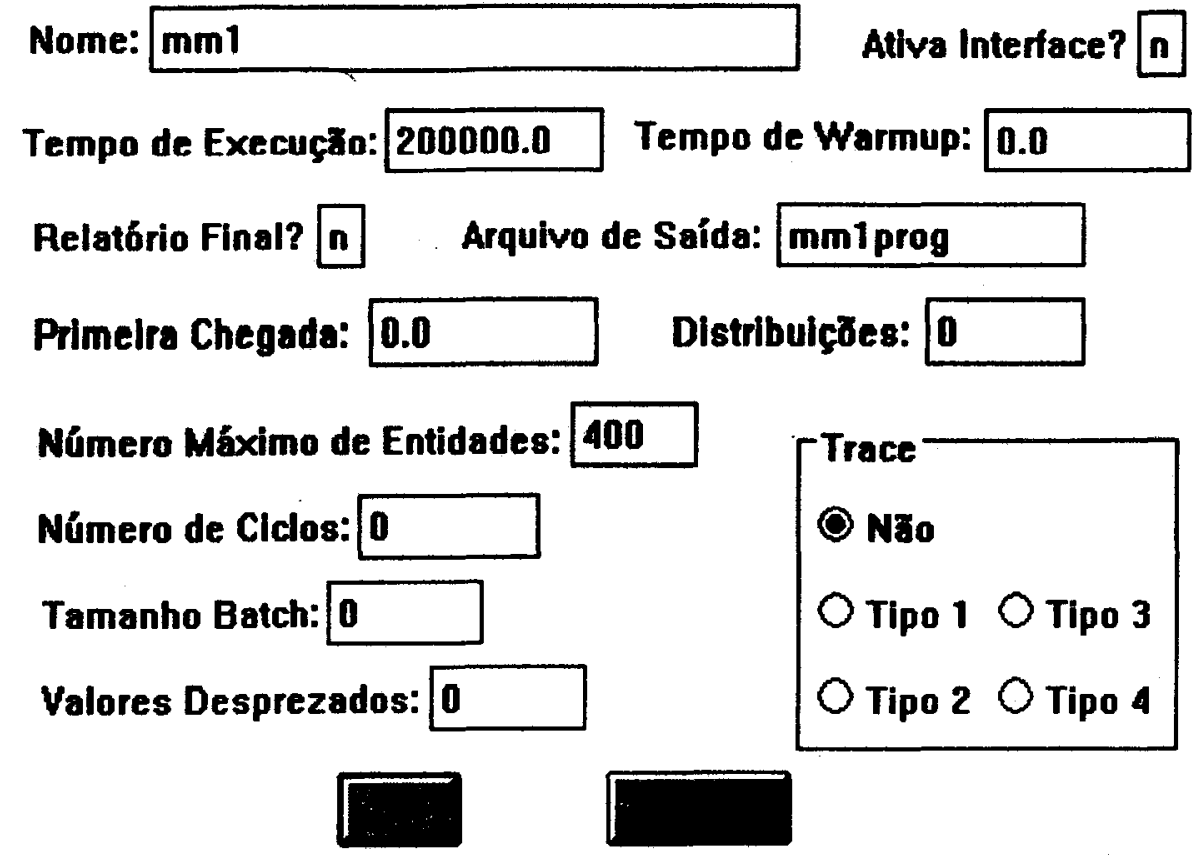

Figura A.8: Parametrizando o Modelo

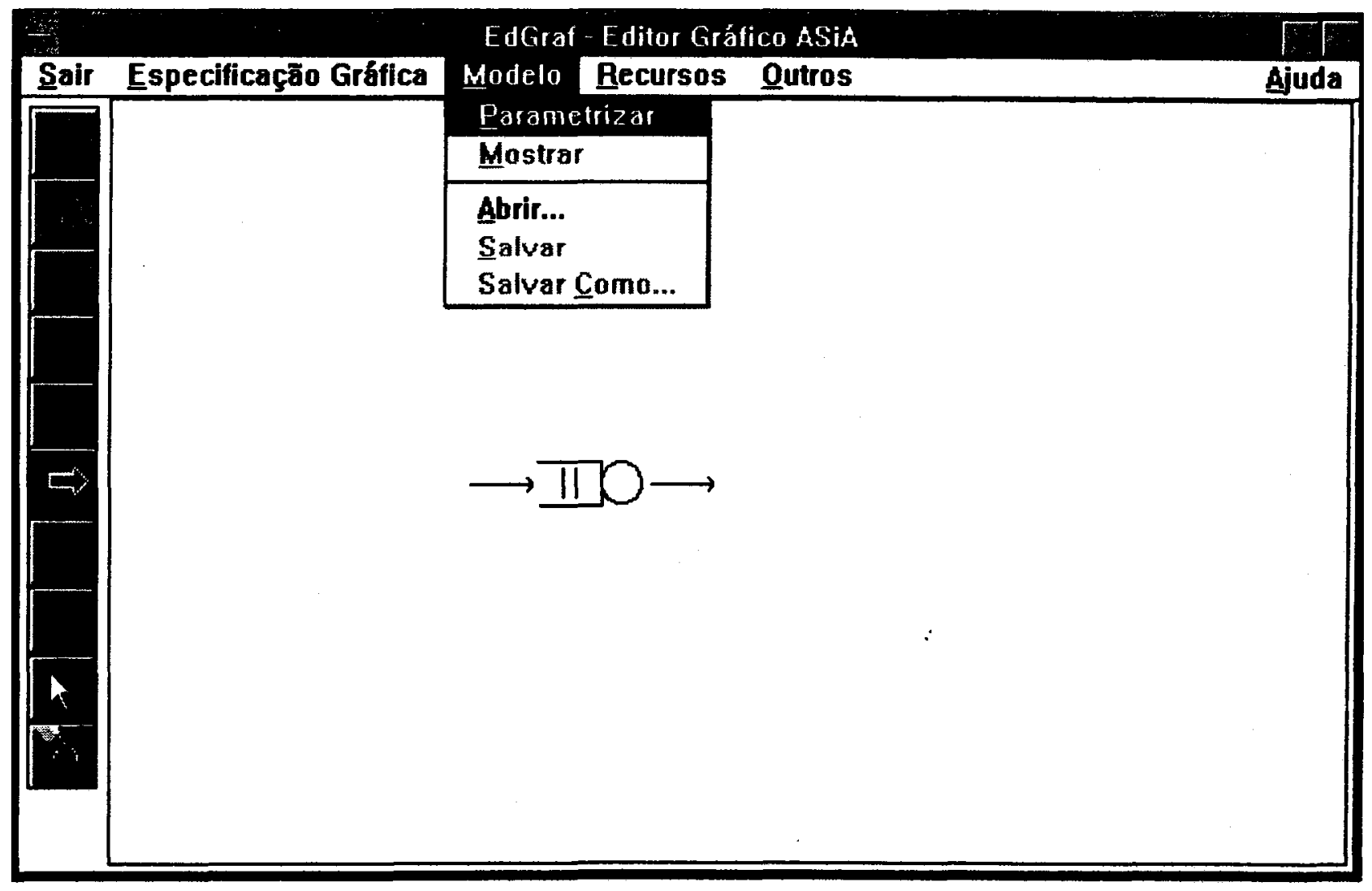

Figura A.9: 0 Menu Modelo 
Com o menu Recursos, o usuário parametriza o único recurso definido no modelo. $O$ item Parametrizar solicita ao usuário para indicar um recurso (figura A.10).

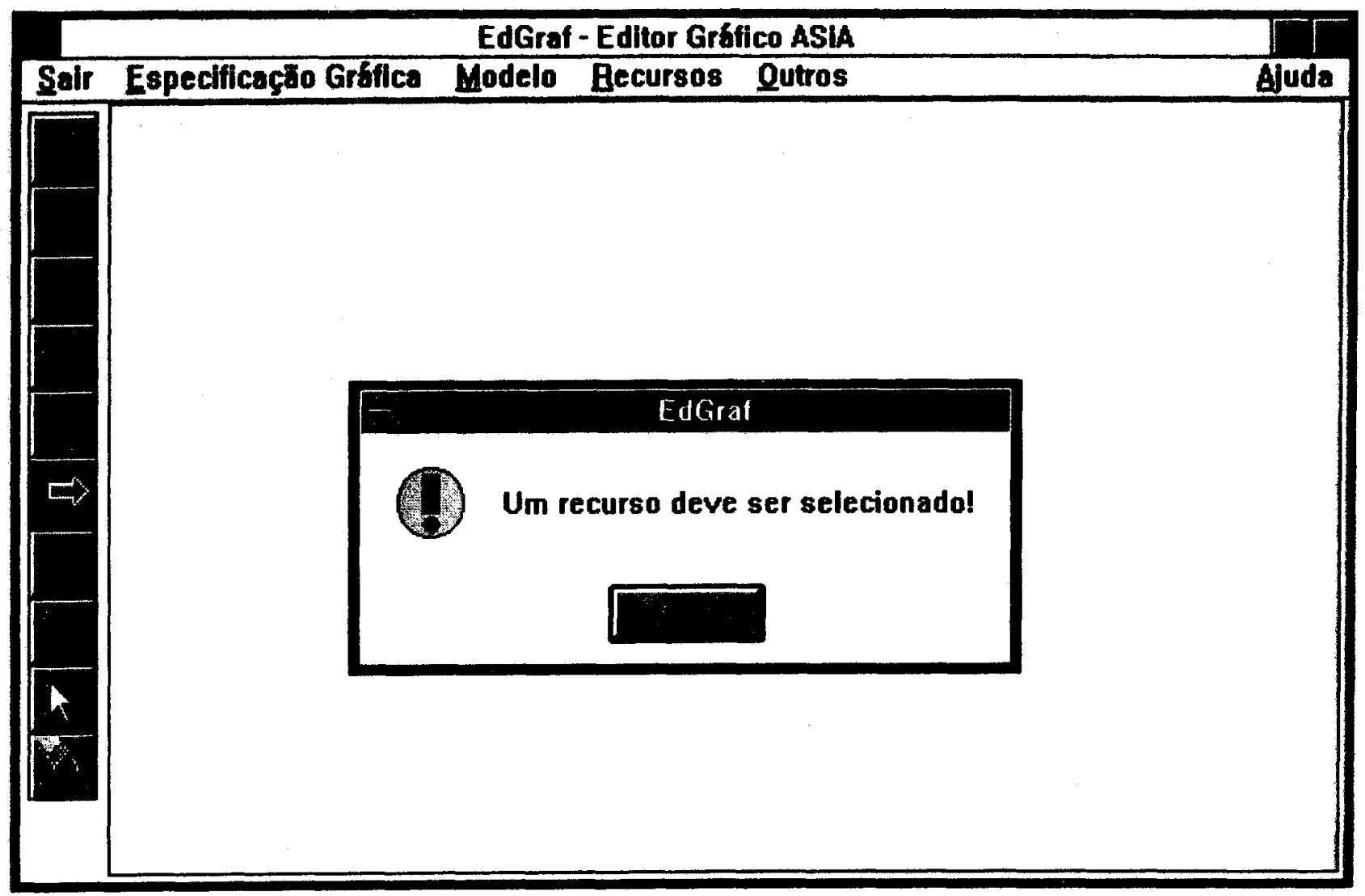

Figura A.10:Utilizando o Menu Parametrizar (Recursos)

Para selecionar o recurso, basta escolher o penúltimo ícone da barra de ferramentas e indicar o recurso com o botão do "mouse". Uma seta indica que o recurso foi selecionado (figura A.11).

Novamente, o usuário deve escolher o item Parametrizar do menu Recursos. Este apresenta um submenu, onde cada item permite ao usuário fornecer os parâmetros, apresentando as caixas de diálogo Dados do Recurso, Chegada, Fila, Serviço (figura A.12). 


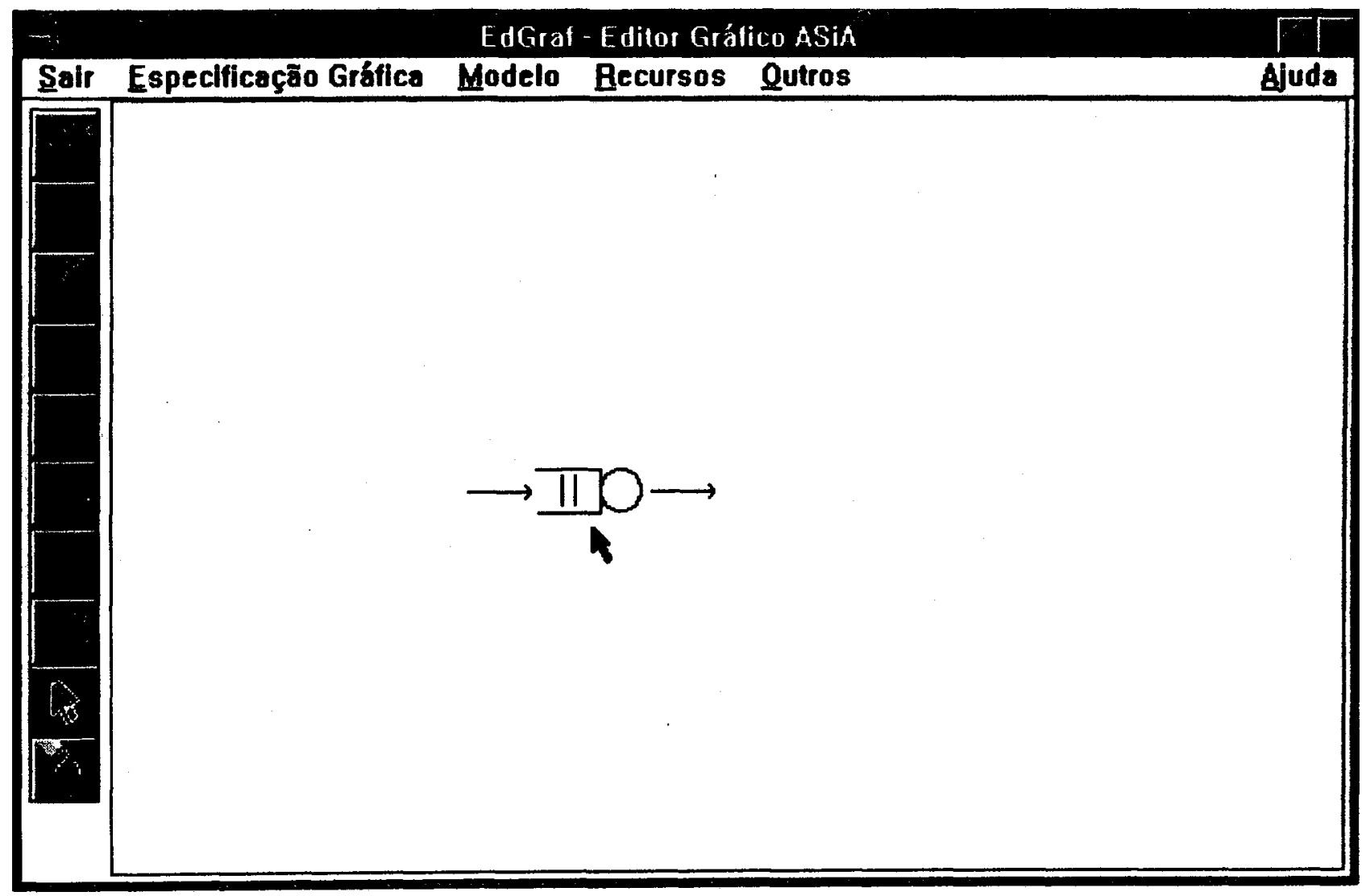

Figura A.11: Recurso Selecionado para Parametrização

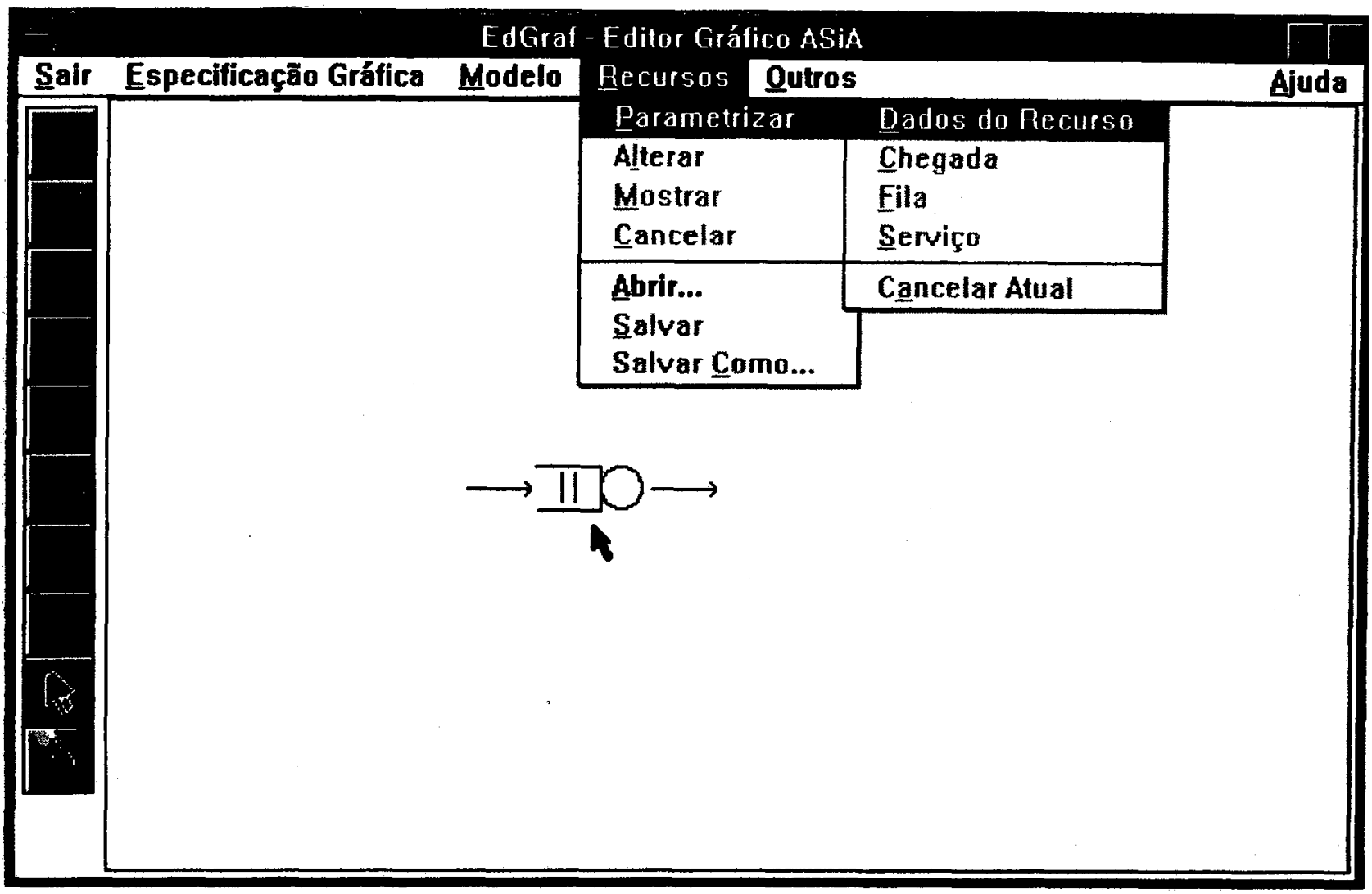

Figura A.12: O Submenu Parametrizar 
Fornecidos os parâmetros do modelo, o usuário pode utilizar os itens. Salvar de cada menu (Especificação Gráfica, Modelo, Recursos) ou então o item Salvar Tudo, do menu Sair (figura A.13).

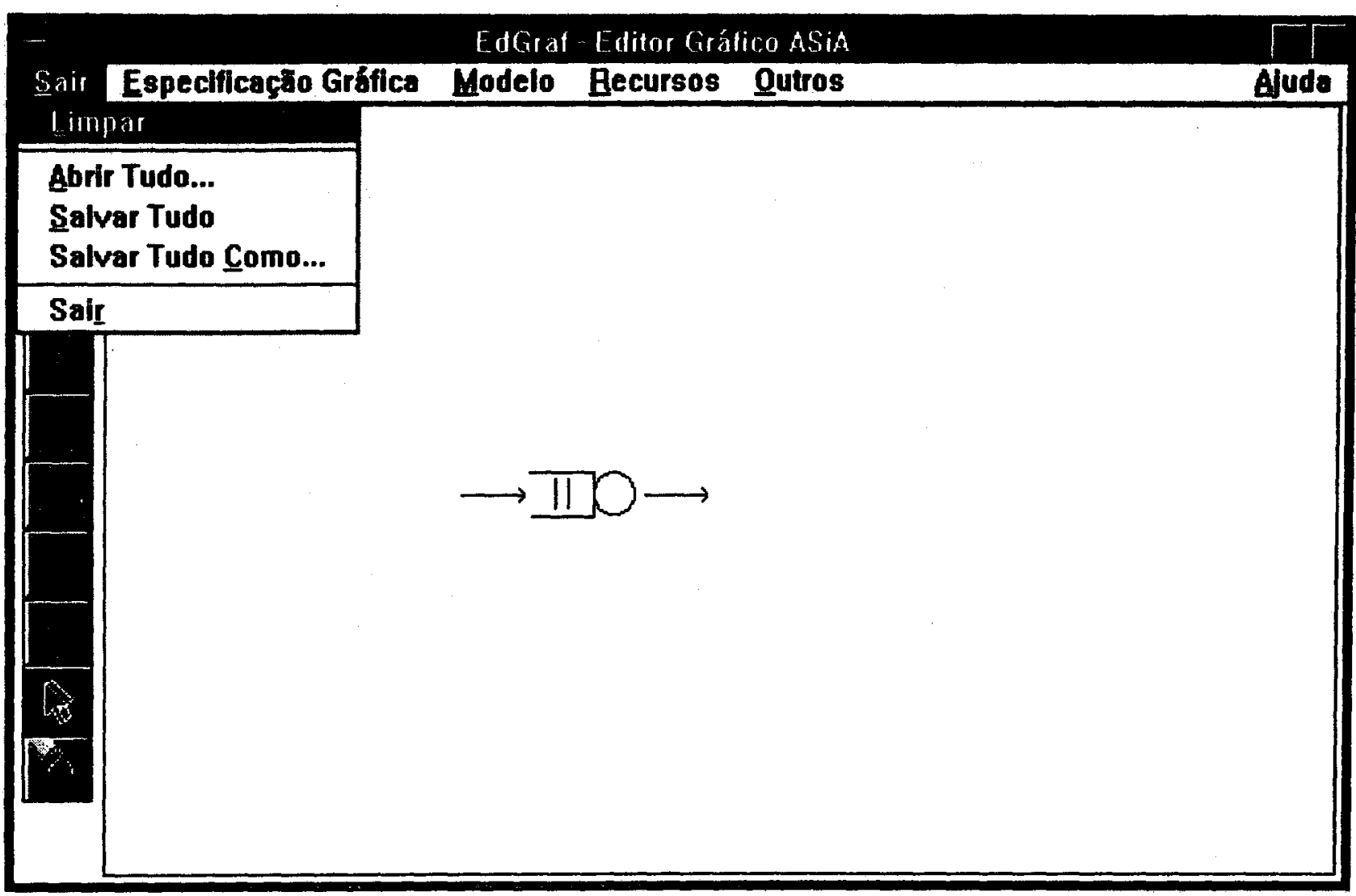

Figura A.13: O Menu Sair 


\section{Outros Modelos}

Basicamente, todos os passos descritos na especificação do modelo anterior devem ser repetidos para qualquer outro modelo suportado pelo EdGraf, além de outros passos.

Para o modelo da figura A.14, é necessário indicar, para cada um dos recursos, sua entrada e saída. Deve ser utilizado o sétimo ícone da barra para unir a saída de um recurso com a entrada de outro. A entrada e saída do modelo são indicadas pelas setas (quinto e sexto ícones da barra de ferramentas). A parametrização é feita do mesmo modo que no exemplo anterior, para os três recursos definidos.

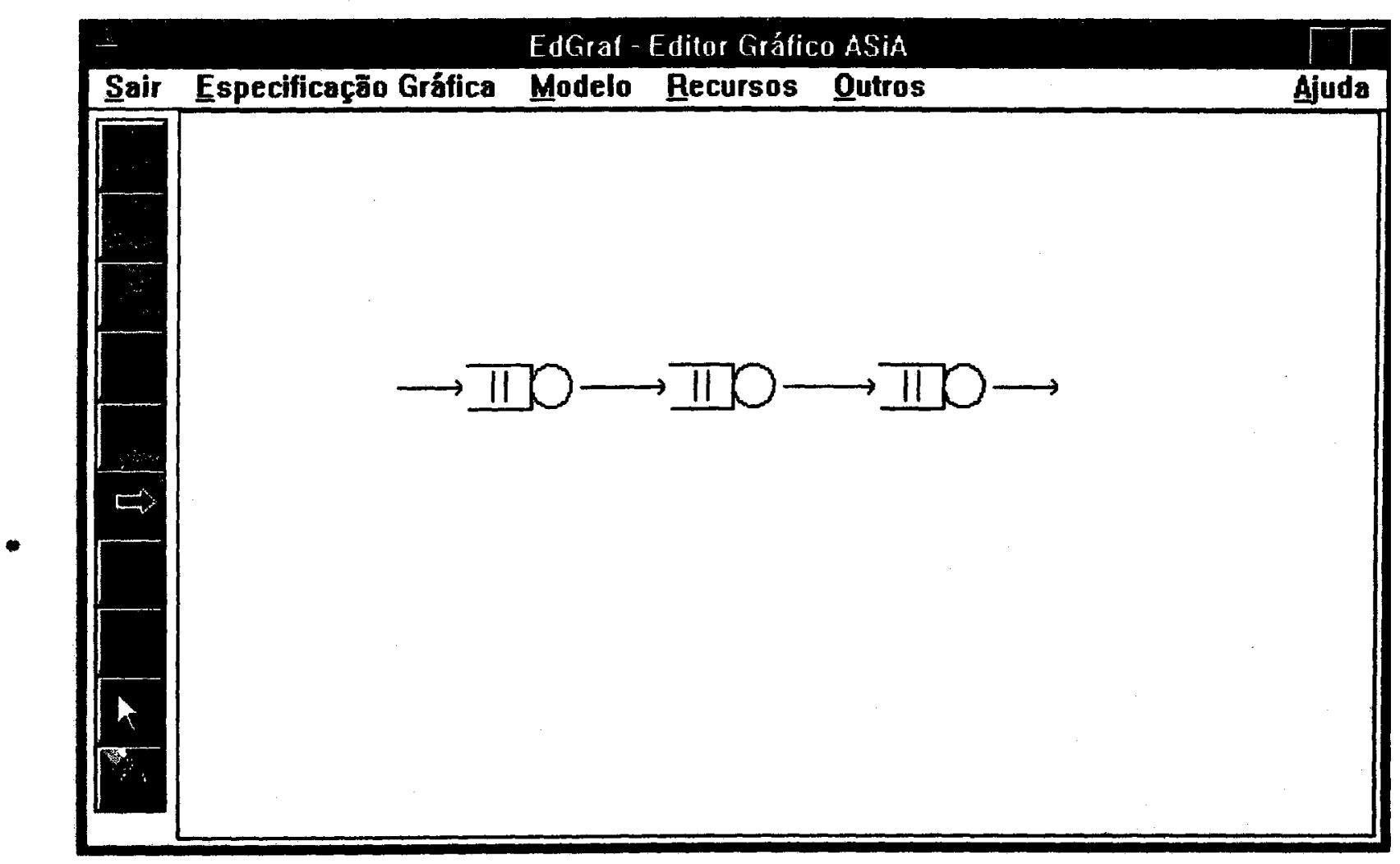

Figura A.14: Modelos Utilizando Vários Símbolos

O modelo da figura A.15 exige a utilização, além do ícone para unir recursos, do ícone para indicar ramificação a partir de uma ligação. Esses ícones permitem unir a 
saída de um recurso com a entrada de outro, quando existe mais de uma saída. Este é o caso do recurso mais a esquerda, da figura A.15.

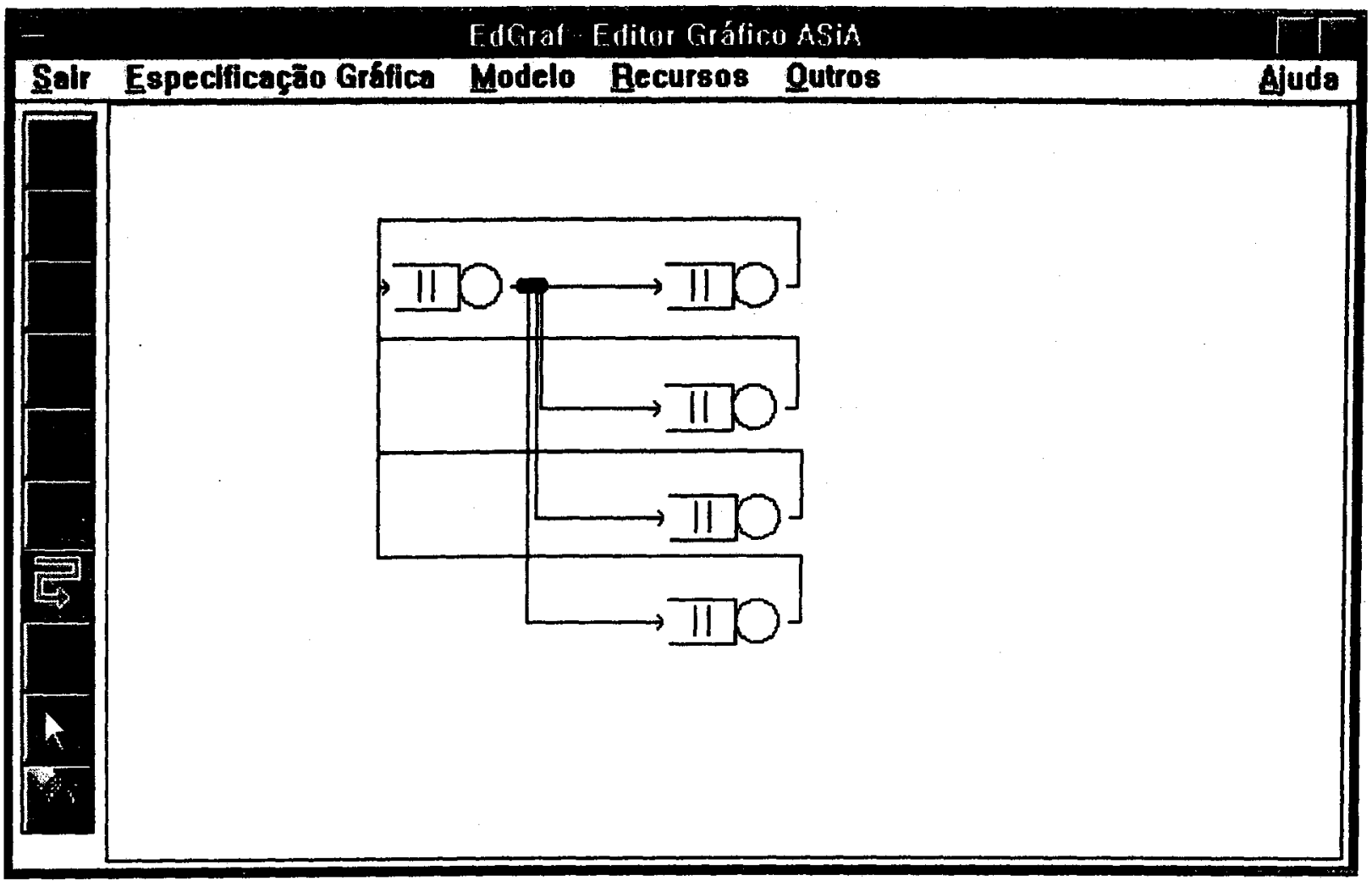

Figura A.15: Um Modelo Fechado

Este modelo difere dos anteriores pelo fato de ser um modelo fechado, não tendo entrada e saída. O que muda em relação aos anteriores é que ao fornecer os parâmetros do recurso mais a esquerda, na caixa Dados do Recurso, o campo Escolha do Próximo Recurso deve ser marcado com o botão Fechado. $O$ restante da parametrização e feito da mesma maneira que nos modelos anteriores.

No modelo da figura A.16 o recurso mais a esquerda apresenta um ciclo, o que pode indicar que o cliente deve passar por esse ciclo um número determinado de vezes, e depois seguir para o próximo, ou então indicar uma escolha entre seguir em frente ou retornar para a fila do recurso. 


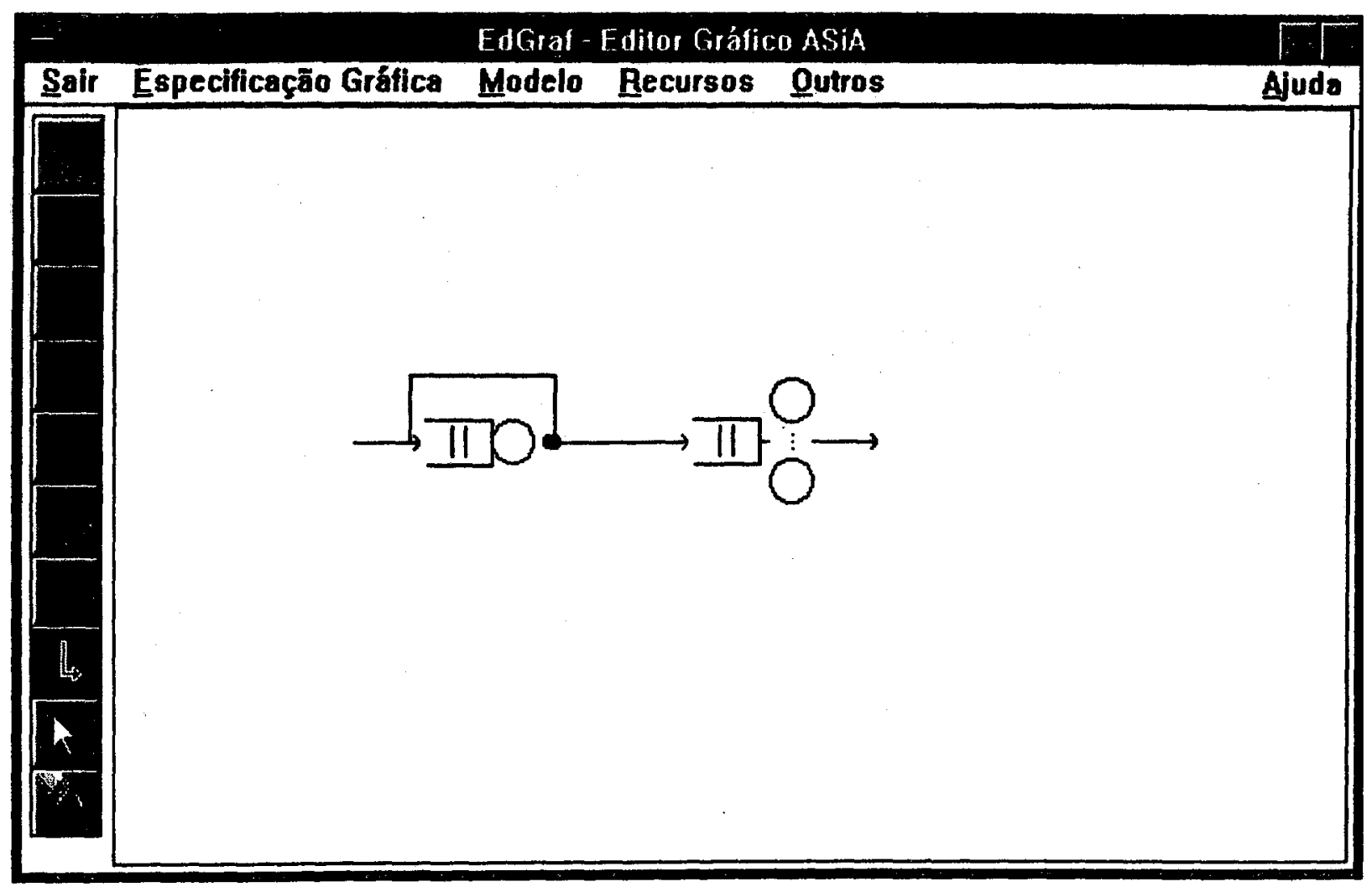

Figura A.16: Um Modelo com Decisão

A especificaçāo gráfica é feita utilizando-se os ícones de símbolos, as setas para indicar entrada e saída do modelo, o sétimo ícone para unir o primeiro ao segundo recurso, e o oitavo ícone para desenhar a ramificação.

A parametrização do modelo é efetuada como nos exemplos anteriores. $O$ número de servidores para o recurso definido mais a direita deve ser indicado na caixa Dados do Recurso. Caso o cliente deva retornar para a fila do primeiro recurso um número determinado de vezes, o usuário indica na caixa Dados do Recurso o botão Ciclos, do campo Escolha do Próximo Recurso. Ao apertar o botão OK, aparece a caixa Ciclo, que solicita o número de vezes que o cliente deve passar pelo ciclo (figura A.17). 


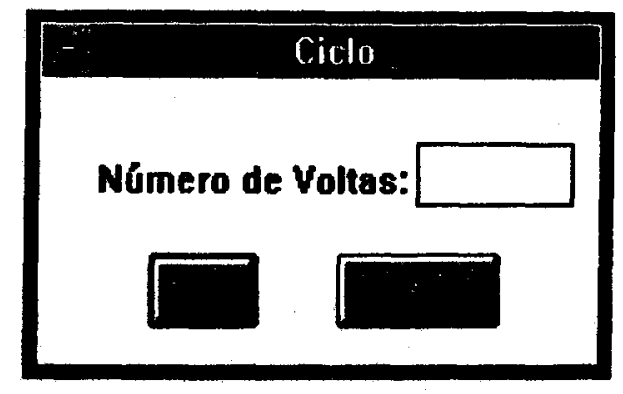

Figura A.17: Caixa Ciclo

Caso haja uma escolha entre seguir em frente ou retornar para a fila do recurso, 0 usuário deve escolher na caixa Dados do Recurso o botão Probabilidade, do campo Escolha do Próximo Recurso. O EdGraf solicita, através das caixas de diálogo Ramificação e Ligação Principal, as probabilidades para cada escolha: seguir ou voltar (figuras A.18 e A.19).

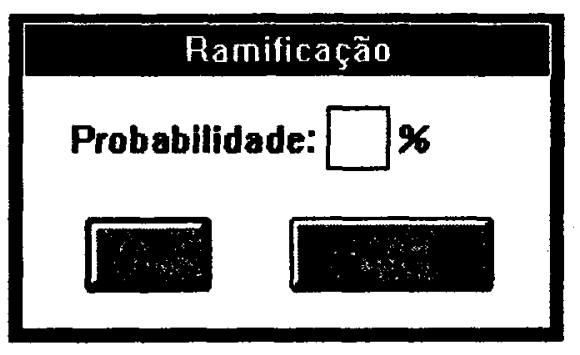

Figura A.18: Caixa Ramificação

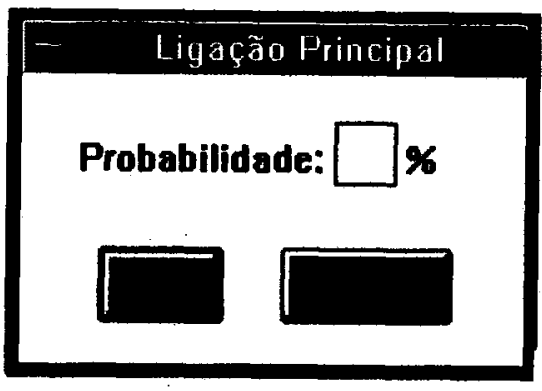

Figura A.19: Cai 
Para facilitar a utilização do EdGraf foi elaborado um manual do usuário, que contém maiores detalhes sobre a definição do modelo e dos parâmetros [SPO94b]. 


\section{Apêndice B}

\section{Lista de Siglas}

ASiA - Ambiente de Simulação Automático

BONeS - Block Oriented Network Simulation

EdGraf - Editor Gráfico para o ASiA

EFC - Extensão Funcional de C

EFM2 - Extensão Funcional de Modula 2

FCFS - First Come First Served

FIFO - First In First Out

GDI - Graphics Device Interface

GPSS - General Purpose Simulation System

GraphSIM - Graphical SImulation Modeling

ICMSC - Instituto de Ciências Matemáticas de São Carlos

LASD - LAboratório de Sistemas Digitais

LCFS - Last Come First Served

LIFO - Last In First Out

PASION - PAScal SimulatION

QMG - Queueing Model Generator

RESQ - RESearch Queueing Package 
RR - Round Robin

SLAM - Simulation Language for Alternative Modeling

WYSIWYG - What You See Is What You Get 